\title{
EXAMINING GENDER DIFFERENCES IN INSTITUTIONAL MISCONDUCT WITHIN THE CANADIAN FEDERAL OFFENDER POPULATION
}

\author{
by \\ Aileen Harris \\ A thesis submitted to \\ the Faculty of Graduate and Postdoctoral Affairs \\ in partial fulfillment of the requirements for the degree of \\ Master of Arts \\ in
}

Psychology

Carleton University

Ottawa, Canada

C2013 Aileen Harris 
Library and Archives

Canada

Published Heritage

Branch

395 Wellington Street

Ottawa ON K1A ON4

Canada
Bibliothèque et

Archives Canada

Direction du

Patrimoine de l'édition

395 , rue Wellington

Ottawa ON K1A ON4

Canada
Your file Votre référence

ISBN: 978-0-494-94304-5

Our file Notre référence

ISBN: $978-0-494-94304-5$
NOTICE:

The author has granted a nonexclusive license allowing Library and Archives Canada to reproduce, publish, archive, preserve, conserve, communicate to the public by telecommunication or on the Internet, loan, distrbute and sell theses worldwide, for commercial or noncommercial purposes, in microform, paper, electronic and/or any other formats.

The author retains copyright ownership and moral rights in this thesis. Neither the thesis nor substantial extracts from it may be printed or otherwise reproduced without the author's permission.
AVIS:

L'auteur a accordé une licence non exclusive permettant à la Bibliothèque et Archives Canada de reproduire, publier, archiver, sauvegarder, conserver, transmettre au public par télécommunication ou par l'Internet, prêter, distribuer et vendre des thèses partout dans le monde, à des fins commerciales ou autres, sur support microforme, papier, électronique et/ou autres formats.

L'auteur conserve la propriété du droit d'auteur et des droits moraux qui protege cette thèse. $\mathrm{Ni}$ la thèse ni des extraits substantiels de celle-ci ne doivent être imprimés ou autrement reproduits sans son autorisation.
In compliance with the Canadian Privacy Act some supporting forms may have been removed from this thesis.

While these forms may be included in the document page count, their removal does not represent any loss of content from the thesis.
Conformément à la loi canadienne sur la protection de la vie privée, quelques formulaires secondaires ont été enlevés de cette thèse.

Bien que ces formulaires aient inclus dans la pagination, il n'y aura aucun contenu manquant. 


\begin{abstract}
The purpose of the study was to examine gender differences in institutional misconduct within a Canadian federal correctional context. Archival misconduct data was analyzed for a sample of 1,902 federally incarcerated adult offenders ( $n=951$ males, $n=951$ females) grouped by security level. Results from chi-square analyses, rate calculations, and ANOVAs demonstrated that the prevalence and incidence of minor misconducts were consistently higher for medium security women in comparison to their male counterparts. Based on survival analysis, findings also demonstrated that medium security women engaged in misconduct earlier than males while Cox regression analysis identified unique predictors. Finally, qualitative analysis of violent misconduct reports highlighted several gender differences regarding the nature of misconduct. Results of the current study offer preliminary support for gender differences in institutional misconduct, specifically in regards to minor misconduct within the medium security group and in relation to the nature of violent misconduct.
\end{abstract}




\section{Acknowledgments}

First and foremost, I would like to thank my supervisors Dr. Kelley Blanchette and Dr. Shelley Brown. I have been so fortunate to be able to work with two individuals who literally wrote the book on women offenders. The knowledge and experience you both possess is incredible and inspiring.

I am also grateful for my committee. Dr. Craig Bennell and Dr. Kevin Nunes thank you for your insight, feedback, and for challenging me to be a more critical thinker and to produce a better document. Dr. Guy Lacroix and Dr. Diana Majury - thank you for contributing your time, knowledge, and assistance in the completion of this project.

I would like to extend my gratitude to the Research Branch at the Correctional Service of Canada and to the Director General, Dr. Brian Grant. Without the support of the Branch, this project would not have been possible.

Thank you to my colleagues who have supported \& helped along the way. Dena Derkzen, thank you for your input and for sharing with me the ups and downs of being a grad student. Jennie Thompson, thank you for your feedback and for teaching me such an essential skill in our world of research. Ashley McConnell, thank you for listening to my many rants and for helping me out with the coding process.

Etelle Bourassa - thank you so much for answering all of my questions while being so caring and supportive. You go above and beyond every day and we are all so lucky to have you guiding us through this process.

Simon - we met halfway through my journey and you have been there every step of the way since. Thank you for your never ending love, patience, and support. Thank you for being so understanding, even when my work took precedence in our lives. 
Finally, I would like to thank my family; I could not have done this without you. Mom and Dad, I am forever grateful for your unwavering love and support. Thank you for encouraging me to push through the hard times and to keep moving forward. Most of all, thank you for instilling in me a passion for knowledge and learning that has brought me to where I am today. I am truly blessed to have you both by my side.

Mark - I have looked up to you since day one. I cannot tell you how much I admire you and how much of an influence you have been and continue to be on my life. Erin - your strength and perseverance have been a constant source of inspiration for me. Thank you for believing in me and reassuring me that I could finish this, while reminding me to step back and appreciate the bigger things in life and to grow as my own person. To the both of you - knowing I had your love \& support is what kept me going. 
Table of Contents

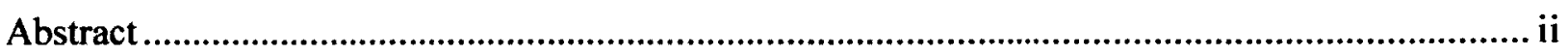

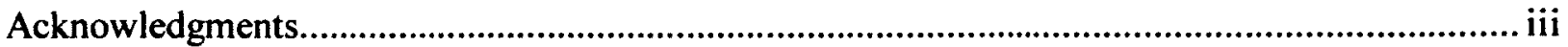

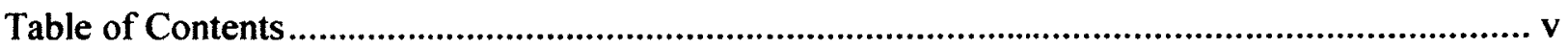

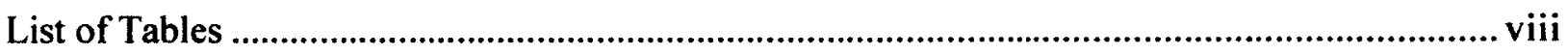

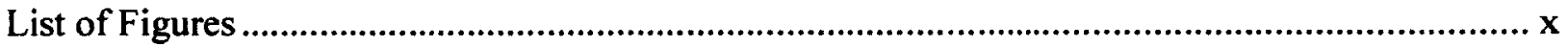

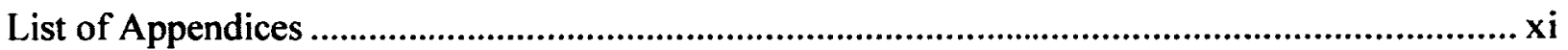

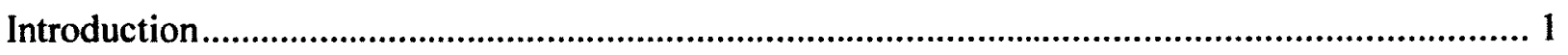

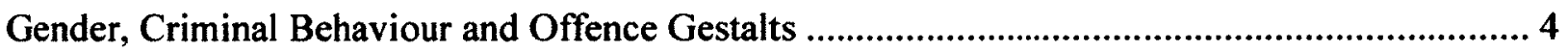

Gender and Criminal Behaviour: Theoretical Perspectives .............................................. 6

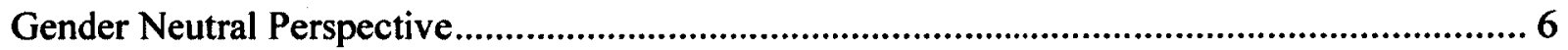

Personal, Interpersonal and Community-Reinforcement Theory (PIC-R)........................ 6

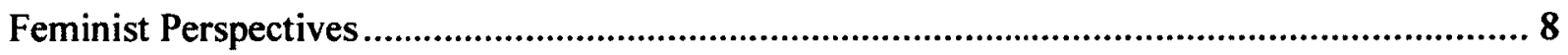

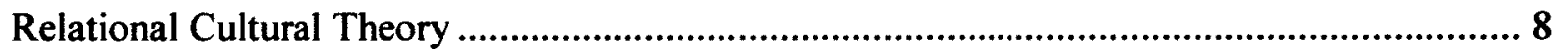

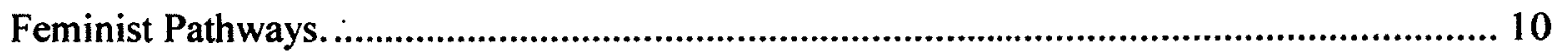

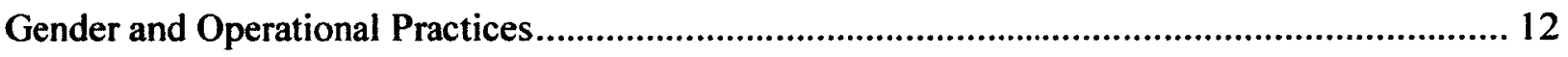

Assessment and Classification ................................................................................. 12

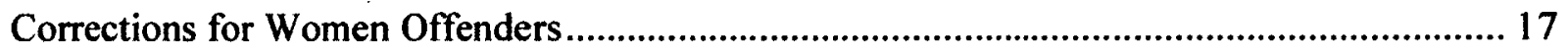

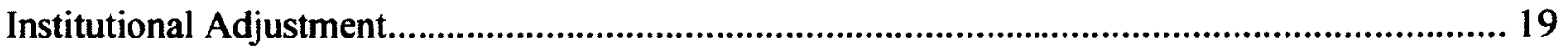

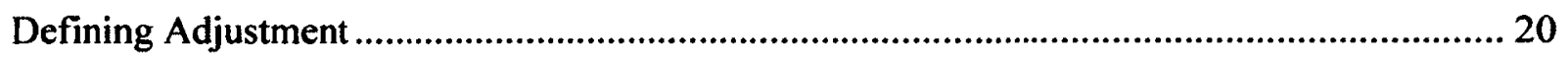

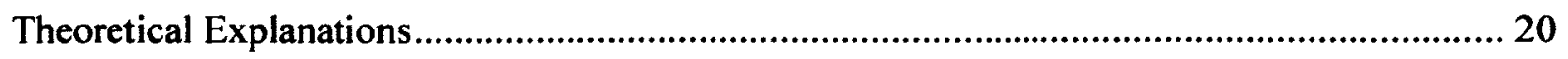

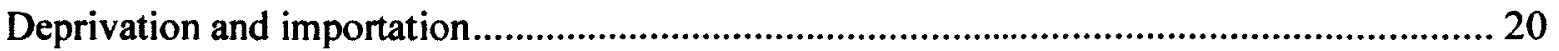




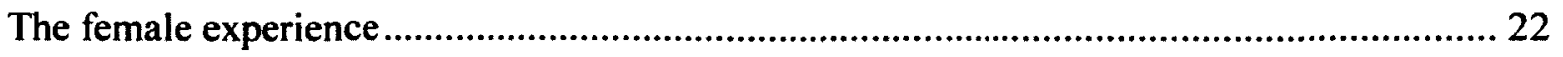

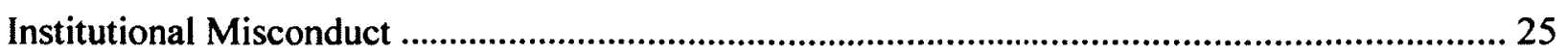

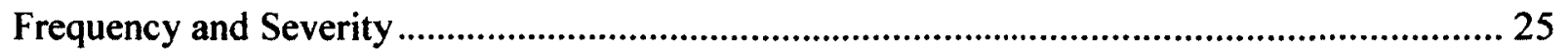

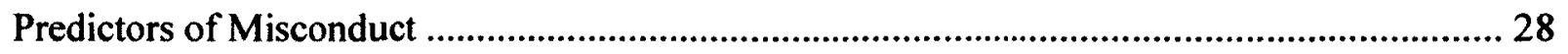

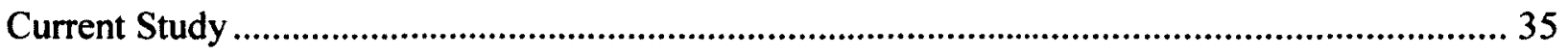

Research Question 1: Are there gender differences in the prevalence and incidence rates of misconduct among federally incarcerated offenders by security level? ........................ 36

Research Question 2: Are there gender differences in the patterns and predictors of survival time to first misconduct among federally incarcerated offenders by security

level?

Research Question 3: Do major incidents of misconduct differ qualitatively based on perpetrator gender?

Method

Sample

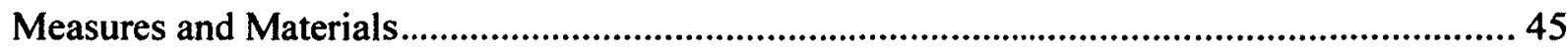

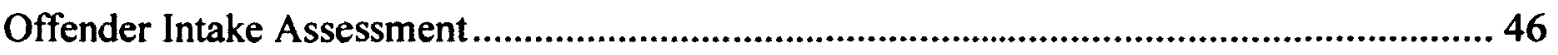

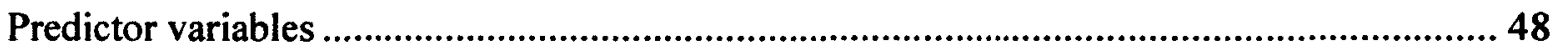

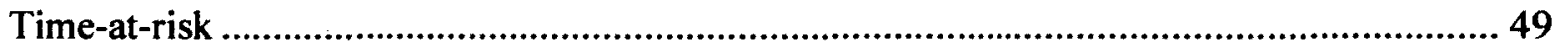

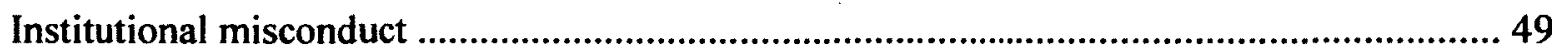

Misconduct reports ........................................................................................................... 49

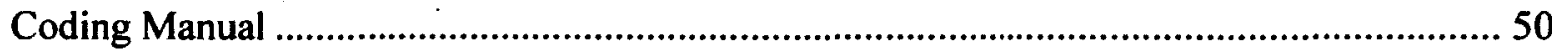

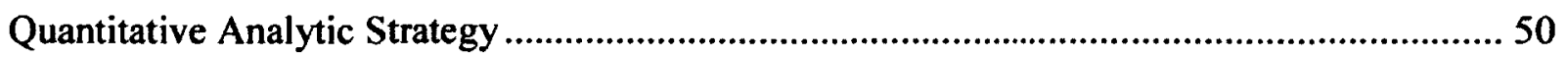

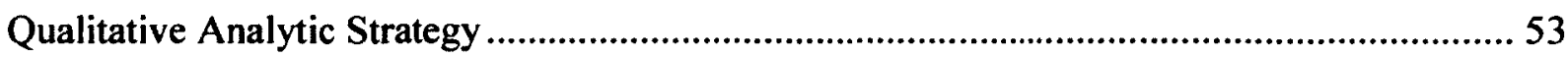


Results

Data Screening

Research Question 1: Are there gender differences in the prevalence and incidence rates of misconduct among federally incarcerated offenders by security level?

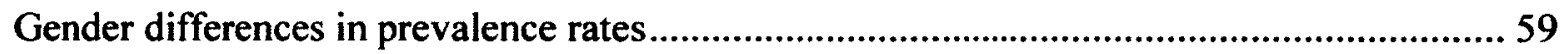

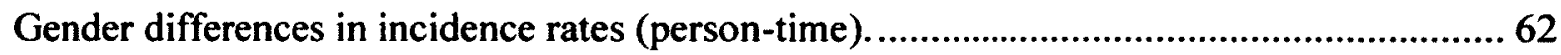

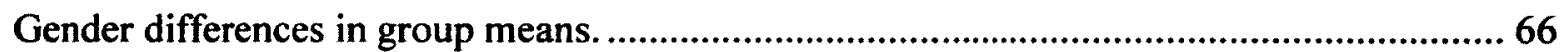

Research Question 2: Are there gender differences in the patterns and predictors of survival time to first misconduct among federally incarcerated offenders by security level?

Gender differences in time to first misconduct ......................................................... 70

Cox regression: the proportional hazards model. ......................................................... 78

Research Question 3: Do major incidents of misconduct differ qualitatively based on

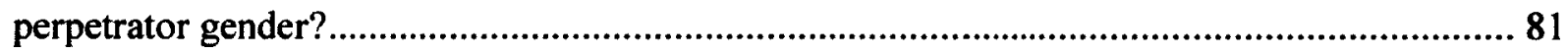

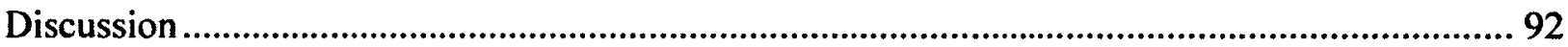

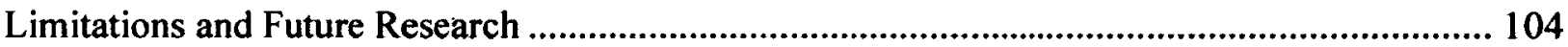

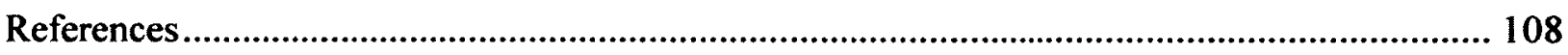

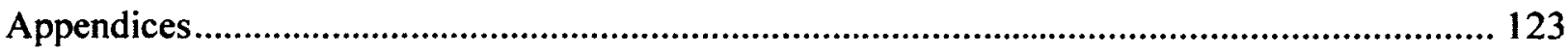




\section{List of Tables}

Table 1 Demographic Characteristics of the Current Sample

Table 2 Incarceration Characteristics of the Current Sample

Table 3 Static Risk, Dynamic Risk, Motivation, and Reintegration Potential of Maximum

Security Offenders as Assessed upon Admission

Table 4 Static Risk, Dynamic Risk, Motivation, and Reintegration Potential of Medium

Security Offenders as Assessed upon Admission .

Table 5 Static Risk, Dynamic Risk, Motivation, and Reintegration Potential of Minimum

Security Offenders as Assessed upon Admission

Table 6 Total Number of Misconduct Events by Gender, Security Level and Misconduct

Type.

Table 7 Mean Number of Misconducts for Total Sample

Table 8 Mean Number of Misconducts for Maximum Security Offenders. 58

Table 9 Mean Number of Misconducts for Medium Security Offenders

Table 10 Mean Number of Misconducts for Minimum Security Offenders

Table 11 The Prevalence of Offenders Engaging in Misconduct by Security Level -

Group 1

Table 12 The Prevalence of Offenders Engaging in Misconduct by Security Level -

Group 2

Table 13 The Prevalence of Offenders Engaging in Misconduct by Security Level -

Group 3

Table 14 Number of Misconduct Events and Person-Time for Male and Female

Offenders in Minimum, Medium and Maximum Security 
Table 15 Rates and Rate Ratios of Misconduct for Men and Women by Security Level ............. 65

Table 16 Rate of Estimated Misconducts per 100 Offenders per 36,500 Person-Days .............. 66

Table 17 Survival Analysis Examining Time to Failure for Major Misconduct by Security

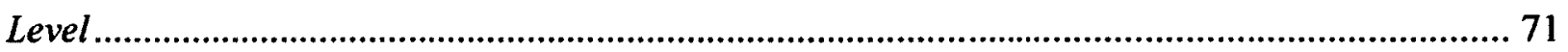

Table 18 Survival Analysis Examining Time to Failure for Minor Misconduct by Security

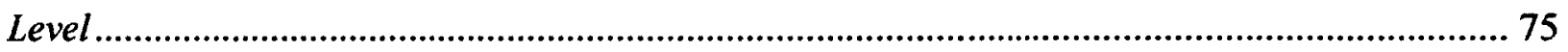




\section{List of Figures}

Figure 1. Graph of a significant interaction between security level and gender for minor misconduct.

Figure 2. Survival Analysis Examining Time to Failure for Major Misconduct between Genders within Maximum Security.

Figure 3. Survival Analysis Examining Time to Failure for Major Misconduct between

Genders within Medium Security.

Figure 4. Survival Analysis Examining Time to Failure for Major Misconduct between Genders within Minimum Security.

Figure 5. Survival Analysis Examining Time to Failure for Minor Misconduct between

Genders within Maximum Security.

Figure 6. Survival Analysis Examining Time to Failure for Minor Misconduct between Genders within Medium Security.

Figure 7. Survival Analysis Examining Time to Failure for Minor between Genders

within Minimum Security. 


\section{List of Appendices}

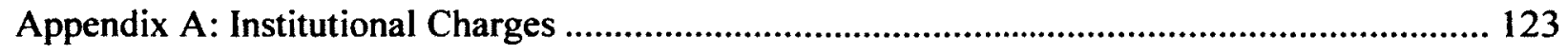

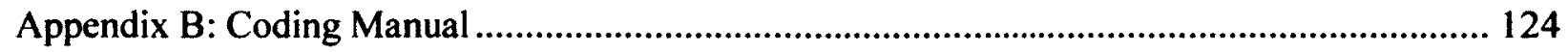

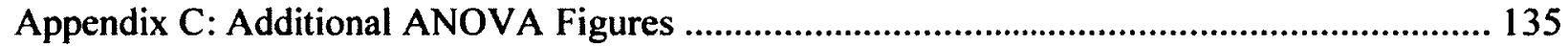

Appendix D: Cox Regression Analysis Results for Women ......................................... 140

Appendix E: Cox Regression Analysis Results for Men ............................................... 143

Appendix F: Qualitative Results by Security Level ..................................................... 146

Appendix G: Use of Force Management Model ........................................................... 150 
Examining Gender Differences in Institutional Misconduct within the

Canadian Federal Offender Population

\section{Introduction}

No longer considered 'correctional afterthoughts' (Ross \& Fabiano, 1986), female offenders have recently received considerable focus in correctional research and literature. Traditionally, correctional practices and explanations for criminal behaviour involving women have been based on practices implemented with male offenders, given that they represent the vast majority (95\%) of the prison population (Correctional Service of Canada, 2012c). Although the breadth of empirical knowledge pertaining to women has yet to parallel the extensive research accumulated on male offenders, genderresponsive theoretical perspectives and operational practices have garnered increasing attention within the past two decades.

Feminist scholars have consistently maintained that female offenders are inherently different from their male counterparts in regards to the onset of criminal behaviour, the frequency and nature of offending, and the criminogenic needs that signify intervention targets. It is therefore argued that correctional practices should reflect these differences rather than mimic the predominantly static nature of men's corrections (e.g., Bloom, Owen, \& Covington, 2003; Chesney-Lind \& Shelden, 2003; Daly, 1992; HannahMoffat, 2009; Reisig, Holtfreter, \& Morash, 2006).

Accordingly, current correctional practices have been developed to acknowledge that women's backgrounds, risks, needs, and security requirements are potentially unique. Although once strongly criticized for its treatment of female offenders (see Task Force on Federally Sentenced Women, 1990), Canada has been at the forefront over the past two 
decades in the development of a holistic, women-centered correctional model. Innovative intervention methods, management strategies and dynamic security practices have been established to better facilitate rehabilitation while maintaining the safety of correctional facilities (Blanchette, 2000; Correctional Service Canada, 2002).

Recent events however, have once again brought into question the institutional environment and its impact on female offenders with the 2007 death of Ashley Smith in segregation while in federal custody (Pate, 2010). Smith's behavioural problems, mental health issues and troubled history as a justice involved youth have been the focus of both media attention (e.g., Pate, 2010) and official reports and inquiries (e.g., Office of the Correctional Investigator, 2008; Report of the New Brunswick Ombudsman \& Child \& Youth Advocate, 2008). It has been argued that the conditions of confinement exacerbated her mental health problems, leading to her maladjustment and increasingly antisocial behaviours within the prison. This in turn, it has been argued, led to a continuous increase in strict static security measures, thus establishing a vicious cycle that lead to the deterioration of her wellbeing and her eventual death by selfstrangulation.

With the rising number of federally incarcerated women over the past decade (Women Offender Sector, 2010) and the increasing rate of mental health disorders among women being filtered into the correctional system, there is a growing cause for concern (CSC, 2009b). Given that this population is already plagued with substance abuse, maladjustment, self-injurious behaviours, and issues with past victimization and abuse (Leschied, 2011), the prison environment and women's behaviour within it, is something that should be further assessed and monitored. 
Given that misconduct and maladjustment can jeopardize the institutional setting and the safety of both staff and inmates (as demonstrated in the Smith case), one of the most important functions of managing behaviour and maintaining prison safety is the ability to assess and classify offenders based on risk and probability of adjustment (Motiuk, 1997). This practice informs appropriate responses regarding custody placement, supervision requirements and treatment needs thus ensuring a secure rehabilitative environment and the effective management of an offender population (Motiuk, 1997). Although progress in the assessment and classification of female offenders in correctional facilities has been made, concerns regarding the accuracy of classification tools and subsequent interventions still remain (Hannah-Moffat, 2009; Hardyman \& Van Voorhis, 2004; Reisig et al., 2006). Rather than assuming a 'one size fits all' mentality, it has been argued that classification, custody level and designated risk level should be considered relative to the population in question (Van Voorhis \& Brown, 1996). In other words, it is important to consider that high-risk females may still be considerably different from male offenders classified at the same level and that institutional adjustment and behaviours may still vary by gender within the same security classification. Evidently, this potential discrepancy holds with it significant implications regarding operational practices and correctional policies (Van Voorhis \& Presser, 2001). The current study consists of (1) a quantitative assessment of gender differences within security level in institutional misconduct rates, (2) survival patterns and predictor variables of misconduct, as well as (3) a qualitative assessment of differences in violent major misconduct. The goal of the study is to advance theory, methodology and operational practices. In comparing misconducts of incarcerated males and females, this 
study will advance theoretical perspectives regarding gender differences in criminal behaviour that extend into the institutional environment. With the inclusion of a male comparison group, samples from all institutional security levels, a mixed-method design, and an assessment of misconduct patterns over time, this study will also address certain methodological gaps that exist in the current research. Given the evident implications of institutional misconduct, the final objective is to contribute knowledge that is relevant to operational policies and practices.

The following review of the literature will therefore provide a brief review of female offence patterns, followed by a broad overview of theoretical perspectives in understanding criminal behaviour; outlining gender-neutral and gender-responsive viewpoints to contextualize the current study. Subsequently, the gender differences debate within the operational literature will be discussed, while highlighting practices of risk assessment and classification with female offenders. The institutional environment will also be addressed by articulating competing explanations of prison adjustment while specifically exploring gender-specific arguments pertaining to women. Finally, extant research regarding prison incidents and offender misconduct in both the male and female offender populations will be examined.

\section{Gender, Criminal Behaviour and Offence Gestalts}

Prior to discussing theoretical explanations for offending, it is important to briefly review the extent of female criminal behaviour and related offence gestalts ${ }^{\prime}$. Disparities

\footnotetext{
' Gestalt is a term rooted in a psychological school of thought which argues that behaviour cannot be understood in parts, but should be studied as a whole (i.e., 'the whole is bigger than the sum of its parts'; Weiten \& McCann, 2010). In the current context it refers to the nature of offending and the context in which it occurs (i.e., the 'bigger picture').
} 
in offending demonstrate that women in general are far less likely to commit crime in comparison to men (Kong \& AuCoin, 2008). In 2009, approximately 233,000 females (youth and adult) were accused of committing a Criminal Code offence in Canada, in contrast to approximately 776,000 adult and youth males. Furthermore, women made up only $21 \%$ of all adults charged under the Criminal Code in the same year (Canadian Centre for Justice Statistics, 2011). This disparity becomes even more evident when looking at violent offences (Steffensmeier, 2001). In terms of violent crime statistics in Canada, women account for less than $20 \%$ of all violent adult offender charges (Canadian Centre for Justice Statistics, 2004; Canadian Centre for Justice Statistics, 2011). These trends have been consistent over the years in both Canadian and international contexts (Kong \& AuCoin, 2008; Steffensmeier, 2001)

Female offences are seen as being qualitatively distinct as well. Femaleperpetrated violence appears to be more relational in nature, often directed towards known victims, whereas male-perpetrated violence is often more predatory and involving strangers. In a landmark study, Greenfeld and Snell (1999) conducted an extensive review of approximately 460,000 homicides in the United States over a 20 year period. Approximately $60 \%$ of female-perpetrated homicides involved intimate partners or family members, while only $20 \%$ of male-perpetrated homicides demonstrated the same victim pattern. Official statistics have demonstrated similar findings. Results of a homicide survey over a 12 year period (1997-2009) in Canada indicate that over $65 \%$ of female homicides involve intimate/familial victims while just over $60 \%$ of male homicides involve acquaintances or strangers as victims (Canadian Centre for Justice Statistics, 2011). Additionally, women's motivational factors for partner homicide are 
often in response to domestic violence and abuse (Belknap, 2007). Koons-Witt and Schram (2003) point out that this type of violence is not likely to repeat or escalate in seriousness. Research on the frequency of offending as well as offence gestalts therefore offers support for gender differences in criminal behaviour.

\section{Gender and Criminal Behaviour: Theoretical Perspectives}

Given these differences, two competing perspectives to explain criminality have emerged within the gender debate: the gender-neutral camp and the gender-specific camp. The following sections first provide an overview of theoretical perspectives from both sides as well as a review of the related operational practices of assessment and classification.

\section{The Gender Neutral Perspective}

\section{Personal, Interpersonal and Community-Reinforcement Theory (PIC-R).}

Grounded in social learning theory, the PIC-R (Andrews \& Bonta, 2010) integrates a diverse range of factors and influences in providing a broad perspective to explain criminal behaviour. The theory suggests that a balance of variables and internal dialogue are what influence the rewards and costs of crime and thus impact the probability of engaging in criminal behaviour. Additionally, the theory outlines that these costs and rewards can stem from four potential sources including situational factors (e.g., substance use), personal factors (e.g., antisocial attitudes), interpersonal factors (e.g., antisocial peers) and community factors (e.g., neighbourhood). It is the interaction and influence of these dimensions that increases the probability of an individual engaging in criminal activity when the rewards outweigh the costs of doing so (Andrews \& Bonta, 2010). 
PIC-R takes into account the overarching role of society in crime, acknowledging the societal influence in regards to the allocation of costs and rewards. That being said, this theory predominantly emphasizes the importance of individual risk factors established as predictors of criminal behaviour (Andrews \& Bonta, 2010). In this regard, central to the PIC-R theory are three fundamental concepts of risk, need and responsivity (RNR).

$\boldsymbol{R N R}$-Principles. The risk principle relates to an individual's risk to reoffend and is guided by two key points: 1) criminal behaviour can be predicted through appropriate assessment and 2) the likelihood of recidivism can be reduced by providing treatment services that match an offender's level of risk (e.g., medium risk offenders should receive medium intensity interventions; Andrews \& Bonta, 2010).

The need principle further highlights that effective correctional interventions should be centered on identified dynamic risk factors (i.e., criminogenic needs), that are related to an individual's risk to recidivate. These needs are considered predominantly dynamic and changeable in nature, and are therefore ideal targets for correctional programming (Andrews \& Bonta, 2010).

Individual factors that are most predictive of recidivism constitute the Central Eight: (1) antisocial attitudes, (2) antisocial associates, (3) history of antisocial behaviour, (4) antisocial personality, (5) substance abuse, (6) family factors, (7) employment/education, and (8) leisure/recreation. Collectively, these factors account for individual criminality and are considered relevant, irrespective of gender, race or social class (Andrews \& Bonta, 2010). 
Finally, the responsivity principle, which relates to program delivery, asserts that treatment should be grounded in cognitive and social learning perspectives while also formatted to take into consideration learning styles, cognitive abilities, and other individual characteristics of offenders (Andrews \& Bonta, 2010).

A tenet of the PIC-R theory is that all principles are applicable, regardless of gender, thus making it a gender-neutral viewpoint. This assumption carries evident operational implications, which will be discussed shortly in addition to relevant empirical support.

\section{Feminist Perspectives}

Female offenders represent a diverse population with unique and diverse offending behaviours, risk factors and treatment needs (Belknap, 2007). In explaining criminal behaviour, feminist scholars argue the existence of gender-specific risk factors that are distinctly related to female offending, and gender-salient factors that are applicable to both genders, but are stronger predictors for females (e.g., Belknap, 2007; Chesney-Lind \& Shelden, 2003). It is emphasized that these factors need to be taken into consideration, and that gender-neutral theories, such as the PIC-R, are inherently male and do not accurately capture such concepts.

Although extant feminist theoretical literature regarding female offending is beyond the scope of the current analysis given its extensive and diverse nature, (see Blanchette \& Brown, 2006), two perspectives that are prominent in the correctional literature will be discussed.

Relational Cultural Theory. Based on the work of Miller (1986), relational cultural theory (RCT) offers a gender responsive perspective in contrast to the 
conventional theories of autonomy and individualism applied to males (e.g., Erikson, 1963). Rather than the practice of rehabilitation through individualism and independence, RCT asserts that healthy and meaningful relationships are what foster psychological development and are especially important for women.

Grounded predominantly in qualitative research, the theory posits that healthy connections which facilitate positive growth and change are defined by five essential aspects: mutual engagement (i.e., perceived mutual involvement and commitment of both parties), empowerment (i.e., empower to act positively and take action), authenticity (i.e., knowledge of the self and others), the ability to accept and effectively manage conflict, and lastly, the want to establish further connection.

It is hypothesized that if relational health is not present or if there is a rupture within a relationship, there may be a negative impact on psychological development (e.g., diminished self-worth, lack of pro-social actions, and a diminished ability to manage conflict; Comstock, Hammer, Strentzsch, Cannon, Parsons, \& Salazar, 2008; Frey, Beesley, \& Miller, 2006; Frey, Tobin, \& Beesley, 2004). Furthermore, the manifestation of these psychological issues and the negative effects of social isolation and disempowerment may play a role in female offending (Bloom, Owen, \& Covington, 2003). Consequently, women are likely to adopt negative coping mechanisms that lead to a criminalized lifestyle (e.g., substance abuse). The link between unhealthy relationships and pathways to criminality is particularly germane to women's offending behaviours. For example, female offenders report significantly higher rates of past victimization, abuse, and neglect (evidence of unhealthy and harmful relationships). It is argued that past abuse often plays a role in the onset of criminal behavior and adjustment 
problems (Salisbury \& Van Voorhis, 2009). Research also suggests that antisocial peers are a powerful predictor of recidivism in women, with ample evidence to support the link between antisocial associates (i.e., unhealthy or ruptured relationships) and female offending (Brown \& Motiuk, 2005).

Although scholars have drawn a link between certain factors researched in criminality (e.g., antisocial attachments, past victimization; e.g., Chesney-Lind, 2006; Salisbury \& Van Voorhis, 2009), direct empirical support for RCT within the forensic field is limited. This theory is predominantly grounded in qualitative research regarding girls' and women's development in general. For this reason, the operationalization and measurement of RCT specifically in relation to female offending has not yet been fully realized. The following pathways model, however, has offered more empirical support. Feminist Pathways. Although RCT is considered a broad theoretical model, applicable to women's development in general, the feminist pathways perspective was derived to specifically explain the trajectory of girls and women into lives of crime. Pathways literature postulates that the majority of women engage in criminal behaviours as a result of an oppressive patriarchal society and as a means to survive and support unhealthy coping behaviours (Daly, 1992). Pathways supporters contend that the nature of female offending is distinctly associated with macro-level factors and societal influences such as economic marginalization, limited community resources, and systemic poverty (Chesney-Lind \& Shelden, 2003).

Similar to RCT, pathways also emphasizes the role of relationships in female offending; arguing specifically that childhood trauma and/or neglect results in young girls leaving their homes to avoid the abuse, and inevitably places them into a criminalized 
lifestyle. Consequently, girls are likely to engage in substance abuse as a coping mechanism as well as prostitution, drug-selling, and other illegal activities as a means to survive. It is therefore argued that girls and women are essentially being criminalized for their methods of survival and coping (Chesney-Lind, 1989).

Recognizing the heterogeneous nature of women's trajectories, work by Daly (1992) and similar research by Reisig and colleagues (2006) suggests that there are five different pathways that lead women to engage in criminal activities. These include: street women (victimized and surviving via prostitution/drugs and less serious crimes), harmed and harming women (victimized with a history of violent behavior and mental health issues), battered women (used violence as self-defence against partner), drug-connected women (involved in a drug dealing lifestyle with partner or associates) and other/economically motivated women. Interestingly, the final group does not fit into the typical 'gendered pathway'. Economically motivated women or those who are unclassified tend to mimic the typical male offender in that the crimes are more acquisitive in nature, based more so on pleasure seeking motivations rather than survival or coping strategies (Daly, 1992).

More recent research has offered support for the pathways literature with both justice involved youth and adult offenders (e.g., Jones, 2011; Perkins, 2010; Salisbury \& Van Voorhis 2009). Work by Jones (2011) for example, investigated risk assessment in young female offenders; examining gender-neutral and gender-salient factors with 1,550 male and 819 female youths on probation in the state of New York. Based on proximity scaling analysis, the results revealed that nearly half of the female youth demonstrated personal factors (e.g., homelessness, victims of abuse, mental health issues) that could be 
mapped onto Daly's categories. A second thematic group also emerged among the females, following a 'stereotypically male' antisocial pathway to crime, thus offering support for both gendered pathways and traditional antisocial pathways.

Although research regarding these categories has been traditionally based on qualitative methods with small samples of women, these emerging studies offer promising results. This prominent theory and relevant research offers a multi-dimensional understanding of female offending and offers insight into the unique experiences of women.

\section{Gender and Operational Practices}

\section{Assessment and Classification}

Given that the aforementioned theories (RNR in particular) guide current correctional practices, the gender debate goes beyond the theoretical spectrum and frequently permeates operational practices of assessment and classification. Risk assessment, which is RNR based, is at the centre of correctional research; a continuously evolving field that has advanced considerably over the last decade. An extensive array of instruments exists for various offender types. For example, the Violence Risk Appraisal Guide (VRAG; Harris, Rice, Quinsey, 1993) and the Historical Clinical Risk Scheme (HCR-20; Webster, Douglas, Eaves \& Hart, 1997) are administered in the prediction of violence. Assessments such as the Spousal Assault Risk Assessment (SARA; Kropp, \& Hart, 2000) are implemented for the prediction of male-perpetrated domestic violence while the Static-99 (Hanson \& Thornton, 2000) and related measures are used for the risk assessment of sex offenders. Over the past two decades there has also been movement from the practice of subjective professional judgment to the implementation of 
empirically driven and actuarial methods, such as the aforementioned measures. Offender assessment methods have also evolved from the use of strictly static factors (e.g., demographics, criminal history) as robust indicators of risk to the incorporation of dynamic factors (e.g., antisocial cognitions) as indicators of treatment objectives and offender progress. Despite generational growth and the burgeoning selection of assessment tools, once again, progress in the assessment of women offenders has been substantially slower.

Gender-Neutral versus Gender-Responsive. The gender-neutral perspective maintains that assessment tools developed based on the Central Eight factors of the RNR model are applicable in the prediction of antisocial behaviour regardless of gender. This therefore assumes similarity of criminogenic needs for males and females.

An extensive amount of correctional research has provided empirical support for the application of the RNR model in the assessment of the general offender population (Andrews \& Bonta, 2010; Andrews \& Dowden, 2006; Brown \& Motiuk, 2005; Gendreau \& Andrews, 1990; Motiuk \& Serin, 2001). Adherence to these principles in correctional programming has shown significant reductions in recidivism rates in comparison to nonRNR based interventions (Andrews \& Bonta, 2010; Andrews et al., 1990; Bourgon \& Armstrong, 2005). Assessment tools grounded in RNR, such as the Level of Service/Case Management Inventory (LS/CMI: Andrews, Bonta, \& Wormith, 2004), have consistently demonstrated accuracy and validity in correctional settings and are considered the 'gold standards' of risk assessment. For example, with a total sample of 14,737 women offenders and 27 effect sizes across 25 studies, a meta-analysis by Smith and colleagues (2009) demonstrated promising results. With an average effect size of $r=$ 
.35 , the LSI-R was equivalent in predicting reoffending in both male and female samples (Smith, Cullen \& Latessa, 2009). It is noteworthy however, that the sampling method in this analysis predominantly included studies from the same researchers while also relying on non-peer reviewed sources.

Despite preliminary research focusing specifically on gender in the RNR model (e.g., Folsom \& Atkinson, 2007; Rettinger \& Andrews, 2010) some scholars and researchers remain skeptical of implementing the use of a male-developed model with women. These researchers maintain that results still demonstrate fairly weak predictive accuracy in comparison to men, and the majority of research still relies on all-male samples or presents methodological issues, such as small female samples (e.g., Folsom \& Atkinson, 2007). Research in this area should therefore be interpreted with caution.

Gender-responsive perspectives reject the concept that the same factors explain criminal behaviour for both men and women. Current criminological and psychological theories are seen as narrow and androcentric in nature. In assessing women through a 'gender-neutral lens', scholars warn that there is a potential to overlook important risk factors that are either specific to women or play a different role in women's criminality (Belknap, 2007; Hannah-Moffat, 1999, 2009). Brown and Motiuk (2005), for example, found that a significant portion of the dichotomous risk indicators used in a standardized Correctional Services of Canada (CSC) assessment tool were female-specific or femalesalient (e.g., education, substance abuse, parenting skills, and coping skills). Marriage, for example, has been identified as a protective factor for males by reducing their risk of recidivism. In contrast, it is considered an indicator of increased risk for females (Benda, 2005). Furthermore, as discussed above, female-perpetrated violence that is in response 
to domestic abuse is unlikely to repeat or escalate in severity (Koons-Witt \& Scram, 2003). This reveals women's criminal history may not be as predictive of future criminal behaviour. This misconception can lead to the overestimation of female risk (Pollock \& Davis, 2005), thus providing further evidence supporting the need for gender-specific and gender-salient factors.

Furthermore, there is the possibility that assessment is overlooking certain populations of women, and that predictive accuracy fluctuates with the typology of female offenders being assessed. Based on the pathways model discussed earlier, Reisig and colleagues (2006) assessed the applicability of the Level of Service InventoryRevised (LSI-R) in a sample of 235 female offenders who had been categorized into three pathway groups for the purpose of the study. These included: economically-motivated women (i.e., male typical pathways), gendered pathways women (this included drugconnected, battered, harmed/harming and street women), and unclassifiable women. The relationship between the LSI-R total score and recidivism was not statistically significant for the full sample as the results demonstrated a fairly weak relationship (Pearson $r=$ $.07)$. When observing subsamples however, risk level as assessed by the LSI-R was in fact predictive of recidivism for the economically-motivated group (Pearson $r=.29$ ) and the unclassifiable women (Pearson $r=.49$ ). Interestingly, the relationship for the women following gendered pathways was not significant. Results, however, should be interpreted with caution given that the typologies are grounded in qualitative research with small sample sizes and the methodology used for categorizing women in the current study was subjective. Notwithstanding these limitations, the authors still emphasize the importance of such findings. Although the LSI-R and its theoretical background may be applicable 
to women who 'mimic' the typical male offender, factors that are pertinent to the gendered pathway women (the majority of women offenders), are still overlooked under the gender-neutral lens (Reisig et al., 2006).

Over-Classification. There is also a concern regarding the potential negative consequences for the women themselves as a result of inaccurate classification. The primary objective of security classification is to "use the least restrictive measure consistent with the protection of the public, staff members and offender" (Corrections and Conditional Release Act, 1992, s.4[d]). Research, however, has demonstrated that classification measures developed based on male offender samples often result in the inaccurate and overclassification of women (i.e., their placement in a risk category or custody level that is higher than what is actually necessary to manage their behavior; Van Voorhis \& Presser, 2001; Wright, Salisbury, \& Van Voorhis, 2007). By omitting genderspecific factors or inappropriately weighting gender-salient factors, the concern is that women, who typically present lower levels of risk in comparison to men, will not be assessed properly. This would lead to unnecessary/inadequate security measures, thus undermining reintegration efforts. Furthermore, the administration of gender-neutral measures poses the risk of inaccurately identifying women offenders' needs, which subsequently impacts the allocation of resources and the effectiveness of interventions (Van Voorhis \& Presser, 2001). Van Voorhis and Presser (2001) further support this argument in stating that "applying any type of prediction instrument to a population other than the one used for its construction and validation is scientifically improper and professionally unethical and can result in inappropriate decisions for the group being (mis)diagnosed" (p. 4). 
For this reason, advocates for the gender-responsive perspective contend that simply adapting a measure developed with male samples is inadequate. Instruments need to be strongly and empirically validated with female samples and developed from the ground up specifically for women (Belknap, 2007; Chesney-Lind \& Shelden, 2003; Hannah-Moffat, 2009). The over-classification argument therefore supports the need for women-specific assessment and operational practices.

\section{Corrections for Women Offenders}

Given the theoretical perspectives, risk assessments and offence patterns, current Canadian correctional practices were developed to reflect these differences and effectively respond to women's needs. Over the past two decades, a new approach to women's corrections in Canada has been established, and the need for gender-responsive interventions recognized (Blanchette, 2000; Blanchette \& Brown, 2006). Current correctional initiatives are based on the guiding principles of Creating Choices, the report of the 1990 Task Force on Federally Sentenced Women, which emphasized the need for a holistic correctional model with women. The Task Force outlined correctional goals based on the principles of empowerment, meaningful and responsible choices, respect and dignity, shared responsibility and a supportive environment (Task Force on Federally Sentenced Women, 1990). The perspective was that women should be managed with different intervention methods and more dynamic security practices so that rehabilitation can be achieved while maintaining safety and security (CSC, 2002). For example, current rehabilitative initiatives are grounded in RCT as it has been a core focus in the development of women-centered methods of intervention. As outlined in The Program Strategy for Women Offenders (Fortin, 2004), programs must take into account the 
psychological development of women and use a trauma-informed approach to better facilitate their institutional adjustment and rehabilitation.

The five principles articulated by the Task Force drove the implementation of new infrastructures and security practices as well. Women's federal institutions are operated using a community-living model, rather than traditional static infrastructures (Blanchette, 2000). Unlike male facilities, all women's institutions are multilevel, where security levels are mixed within the housing units (minimum and medium), and a separate unit exists for maximum security women. In contrast to the traditionally static security practiced in male institutions, dynamic security is an integral component in this holistic approach to women's corrections. As outlined in policy (Commissioner's Directive 560), the objective of dynamic security is to "optimize a safe environment for employees, offenders and the public through meaningful interactions between [correctional staff and inmates]" (CSC, 2006). Correctional Officers at women's sites, for example, are instead identified as "Primary Workers" to provide a label that holds less 'punitive' connotation, and to reflect their dual security/social worker type role. Static security measures, such as the regulation stab-proof vests, are only implemented at maximum security level in women's institutions. The vests are mandatory, however, at both medium and maximum security prisons for men (CSC, 2009c). Variations in movement and escort policies as well as the use of other static security tools, such as Oleoresin Capsicum (OC) Inflammatory Spray, are also indicative of differential practices in the institutions (CSC, 2012a). In other words, the women's federal sites still attempt to use an interactive, rather than reactive approach, using less restrictive measures to develop a positive institutional environment and a 'teamwork' culture. This approach, it is argued, is reflective of the 
relatively lower risk of women and strives to ensure the safety and psychological wellbeing of female inmates, as well as their institutional adjustment and rehabilitation.

Notwithstanding these advancements, it is important to note that women's corrections in Canada is not without criticism, as some argue that the principles of Creating Choices have not been fully realized (e.g., Hannah-Moffat, 2000; Jackson \& Stewart, 2009; Office of the Correctional Investigator, 2010). Furthermore, although these practices are seen as being positive and innovative, controlled research assessing the effectiveness of these methods has not yet been conducted. Adequate empirical validation regarding the efficiency of certain practices, such as dynamic security, is needed in order to better justify their use. Nevertheless, it is still important to note the developments made in women's corrections in Canada as well as the contrasting environments between men and women's institutions.

\section{Institutional Adjustment}

The overall purpose of the aforementioned practices of classification, assessment, and gender-responsive corrections, is to ensure population management and effective intervention strategies. This in turn is to facilitate offender rehabilitation and minimize institutional misconduct (Blanchette, 2000, 2005). In addition to posing a safety risk, prison misconduct can lead to negative institutional consequences (e.g., increase in security level, restrictions to privileges, programs, or services) as well as long term consequences such as additional criminal sanctions, lengthened sentences, and reduced likelihood of parole (Blackburn \& Trulson, 2010). Accordingly, understanding inmate adjustment is important not only to be able to predict and prevent misbehaviour, but also to facilitate rehabilitation and successful release into the community. Explanations 
regarding offender adjustment, however, vary in nature while research regarding gender differences and predictors is still in its infancy.

\section{Defining Adjustment}

Adjustment is the process of adapting to a surrounding environment by modifying one's behaviors to conform (Islam-Zwart \& Vik, 2004). Prison can be a stressful and harsh environment that does in fact require one to adapt to new surroundings and therefore, adjust (Van Tongeren \& Klebe, 2010). There is an ambiguity, however, in correctional research surrounding the definition of institutional adjustment. Some researchers focus on positive factors such as successful intervention strategies and offender rehabilitation as indicators of adjustment (e.g., Loper, 2002). Others refer to environmental necessities (e.g., privacy, food, exercise) pertaining to an inmate's quality of life (e.g., Warren, Hurt, Loper, \& Chauhan, 2004) while behavioural adjustment is assessed strictly on patterns of misconduct (e.g., Craddock, 1996). The notion that adjustment is a multidimensional construct (social, behavioural, and environmental) has also been argued in the literature (e.g., Van Tongeren \& Klebe, 2010). For the purpose of the current study, the focus will be on behavioural adjustment alone with offender misconduct as the main measure of adaptation to incarceration. That being said, a broad overview regarding theoretical explanations of adjustment patterns as well as existing misconduct research is necessary to contextualize the current study.

\section{Theoretical Explanations}

Deprivation and importation. The deprivation theory asserts that the prison environment alters offenders' values, attitudes and behaviours (Goodstein \& Wright, 1991), suggesting that inmate misbehaviour is the result of having to adapt to the stressful 
environment. First articulated by Sykes (1958), deprivation represents the 'pains of imprisonment' that include the "loss of liberty, loss of goods and services, loss of heterosexual relationships, loss of autonomy and loss of security" (p.65). The model hypothesizes that these losses lead to the development of an institutional subculture (i.e., the inmate code) that opposes prison staff and other figures of authority (Goodstein \& Wright, 1991). Essentially, this theory explains inmate adjustment and misconduct based on aspects specifically related to the prison environment as influential and predictive factors (Gover, Perez, \& Jennings, 2008). Frequent variables measured in the literature include type of institution, length of incarceration, prison infrastructure, quality of life, and level of security (Gover, Mackenzie, \& Armstrong, 2000).

In contrast, Irwin and Cressey (1962) assert that offenders do not enter the correctional system as innocent individuals to be shaped by their institutional circumstances. Accordingly, the importation theory purports that behavior is determined by individual offender characteristics and values that are engrained prior to incarceration. In this view, adjustment is pre-determined by offender attributes which are brought into the prison environment. The focus is therefore placed on the individual characteristics to explain offender adjustment while incarcerated. Variables measured when assessing importation include prior incarceration, index offence, age, race, and gender (Gover et al., 2000; Gover et al., 2008).

Both theories have been criticized as being broad and ambiguous, with multiple potential variables to consider and results that are inconsistent (Jiang \& Fisher-Giorlando, 2002). Notwithstanding this critique, sufficient empirical support has been demonstrated for such importation variables as age, ethnicity, and prior incarcerations in relation to 
poor adjustment and increased misconduct (e.g., Casey-Acevedo \& Bakken, 2004; Gover et al., 2000; Gover et al., 2008; Steiner \& Wooldredge, 2009; Way, Miraglia, Sawyer, Beer, \& Eddy, 2005). Similarly, research has also demonstrated support for deprivation factors such as length of sentence, level of security, overcrowding, prison infrastructure, and perceived quality of life in relation to maladjustment and misconduct (e.g., Franklin, Franklin, \& Pratt, 2006; Gendreau, Goggin \& Law, 1997; Gover et al., 2000; Steiner \& Wooldredge, 2009). More detailed examples regarding predictors of misconduct (rooted in both importation and deprivation theories) and gender differences will be addressed shortly.

The female experience. Empirical research based on these theories has been conducted in different institutional settings across different offender groups (e.g., youth versus adult offenders). However, with the exception of a few studies, the majority of research in this area has been conducted with male samples. Gender-specific perspectives maintain that understanding offending behavior based on male research is insufficient and that the nature of women's maladjustment is different. In line with the pathways perspective, female inmates bring with them distinct backgrounds and characteristics into the institutional setting (e.g., mental health issues, substance abuse and past victimization) that potentially set them up for poor institutional adjustment (Belknap, 2007; Blackburn \& Trulson, 2010).

In accordance with RCT (Miller, 1986), research has also demonstrated that female prisoners require considerable social/relational support from family, children, friends and correctional staff in their rehabilitative process both within the facility and upon release into the community (Pollock, 2002; Gobeil, 2008). Given that female 
offenders are family and relationship oriented, isolation from those key support systems can impact female adjustment differently than males (Greer, 2000).

Research in the area of prison networks and offender interpersonal relationships further supports the notion that women's relational health is at the centre of their adjustment and behavior in prison. Traditionally, it is believed that males adjust through autonomy and individualism while focusing on "doing their own time, being tough, and relying on their feelings of inner strength $[\ldots]$ to get themselves through their time in prison" (Jiang \& Winfree, 2006, p.36). In contrast, women tend to remain invested in outside familial/supportive relationships during incarceration, while also engaging in pseudofamilies, assuming familial roles and establishing relationships that mimic a 'traditional' family structure (Owen, 1998). Intimate relationships have also been discussed as another aspect of the female prison subculture. Women tend to form connections that also imitate traditional relationships (similar factors including jealousy, co-dependency and separation), regardless of their sexuality prior to incarceration.

Conversely, some researchers proclaim that studies regarding kinship networks are dated, and that pseudofamilies are not as defined or prominent as once thought (Greer, 2000; Pollock, 2002). Although to a lesser extent, it is still hypothesized that women continue to build relationships as a method of adjustment and coping. The contrast is that women tend to develop relationships based more so on forming interpersonal ties rather than coercive power hierarchies that are more prominent among male prisoners (Greer, 2000).

Overall, feminist theory argues that women's unique patterns and determinants of behavior do not simply become obsolete or irrelevant once incarcerated. It is more likely that women carry gender-specific needs and predictors of adjustment with them into the 
prison environment. There is even the potential that current measures of adjustment are not fully capturing the female experience and are presenting conflicting results. For example, the Prison Adjustment Questionnaire (PAQ: Wright, 1985), assesses prisoner adjustment based on comparing the quality of life experienced within the institution in comparison to that in the community. It was developed for use with males and is used frequently in the adjustment literature as a gold standard of measurement. Research by Warren and colleagues (2004) showed that women's PAQ scores were indicative of more positive experiences for women in prison in comparison to the community, which is a stark contrast to what is found in the male offender research. Although some researchers purport that prison offers positive structure for women, authors contend that these results could be highlighting that the scoring method is not accurately capturing adjustment constructs within a female sample. Instead, this could be an indication that the assessments "inappropriately suppress and hide problems with adjustment that this sample experienced in prison, due to the unusually harsh nature of their lives prior to being sentenced" (Warren et al., 2004, p. 640), thus reiterating support for the pathways model.

From a theoretical perspective it can therefore be argued that adjustment to prison is a complex concept that can vary based on importation and deprivation models, and women-centered perspectives. Before addressing the potential gender-neutral and gender-specific predictors of behaviour, it is important to highlight differences in prison misconduct patterns. 


\section{Institutional Misconduct}

\section{Frequency and Severity}

The majority of research indicates that institutional misconduct is far more common among male inmates in comparison to females, especially when considering serious forms of violations (e.g., assault on staff or inmate; Craddock, 1996; Harer \& Langan, 2001; McClellan, 1994; Sorensen \& Cunningham, 2010; Sorensen, Cunningham, Vigen, \& Woodes, 2011). In a sample of 3,551 males and 1,315 females admitted to the North Carolina Division of prisons in the United States, Craddock (1996) assessed offender misconduct behaviours over a five year period to measure the prevalence and types of rule violations. Results demonstrated that the most prominent gender difference was that approximately half of the male sample had incurred rule violations while only a third of the women had. Frequency differences were also prominent with $90 \%$ of the men having fewer than 15 violations while $90 \%$ of women had less than 10 violations on file. Overall, males were more likely than females to have violent infractions whereas females were more commonly sanctioned for less serious infractions. Interestingly, however, nonviolent sexual offences, minor assault, escapes and attempted escapes were slightly more common among the females, while fighting was more common among men. Craddock (1996) suggests that these findings are likely due to sanctioning rather than behavioural patterns. It is proposed that staff may view women's assaultive and sexual behavior as being more deviant and thus requiring formal sanctions. Additionally, there is the possibility that staff view men's assaultive behaviour as more typical and expected in comparison to women's. Despite potential similarities in actions, the behaviour may be designated as a 'fighting' incident among the men which is less serious 
than assault (Craddock, 1996). Finally, it is important to note that because the results are based on data that is quite dated (1976-1980) and the conditions of female facilities were less secure at this time, the greater escape rates among women were again more likely indicative of situational, rather than behavioural differences (Craddock, 1996).

Harer and Langan (2001) also support that women are less violent than men during incarceration and that the nature of women's violence is different as well. With a large sample of 24,765 incarcerated women and 177,767 incarcerated men, the researchers found that the mean annual violent incident rates per 100 inmates over a seven year period (1991-1998) varied by gender. The rate for serious violent offences ${ }^{2}$ was 0.144 per 100 for females and 1.770 per 100 for males. The rates for less serious violent offences ${ }^{3}$ were 5.060 and 7.798 per 100 for females and males respectively. Only $2.77 \%$ of the overall female rate was due to serious violent offences, while $18.5 \%$ of the overall male rate was. Additionally, results demonstrated that women were less likely to use a dangerous weapon (i.e., sharp or pointed object) than men ( $1.8 \%$ of violent women and $5.0 \%$ of violent men). Consequently, none of the offences committed by women resulted in serious injury to the victim, whereas $6.3 \%$ of men's violent offences resulted in moderate to major victim injury, including two deaths. The authors therefore state that the extent of the violent offender behaviour may be predicted by gender (Harer \& Langan, 2001).

\footnotetext{
${ }^{2}$ Serious violent offences consisted of homicide or attempted homicide, serious assault, and possession of a weapon (Harer \& Langan, 2001).

${ }^{3}$ Less serious violent offences consisted of fighting, threatening bodily harm, and minor assault (Harer \& Langan, 2001)
} 
In sum, these studies illustrate that women's behaviour while incarcerated tends to mirror what has been found in overall offence rates; women offend less frequently and are less violent than men. There are still, however, some research findings that do not demonstrate such a distinct division and provide contradictory evidence. Some studies suggest that the rates of misconduct among women may be comparable to the rates of misconduct found with men. Camp and colleagues, for example, explored environmental and individual level variables in relation to institutional misconduct using data from the United States Federal Bureau of Prisons (Camp, Gaes, Langan, \& Saylor, 2003). The data consisted of 120,855 federal inmates (approximately 8,460 of whom were female) from 156 facilities. Using hierarchical modeling techniques, authors found that females only differed significantly from males when assessing drug-related incidents, in that females were less likely to engage in this type of misconduct. After controlling for individual variables (age, misconduct history, custody, time at risk) and aggregate variables (crowding, racial composition index, average age of inmates, staff characteristics and average custody level), females did not differ significantly from males in their likelihood of engaging in other forms of misconduct. Although interesting, information regarding these gender findings was minimal in comparison to other variables measured. Unlike some of the previous research, gender was not the central focus of this study and the authors therefore did not provide in-depth information or elaborate further on these findings, thus limiting interpretation. Additionally, the results may have been diluted and key differences overlooked given that so many variables were matched and controlled for. 
Markedly, inconsistencies continue to permeate the misconduct literature. Frequency and severity patterns are conflicting and clarity surrounding distinct gender differences is still lacking. Furthermore, studies have predominantly taken a quantitative approach to assess differences and details regarding the context and nature of misconducts are rarely explored. Our understanding of the etiology of misconduct is therefore still in its infancy.

\section{Predictors of Misconduct}

Evidently, an important tool would be to identify factors that indicate increased risk of misconduct while incarcerated. There is a general agreement that certain factors are predictive of both male and female behaviours (e.g., factors such as age, sentence length, index offence, criminal history), with some conflicting evidence which may be indicative of gender-specific/salient predictors.

Gendreau, Goggin and Law (1997) conducted a meta-analysis examining factors that best predict prison misconduct. Based on 39 studies and 695 effect sizes, predictors pertaining to situational, personal and actuarial factors were assessed in relation to violent and non-violent incidents. Within the personal domains, age $(r=-.14)$, antisocial attitudes/behaviours $(r=.13)$, and criminal history $(r=.13)$ were associated with misconduct. Although the situational factor of crowding produced a weak correlation with the criterion variable $(r=.03)$, institutional factors (e.g., security level, inmate turnover, inmate-staff ratio) demonstrated a much stronger correlation $(r=.26)$. Overall, greater effect sizes were associated with the prediction of violent incidents rather than non-violent. The studies, however, were fairly dated (1940 to 1995) and results were only somewhat representative given that all studies included within the meta-analysis 
consisted of only male samples. Authors also noted that multiple studies were missing important information (e.g., offender characteristics, sentence information, prison locations) and aggregate data was used in some cases, thus potentially inflating correlation results (Gendreau et al., 1997).

In exploring predictors rooted in the importation and deprivation theories, Gover and colleagues (2008) found that males and females varied on designated predictors of misconduct. For importation measures, factors of prior incarceration, index offence (drug offences in particular), and low self-control were significantly associated with increased misconduct among male offenders, whereas age (younger), ethnicity and higher education were related to increased misconduct in women. As for deprivation factors, medium and maximum security levels as well as length of current stay within the correctional facility were significantly linked to increased male misconduct, while institutional employment was related to a decrease. In contrast, longer aggregate sentences upon admission and perceptions of safety emerged as predictors for reduced misconduct among female inmates.

In estimating differential effects of the measures on misconduct for both males and females, authors noted that overall, only history of incarceration and a longer length of stay were significantly related to infractions for both groups. Interestingly, prior incarceration was significant in opposing directions as it was linked to a decrease in misconduct among women, but an increase among men. Additionally, length of time spent within the institution was still a stronger predictor for women. Similar differences have been found even within female samples. Studies categorizing females based on time spent within a facility have also found that long-term and medium-term female inmates 
commit significantly higher rates of violent and non-violent misconduct in comparison to short-term inmates. This is in contrast to previous research where long-term male offenders actually engage in fewer violations in comparison to short-term males (Toch \& Adams, 2002).

Gover and colleagues (2008) point out that despite the inclusion of females, the study sample was still predominantly male and not all security levels were represented. The female institutions sampled were equivalent to a male minimum security facility while the males were sampled from multiple security levels. It was therefore recommended that additional research should assess gender differences in misconduct across multiple levels of security classification (Gover et al., 2008).

In addition to frequency comparisons, the Craddock study (1996) discussed above is also one of the few studies to assess gender differences in predictor variables and event history (i.e., survival) analysis patterns. Using Cox-regression analysis, results demonstrated that age (younger) and sentence length were the most influential variables in the initiation of misconduct careers among women. Maximum custody classification and prior incarceration were the strongest predictors for males. As for the survival curves, results demonstrated that men violated rules sooner than women and at a higher rate, but that the overall patterns were similar. Although women showed more fluctuations, the hazard rate of first rule violation gradually increased over time for both groups. While the covariates and patterns of misconduct are fairly similar, the author states that mechanisms of adjustment may still vary between men and women. Furthermore, obvious disparities between genders in the actual incident types were evident, thus suggesting notable differences still exist that are pertinent to operational 
practices. Craddock concludes that the study, being the first of its kind, is only the first step and further work is needed. Future directions state that a multi-method approach would be key to advancing theory and operational practices and that studies should therefore combine both qualitative and quantitative techniques to provide a more comprehensive assessment and understanding (Craddock, 1996).

Although the work of Craddock was ground-breaking for its time, and the study of Gover and colleagues (2008) is one of the more recent prominent works in this area, the predictors that were used to assess misconduct were selected by the researchers and are considered to be gender-neutral. Factors that could be specific to women's adjustment were therefore overlooked. In contrast, Wright and colleagues (2007) contend that women's needs and characteristics are qualitatively different than those of male offenders. The authors also argue that these needs (e.g., mental health, victimization, self-concept, relationships) are more relevant in the consideration of prison adjustment in comparison to the demographic and historical variables that are typically used in prediction practices (Wright et al., 2007). In a sample of 272 women, proposed gender-responsive measures (i.e., self-esteem, self-efficacy, childhood abuse, adult emotion/physical abuse, adult harassment, low relationship support, high relationship conflict/dysfunction, parental stress, current depression/anxiety and current psychosis) were used and compared with gender-neutral measures (e.g., antisocial attitudes, antisocial friends, education, employment, substance abuse) in the prediction of adjustment as measured by serious prison misconducts (minor rule violations were excluded). 
Results demonstrated that experiencing childhood abuse, depression or anxiety, current psychosis and involvement in unsupportive relationships were significantly correlated with both prevalence and incidence rates of serious institutional misconduct within 6 and/or 12 months of incarceration (Wright et al., 2007). Childhood victimization increased the likelihood of misconduct with significant correlations ranging from $r=.20$ to $r=.25$ as was experiencing harassment as an adult, but to a lesser extent $(r=.08)$. Other research has produced similar findings (e.g., Salisbury, Van Voorhis \& Spiropoulos, 2009; Steiner \& Wooldredge, 2009) with adult victimization being more predictive of community recidivism and childhood victimization being more predictive of institutional maladjustment among female inmates. Islam - Zwart and Vik (2004) also found that adult sexual victimization was related to external adjustment problems (e.g., fighting) among women in prison while childhood victimization was associated with internal adjustment problems (e.g., emotional problems, anger issues).

Moreover, mental health issues were also significant in the Wright et al. study (2007) with correlations ranging from $r=.13$ to $r=.23$ for depression and anxiety, and $r$ $=.16$ to $r=.31$ for current psychosis. Although mental health is not necessarily womenspecific, the mental health needs of female offenders differ substantially from those of males both quantitatively and qualitatively (Bloom et al., 2003; Leschied, 2011). This is evident in the much higher rates of mental health issues among women which are often exacerbated by co-occurring needs, such as depression and substance abuse (Bloom et al., 2003; Leschied, 2011). Evidence supporting the negative impact mental health has on institutional adjustment has been supported with both adult females and justice involved youth (Belknap, 2007; Blackburn \& Trulson, 2010; Steiner \& Wooldredge, 2009). 
Finally, although factors of parenting stress $(r=.09$ to $r=.10)$ and dysfunctional relationships $(r=.09)$ approached significance, Wright and colleagues (2007) underscore that these were fairly weak relationships, while the remaining gender-specific factors did not produce significant results. That being said, Thompson and Loper (2005) argue that poor adjustment among females with longer sentences is likely due to distance from and limited contact with family members and children over the course of longer sentences.

Additionally, although self-esteem was not found to be predictive, a study by Van Tongeren and Klebe (2010) demonstrated different results. Using Self-Esteem scales and the PAQ (Wright, 1985) with a sample of 88 female offenders incarcerated in a maximum security facility, good self-esteem was found to be a stronger indicator of positive adjustment compared to other measures (e.g., motivation to change, locus of control, criminal thinking scale). It was related to better environmental and societal adjustment, lower conflict, and lower antisocial cognitions.

In sum, previous victimization, anxiety, depression, current psychosis and unsupportive relationships were the strongest gender-specific predictors of misconduct. Overall, results indicated that these needs performed at similar levels as the genderneutral factors, but still produced more consistent and less varied correlations (Wright et al., 2007). Authors concluded that combining both gender-neutral and gender-specific factors yields the strongest relationship with misconduct. This approach would therefore provide the most comprehensive understanding of women's adjustment to prison.

Based on the literature reviewed, it is evident that although research regarding women's experiences in prison has begun to accumulate, results are conflicting and there are gaps in several areas that need to be addressed to further our understanding of gender 
differences in institutional adjustment. Due to the ambiguity of adjustment and how it is measured, varying categories of severity (major vs. minor) and frequency (prevalence vs. incidence) and the selection of predictors, different constructs are being measured in the research and resulting inconsistencies have emerged. Also, the research tends to be heavily quantitative in nature. Although this approach provides statistical support, there is little qualitative research regarding the nature and context of misconduct which, in combination with quantitative research, may further highlight differences in behaviour patterns (Craddock, 1996). The importance of combining qualitative and quantitative methods has also been emphasized in the women offender literature (Blanchette \& Brown, 2006).

Furthermore, samples are still male dominated and the research is predominantly based in the United States, which is a significant factor to consider given the contrasting correctional environments and practices in Canada. Other methodological gaps include the lack of male comparison groups in most studies thus the notion of gender differences has still only been preliminarily explored. Additionally, research consisting of samples from all possible security categories is limited, and gender differences have not sufficiently been assessed based on all security levels. For example, given the smaller number of females, some studies have only included minimum security female facilities versus multi-level facilities for men, making comparisons imbalanced and not fully representative.

Finally, given that risk prediction is the most popular topic of interest in correctional research, the majority of adjustment literature has followed this assessment trend, focusing predominantly on predicting misconduct rather than the misconduct itself. 


\section{Current Study}

The purpose of the current study is to expand our knowledge of gender differences in institutional misconduct within a Canadian federal correctional context. As argued in the literature, although gender-neutral concepts may apply to women's adjustment, the degree of misconduct and the nature of the behaviours should still be considered separately by gender, even across similar custody levels and risk designations (Harer \& Langan, 2001). Offender risk, seriousness of misconduct, and subsequent security responses should be considered relative to the population in question (Van Voorhis \& Brown, 1996). As VanVoorhis and Presser (2001) aptly state, despite designated custody levels, "high-risk females may be quite different from high-risk males" (p.5). This applies to other custody levels as well, suggesting that institutional behaviours may still vary by gender within the same security classification. Women's risk scores, for example, typically have to be higher than men's before a given custody level shows similar rates of misconduct for both genders. This has clear implications in regards to correctional policies and operational practices (Van Voorhis \& Presser, 2001).

Several studies argue that the nature of women's offending and the context in which female violence occurs differs from the offence patterns seen in males (e.g., Greenfeld \& Snell, 1999; Kong \& AuCoin, 2008; Koons-Witt and Schram, 2003; Steffensmeier, 2001). There has been no evidence to suggest that these differences stop at the prison walls, but there has been limited research to support this - yet another significant gap in the literature that would add to our understanding of women's adjustment and behaviours during incarceration. As stated by Blanchette and Taylor (2005) in a study regarding gender-informed security classification for federally 
incarcerated women, the causes and etiology of adjustment problems among women warrant investigation. The authors argued that etiological studies of misconduct "seeking to understand and explain inmate (mis)behaviour will further assist in the development of better predictions tools and intervention strategies for women offenders" (p.51).

Accordingly, with the inclusion of a male comparison group and a mixed-method design, the goal of the current study is to contribute to methodology, theoretical perspectives and operational practices relating to gender and crime. This will be done by focusing on gender differences in incidence and prevalence rates, misconduct over time and predictors of misconduct. In supplementing this information with a qualitative understanding of major misconduct, the ultimate goal is to further our understanding of offender behaviour and potentially inform intervention strategies and practices in women's correctional facilities.

Research Question 1: Are there gender differences in the prevalence and incidence rates of misconduct among federally incarcerated offenders by security level?

Based on a review of the literature (e.g., Craddock, 1996; Harer \& Langan, 2001), it was hypothesized that the frequency and prevalence rates of misconduct would be higher within the male offender sample. It was expected that this would hold true, even when comparing by gender within each of the three security levels (minimum, medium, maximum). Additionally, as demonstrated in the U.S. research (e.g., Harer \& Langan, 2001), it was predicted that male-perpetrated misconduct would be more severe in comparison to women. More specifically, it was expected that the proportion of men engaging in major misconduct would be higher than that for women, and the proportion of major misconducts perpetrated by men would also exceed that for women. 
Research Question 2: Are there gender differences in the patterns and predictors of survival time to first misconduct among federally incarcerated offenders by security level?

In order to further understand differences in behavioural patterns within the institution, this research question was assessed by examining variations in survival time (time from admission to first misconduct) based on gender and custody level. Given that research is limited and inconsistent in this area, this question was considered exploratory in nature.

Predictor variables of survival patterns were also assessed. Based on previous literature, core demographic and offender-related variables were measured, including age, race, major index offence, aggregate sentence length, prior incarcerations, and risk, need, motivation and reintegration levels. Based on the literature reviewed (e.g., Gover et al., 2008), it was broadly hypothesized that all factors would have some degree of impact on misconduct, with some variables as stronger predictors for females (e.g., race, dynamic

risk, sentence length) and others as stronger predictors for males (e.g., index offence, static risk).

Research Question 3: Do major incidents of misconduct differ qualitatively based on perpetrator gender?

Given the literature suggesting differences in offence gestalts, it was expected that gender differences would be found in the nature of major misconducts based on a qualitative analysis of violent incident reports. Although the analysis was predominantly exploratory and for descriptive purposes, it was expected that differences in incident factors, such as victim type, relationship to the victim, weapons used and the degree of 
injury inflicted, would be associated with perpetrator gender. For example, it was expected that:

- Women's violence would be more relational in nature (i.e., the perpetrator would likely have a relationship/association with the victim; violence would be as a result of a relational rupture/dispute).

- Men's violence would be more acquisitive in nature (i.e., the violence would be to achieve a goal such as gaining possession of contraband or gaining power/authority within the inmate structure).

- Men would be more likely to use weapons.

- Men would be more likely to inflict serious victim injury.

\section{Method}

\section{Sample}

The sample consisted of 1914 adult offenders ( $n=957$ females, $n=957$ males $)$ admitted into federal custody between April 1, 2008 and March 31, 2011 on a new warrant of committal. ${ }^{4}$ The full sample was used to address hypotheses one and two while sub-samples ( $n=28$ females, $n=28$ males) were used for the qualitative assessment in the third hypothesis.

A total of 12 cases out of the 1914 were missing data associated with offender security level. Given that security level is the basis for all statistical analyses, these cases were subsequently dropped. This will be explained further when describing data

\footnotetext{
${ }^{4}$ Offenders admitted for conditional release revocations during the timeframe were excluded given the likelihood of data quality issues and shorter time spent within the institution.
} 
screening, however, it is important to note that the following descriptive analysis was conducted using the final reduced sample $(N=1902)$.

Given that the samples were matched on security level, there was an approximately equal number of men and women at each level: maximum security $(n=55$ males, $n=55$ females), medium security ( $n=400$ males, $n=399$ females $)$, and minimum security ( $n=496$ males, $n=497$ females). ${ }^{5}$

Although the majority of analyses are conducted within security level in the current study, the demographic and incarceration characteristics are provided for the full sample to provide an overall presentation. A comparison of demographic variables using chi-square analysis and $t$-tests indicated several group differences. The mean age of the male sample upon admission $(M=37.08, S D=12.62)$ indicated that males were significantly older than females $(M=34.54, S D=10.40), t(1900)=4.79, p<.001, d=$ $0.22^{6}$, with a sample range of 18 to 74 years for females, and 18 to 86 years for males. Significant differences in ethnicity were also evident, $\chi^{2}(3, N=1902)=49.74, p<.001$, $\Phi_{c}{ }^{7}=.16$. The majority of women were Caucasian (58.04\%) as was the case with the male sample (66.25\%). Although the other categories were also relatively similar between men and women, a substantially larger portion of the female sample was identified as being Aboriginal (28.08\%) in comparison to the men (15.03\%). Table 1 presents further detail and an overview of additional demographic characteristics.

\footnotetext{
${ }^{5}$ The slight difference in group size was due to issues with offenders having sub-sentences and security information that did not correctly correspond to the sentence in question. The error was adjusted for by imputing the correct data from offender file information for the original sentence, thus resulting in a change of security level for one case.

${ }^{6} d=$ Cohen's d effect size: .2 = small, $.5=$ medium, $.8=$ large (Howell, 2007).

${ }^{7} \boldsymbol{\Phi}_{\mathrm{c}}=$ Cramer's $V$ effect size: $.1=$ small, $.3=$ medium, .5 = large (Green \& Salkind, 2008).
} 
Table 1

Demographic Characteristics of the Current Sample

\begin{tabular}{|c|c|c|c|c|}
\hline & $\begin{array}{c}\text { Female } \\
N=951 \\
\%(n)\end{array}$ & $\begin{array}{c}\text { Male } \\
N=951 \\
\%(n)\end{array}$ & $\chi^{2}$ & $\Phi_{c}$ \\
\hline \multicolumn{5}{|l|}{ Ethnicity } \\
\hline Caucasian & $58.04(552)$ & $66.25(630)$ & $49.74 * * *$ & 0.16 \\
\hline Aboriginal ${ }^{a}$ & $28.08(267)$ & $15.04(143)$ & & \\
\hline Black & $7.05(67)$ & $8.94(85)$ & & \\
\hline Other/Unknown ${ }^{\mathrm{b}}$ & $6.83(65)$ & $9.78(93)$ & & \\
\hline \multicolumn{5}{|l|}{ Marital Status } \\
\hline $\begin{array}{l}\text { Single/Widowed/ } \\
\text { Divorced }\end{array}$ & $64.46(613)$ & $52.58(500)$ & $27.76 * * *$ & 0.12 \\
\hline $\begin{array}{l}\text { Married/Common } \\
\text { Law }\end{array}$ & $33.54(319)$ & $45.01(428)$ & & \\
\hline Other/Unknown & $2.00(19)$ & $2.42(23)$ & & \\
\hline
\end{tabular}

Note. $\Phi_{c}=$ Cramer's V.

${ }^{a}$ This category included Inuit, Métis and First Nations. ${ }^{b}$ This included several categories collapsed together due to small $n$ 's (e.g., East Indian, Hispanic, Chinese, Latin American).

${ }^{* * *} p<.001$.

The mean length of aggregate sentence (days) was significantly longer for males $(M=1155.70, S D=632.20 ;$ approximately 3.20 years $)$ than for females $(M=1033.60$, $S D=568.10 ;$ approximately 2.83 years $), t(1900)=4.43, p<.001, d=0.20$. On average, the male sample was also incarcerated for a longer period of time during the study timeframe ${ }^{8}(M=433.70$ days, $S D=248.20)$ in comparison to the female sample $(M=$ 341.40 days, $S D=205.00), t(1900)=8.84, p<.001, d=0.41$. Additional incarceration characteristics are provided in Table 2.

${ }^{8}$ The number of days incarcerated were only calculated for the designated timeframe: from admission until (1) first release, (2) security reclassification, (3) March 21, 2012. 
Table 2

Incarceration Characteristics of the Current Sample

\begin{tabular}{ccccc}
\hline Female & Male & & \\
$N=951$ & $N=951$ & $\chi^{2}$ & $\Phi_{\mathrm{c}}$ \\
$\%(n)$ & $\%(n)$ & &
\end{tabular}

\section{Length of Aggregate}

\section{Sentence}

3 Years or Less

More than 3 Years

Life Sentence

\section{Type of Offence ${ }^{c}$}

Homicide

Sexual Offence

Robbery

Asssault

Drug Related

Property

Other Violent

Other Non-Violent
$71.92(684)$

$63.20(601)$

20.03

0.10

$25.24(240) \quad 34.60(329)$

$2.84(27) \quad 2.20(21)$

$N=950^{\mathrm{a}} \quad N=946^{\mathrm{b}}$

$N=950^{\mathrm{a}} \quad N=946^{\mathrm{b}}$

$9.05(86)$

$5.71(54)$

$7.75^{* *}$

0.07

$2.21(21)$

13 (123)

$78.66^{* * *}$

0.20

15.79 (150)

12.47 (118)

4.29

0.05

$8.84(84)$

$7.40(70)$

1.32

0.02

32.21 (306)

30.02 (284)

1.06

0.02

$18.21(173)$

$15.86(150)$

1.86

0.03

$5.16(49)$

$5.39(51)$

.05

0.00

$8.53(81)$

$10.15(96)$

0.03

Note. $\Phi_{\mathrm{c}}=$ Cramer's V.

${ }^{a} n=1$ missing. ${ }^{b} n=5$ missing. ${ }^{c}$ Most serious offence on the offender's sentence. Due to the number of comparisons to assess offence type, a Bonferroni adjustment was made $(p=.05 / 8=$ $.006)$.

${ }^{* *} p<.006,{ }^{* * *} p<.001$.

The final descriptive characteristics pertain to the offenders' level of risk, need, motivation and reintegration. Because these variables are considered to be pertinent to an offender's criminal behaviour (Andrews \& Bonta, 2010) and are of interest in subsequent 
analyses, the following group comparisons were conducted with the sample divided by security level. Given that this involved 3 sets of comparisons, a Bonferroni adjustment ( $p$ $=.05 / 3=.02)$ was applied

As demonstrated in Table 3, significant differences were found between males and females in maximum security for motivation level, $\chi^{2}(2, N=110)=16.16, p<.001$, $\Phi_{\mathrm{c}}=0.38$, and reintegration level, $\chi^{2}(1, N=107)=13.05, p<.001, \Phi_{c}=0.35$, while differences in static and dynamic risk were not significant. 
Table 3

Static Risk, Dynamic Risk, Motivation, and Reintegration Potential of Maximum Security Offenders as Assessed upon Admission

\begin{tabular}{|c|c|c|c|c|}
\hline & $\begin{array}{c}\text { Female } \\
N=55 \\
\%(n)\end{array}$ & $\begin{array}{c}\text { Male } \\
N=55 \\
\%(n)\end{array}$ & $x^{2}$ & $\Phi_{c}$ \\
\hline \multicolumn{5}{|c|}{ Static Risk Level } \\
\hline Low & - & - & 5.69 & 0.23 \\
\hline Medium & $29.09(16)$ & $10.91(6)$ & & \\
\hline High & $70.91(39)$ & $89.09(49)$ & & \\
\hline \multicolumn{5}{|c|}{ Dynamic Risk Level } \\
\hline Low & - & - & 1.83 & 0.13 \\
\hline Medium & $18.18(10)$ & $9.26(5)$ & & \\
\hline High & $81.82(45)$ & $90.74(49)$ & & \\
\hline \multicolumn{5}{|c|}{ Motivation Level } \\
\hline Low & $12.73(7)$ & $32.73(18)$ & $16.16^{* * *}$ & 0.38 \\
\hline Medium & $61.82(34)$ & $65.45(36)$ & & \\
\hline High & $25.45(14)$ & $1.82(1)$ & & \\
\hline \multicolumn{5}{|c|}{ Reintegration Potential } \\
\hline Low & $67.31(35)$ & $94.55(52)$ & $13.05 * * *$ & 0.35 \\
\hline Medium & $32.69(17)$ & $5.45(3)$ & & \\
\hline High & - & - & & \\
\hline
\end{tabular}

Table 4 and Table 5 demonstrate that males and females differed on three of the four factors, with dynamic risk being the only non significant difference found at both the medium, $\chi^{2}(2, N=797)=6.42, p=.04, \Phi_{c}=0.09$ and the minimum, $\chi^{2}(2, N=993)=$ $5.84 p=.05, \Phi_{c}=0.08$ security levels. 
Table 4

Static Risk, Dynamic Risk, Motivation, and Reintegration Potential of Medium Security Offenders as Assessed upon Admission

\begin{tabular}{|c|c|c|c|c|}
\hline & $\begin{array}{c}\text { Female } \\
\begin{array}{c}N=398^{\mathrm{a}} \\
\%(n)\end{array}\end{array}$ & $\begin{array}{c}\text { Male } \\
N=399^{\mathrm{b}} \\
\%(n)\end{array}$ & $x^{2}$ & $\Phi_{\mathrm{c}}$ \\
\hline \multicolumn{5}{|c|}{ Static Risk Level } \\
\hline Low & $15.08(60)$ & $5.51(22)$ & $36.34 * * *$ & 0.21 \\
\hline Medium & $49.25(196)$ & $40.35(161)$ & & \\
\hline High & $35.68(142)$ & $54.14(216)$ & & \\
\hline \multicolumn{5}{|c|}{ Dynamic Risk Level } \\
\hline Low & $4.52(18)$ & $2.76(11)$ & 6.42 & 0.09 \\
\hline Medium & $32.16(128)$ & $25.81(103)$ & & \\
\hline High & $63.32(252)$ & $71.43(285)$ & & \\
\hline \multicolumn{5}{|c|}{ Motivation Level } \\
\hline Low & $4.27(17)$ & $14.79(59)$ & $133.91 * * *$ & 0.41 \\
\hline Medium & $50.50(201)$ & $75.44(301)$ & & \\
\hline High & $45.23(180)$ & $9.77(39)$ & & \\
\hline \multicolumn{5}{|c|}{ Reintegration Potential } \\
\hline Low & $25.88(103)$ & $37.34(149)$ & $22.43 * * *$ & 0.17 \\
\hline Medium & $57.04(227)$ & $40.35(161)$ & & \\
\hline High & $17.09(68)$ & $22.31(89)$ & & \\
\hline
\end{tabular}

Note. $\Phi \mathrm{c}=$ Cramer's V.

${ }^{\mathrm{a}} n=1$ missing. ${ }^{\mathrm{b}} n=1$ missing.

$* * * p<.001$. 
Table 5

Static Risk, Dynamic Risk, Motivation, and Reintegration Potential of Minimum Security Offenders as Assessed upon Admission

\begin{tabular}{|c|c|c|c|c|}
\hline & $\begin{array}{c}\text { Female } \\
N=496^{\mathrm{a}} \\
\%(n)\end{array}$ & $\begin{array}{c}\text { Male } \\
N=496 \\
\%(n)\end{array}$ & $\chi^{2}$ & $\boldsymbol{\Phi}_{\mathrm{c}}$ \\
\hline \multicolumn{5}{|c|}{ Static Risk Level } \\
\hline Low & $57.46(285)$ & $40.73(202)$ & $28.80^{* * *}$ & 0.17 \\
\hline Medium & $34.88(173)$ & $48.59(241)$ & & \\
\hline High & $7.66(38)$ & $10.69(53)$ & & \\
\hline \multicolumn{5}{|c|}{ Dynamic Risk Level } \\
\hline Low & $25.20(125)$ & $31.19(155)$ & 5.87 & 0.08 \\
\hline Medium & $51.61(256)$ & $50.20(249)$ & & \\
\hline High & $23.19(115)$ & $18.55(92)$ & & \\
\hline \multicolumn{5}{|c|}{ Motivation Level } \\
\hline Low & $2.42(12)$ & $4.43(22)$ & $67.92 * * *$ & 0.26 \\
\hline Medium & $31.05(154)$ & $55.13(274)$ & & \\
\hline High & $66.53(330)$ & $40.44(201)$ & & \\
\hline \multicolumn{5}{|c|}{ Reintegration Potential } \\
\hline Low & $4.03(20)$ & $3.02(15)$ & $17.96^{* * *}$ & 0.14 \\
\hline Medium & $34.07(169)$ & $22.58(112)$ & & \\
\hline High & $61.90(307)$ & $74.40(369)$ & & \\
\hline
\end{tabular}

Note. $\Phi_{\mathrm{c}}=$ Cramer's V.

${ }^{\mathrm{a}} n=1$ missing.

$* * * p<.001$.

\section{Measures and Materials}

The data used for this study were archival in nature and were retrieved from the Correctional Service of Canada's Offender Management System (OMS). OMS is an automated database of offender file information containing all computerized records 
pertaining to a federal sentence. The extracted data were related to offender demographic information, incarceration characteristics (e.g., security level, sentence length), level of risk and need as well as institutional misconduct (e.g., charges).

Offender Intake Assessment. Data pulled from OMS included information taken from the Offender Intake Assessment (OIA) database. The OIA is conducted upon an offender's arrival and official admission into the federal correctional system to collect all pertinent offender information (e.g., risks, needs, immediate concerns). The OIA consists of two core components: the Assessment of Static Factors and the Assessment of Dynamic Factors. The static portion focuses on historical factors (e.g., history, offence severity) and the probability of future re-offending. The dynamic portion consists of the Dynamic Factors Identification Analysis (DFIA) which is comprised of the seven dynamic factor domains (employment, marital/family, associates, substance abuse, community functioning, personal/emotional, attitude; Brown \& Motiuk, 2005). As previously indicated, these factors are significantly related to the prediction of an offender's risk to recidivate and are also related to reductions in reoffending if targeted through correctional treatment. Where available, the following variables were obtained and used for the current analysis: 1) overall static risk: assessed as low, medium, or high risk based on and assessment of static and historical criminal factors; 2) overall dynamic risk: criminogenic needs which are indicative of an offender's required level of intervention and can be modified through treatment. These are assessed as low, medium or high based on the number and severity of identified needs; 3) motivation level: assessed as low, medium, or high based on an offender's motivation to complete his/her correctional plan; 4) reintegration potential: assessed as low, medium, or high; indicating the probability of 
successful offender reintegration back into the community. This rating is based on the Custody Rating Scale (Solicitor Gender of Canada, 1987), the Revised Statistical Information on Recidivism (SIR-R1; Nuffield, 1982) and the Static Factor Rating for non-Aboriginal male offenders (Brown \& Motiuk, 2005; CSC, 2012b). For Aboriginal and female offenders, this level is determined by using the Custody Rating Scale, the Static Factor Rating and the Dynamic Factor Rating (Brown \& Motiuk, 2005; CSC, 2012b).

Research has shown that the DFIA demonstrates strong to moderate concurrent validity (Brown \& Motiuk, 2005) with correlations between risk level and the Criminal Risk Assessment components $(r=.17$ to $r=.49$ ). Internal consistency of the domains have also demonstrated acceptable to superior results with men, women and Aboriginal offenders with Cronbach's alpha ranging from .62 to .96 (Brown \& Motiuk, 2005). Brown and Motiuk (2005) also demonstrated that the overall domain ratings of the DFIA significantly predicted re-admission rates for men, women, and Aboriginal offenders (as assessed during a three year follow-up period after offender release). As expected, offenders with higher dynamic factor ratings were more likely to be readmitted after release in comparison to offenders with low factor ratings.

Although inter-rater reliability has not been discussed in the literature, it is important to note that there are strict guidelines, staff training initiatives, and operational reviews that are in place to ensure consistency and proper administration of the OIA process (CSC, 2012c).

Offender security level. As part of the OIA process, offenders are assigned a security classification upon admission into federal custody. The classification is based, in 
part, on the results of the Custody Rating Scale (CRS; Solicitor Gender of Canada, 1987) which assesses an offender's institutional adjustment (IA) and security risk (SR). The measure provides an overall score, with higher scores being indicative of higher classification recommendation. There are designated score cut-off points which indicate if an offender should be placed in minimum, medium, or maximum security. Although the CRS was originally developed based on male offender samples, it has demonstrated sufficient reliability and validity when used with both women and Aboriginal offenders (Blanchette, Verbrugge, \& Wichmann, 2002). Despite some criticisms of the measure (e.g., Webster \& Doob, 2004), it has shown overall good predictive validity; demonstrating a linear relationship between security designation and involvement in institutional misconducts for both Aboriginal and non-Aboriginal women (Blanchette et al., 2002)

Security level is the basis of all analyses in the current study given that that all tests will be conducted with males and females grouped by security level. Only an offender's first security designation upon admission up until the end of the study period is used in the current study (i.e., information following security reclassifications was not considered).

Predictor variables. The predictor variables for the second research question are based on an amalgamation of several variables previously discussed. These include the following: age upon admission, ethnicity (Aboriginal, non-Aboriginal), aggregate sentence, major admitting index offence (violent, non-violent), previous incarcerations, as well as static risk, dynamic risk, reintegration potential, and motivation level. 
Time-at-risk. This variable indicates the amount of time each offender is incarcerated during the study timeframe. It is defined as the number of days incarcerated from offender admission until the end of study period (i.e., first release, first security reclassification, or March 31, 2012). Given that days incarcerated indicates the amount of time an offender has the opportunity to engage in misconduct, it was designated as the 'time-at-risk'. This variable is divided into the following three groups to test the first research question: group 1 ( 365 days or less of incarceration), group 2 (between 366 and 730 days) and group 3 (731 days or more). For analyses in the second research question using survival and cox regression techniques, time at risk is defined as the time from admission to the first event of misconduct.

Institutional misconduct. For the current study, institutional misconduct is defined as an event of misconduct which resulted in a formal charge process (as opposed to 'incidents' which warrant documentation on an offender's case file, but do not generally result in a formal charge process). These are classified as being either major (e.g., assault) or minor (e.g., minor disturbance) in severity when the charges are laid (for a complete list of charges, please refer to Appendix A). Only those offenders designated as instigators or associates were selected, and only those offenders who were found guilty were considered for analysis.

Misconduct reports. Misconduct reports completed by institutional staff were accessed via OMS to complete the qualitative component of this study. Reports provide information pertaining to individual misconduct incidents, including details regarding the nature of the misconduct, the victim involved, use of weapons and degree of harm. 
Given the potential harm and negative implication of more serious or violent behaviour, only major misconduct reports involving assaults were considered.

Coding Manual. A coding manual was used for the collection of qualitative information from the misconduct reports. Researchers coded for such items as misconduct type, misconduct severity, offender role, victim involved, and relationship with victim, method/weapon used and degree of harm inflicted (please refer to Appendix B for the full coding manual).

\section{Quantitative Analytic Strategy}

Descriptive statistics were used to present sample characteristics and information related to offences, incarceration and criminogenic factors. Using chi-square analysis for categorical variables and univariate t-tests for continuous variables, a profile comparison was conducted to identify between-group differences.

The prevalence of offenders involved in misconduct was calculated and chisquare analysis was used to demonstrate gender differences within each security level for major and minor misconducts. In order to take time-at-risk into consideration, the tests were run within the three different time periods, thus producing a total of nine tests. Due to the number of comparisons, a Bonferroni adjustment was applied to reduce the risk of Type I error (false positive) and Cramer's V was used to indicate effect sizes.

Following methods often used in epidemiological research and in recent offender self-injurious behaviour literature (e.g., Power, 2011), incidence rates were also calculated. The incidence rate is the sum of documented events (i.e., misconducts) relative to the weighted sum of years of incarceration, also known as person-years or person-days. Person-days at risk is the measurement of person and time combined and 
used as a denominator in a rate calculation (Gallagher \& Dobrin, 2007). This method offers more detailed descriptive information regarding misconduct, while automatically incorporating time-at-risk. Rate ratio calculations were then used to identify gender differences within each security level.

Additionally, analysis of variance (ANOVA) was used to determine whether or not the mean number of misconducts varied as a function of gender and security level. More specifically, six factorial ANOVA tests were conducted using a two (male, female) by three (minimum, medium, maximum) design for each time period (12 months, 24 months, 36 months) and each misconduct type (major, minor). Again, Bonferroni corrections were used to control for familywise error. Post hoc analyses using the Tukey method and simple effects analyses were conducted to identify where the significant differences existed.

To assess survival patterns for the second research question, survival analysis was used to measure the length of time between offender admission and first event of misconduct. This technique was appropriate given the nature and timeframe of the study and the probability of censored data (i.e., offenders who do not engage in misconduct within the period of study). Using the Kaplan-Meier procedure, six survival plots were used to assess the time to first misconduct (major/minor) for both males and females at all three security levels. The non-parametric log-rank test (also known as the MantelHaenszel test) was then used to test for gender differences in survival curves within each level of security (Allison, 1995).

Based on the work of Craddock (1996) and more recent survival research in correctional psychology (e.g. Benda, 2005; Benda \& Toombs, 2002; Harer \& Langan, 
2001), a Cox regression survival analysis (also referred to as a proportional hazards model) was conducted to assess potential predictors of misconduct. As stated above, given the literature reviewed and the OMS information available for assessment, the predictor variables included: age, race, major index offence, aggregate sentence length, previous incarcerations, and risk, need, motivation and reintegration levels. Rather than assessing the percentage of the sample that 'survives' over time (as conducted in survival analysis), the proportional hazards model examines the risk (i.e., hazard) of an event occurring (e.g., misconduct) as a function of time and predictor variables. With Cox regression, each individual has his or her own hazard rate, based on the fact that one has survived up until a given point. It is important to note that the hazard ratio $(H R)$ is not a probability and can therefore exceed 1.0. More specifically, if an assessment of offence type (e.g., $0=$ non-violent, $1=$ violent), resulted in a hazard ratio of 1.0 , this would indicate that offence type has no impact on the hazard rate of misconduct. Significant ratios, however, deviate from 1.00 (in either direction) and the greater the deviation, the stronger the variable is in effecting the outcome. Using dichotomous variables ( 0 and 1$)$ and variables with three or more categories (dummy coded) the hazard ratios are interpreted as "the ratio of the estimated hazard for variables with a value of 1 to the estimated hazard for those with a value of 0 while controlling for other covariates" (Allison, 1995, p. 117). This technique is an ideal method given that it can easily accommodate for differential time at risk as well as continuous and discrete variables (Allison, 1995).

Given the complexities of attempting to compare magnitude differences and establish effect sizes in Cox regression between two groups, a split gender model was 
used. The a priori assumption of gender differences also supported the examination of hazard models separately for men and women. The purpose was to simply identify which predictors significantly increased or decreased the hazard of misconduct for men and women individually.

\section{Qualitative Analytic Strategy}

The coding manual (Appendix B) was developed by the primary researcher based on available OMS data ${ }^{9}$ and misconduct descriptors previously used in the literature (e.g., Sorensen et al., 2011). All reports were coded by the primary author. Ten percent $(n=6)$ of the reports were coded by both the author and a research assistant to establish interrater reliability (i.e., examine the consistency between coded responses of independent coders; Lombard, Snyder-Duch, \& Braken, 2002). Interclass correlation coefficients (ICC) were computed for assessing continuous variables (e.g., severity rating) and kappa coefficients were calculated for categorical variables (e.g., offender role). For $78.6 \%$ of the variables there was perfect agreement between the coders. For the remaining variables, reliability ranged from .714 for the degree of harm rating to .828 , for the overall severity rating. Given that the predetermined criterion was set at .70 , these results were considered acceptable and all variables were retained.

\section{Results}

\section{Data Screening}

All data were analyzed using SAS software, version 9.2. Data were examined for errors and missing information. Missing data ranged from $0.11 \%$ for the OIA indicators

\footnotetext{
${ }^{9}$ There is an OMS report template that institutional staff are typically supposed to follow in order to provide sufficient detail regarding incidents of misconduct.
} 
(e.g., static and dynamic risk) to $21.08 \%$ for the variables regarding prior incarcerations. Although there were only 12 cases $(0.63 \%)$ of missing data for offender security level, this variable was addressed first given that all analyses depended on this information. There was no additional OMS information available to impute a security level based on offender records, suggesting that deletion of these cases was an ideal solution. A series of individual chi-square analyses and $t$-tests were conducted comparing the sample grouped by missing versus non-missing security level against the following demographic and incarceration characteristics: age, offence type, sentence length, static risk level, dynamic risk level, motivation level and reintegration level. The results failed to yield any significant differences, thus it appeared that the missing security data was missing at random. The 12 cases were therefore dropped, reducing the sample size to $N=1902$.

There were two variables originally designated to be used for the Cox regression analysis that presented potential data quality issues. The dichotomous variables of previous incarcerations had a significant amount of data missing for provincial (20\%) and federal $(21 \%)$ incarcerations, suggesting that original data collection methods may have resulted in data entry errors for these variables. The researcher also noted that it was unclear whether the variable pertained specifically to previous incarcerations (e.g., time spent within a correctional facility) versus previous sanctions (e.g., community service, probation). These variables were therefore dropped and were not included in the Cox Regression analysis. After adjusting for these extreme cases, the missing data was minimal with a range of $0.11 \%$ to $0.32 \%$ for offence type. Missing data for each analysis are therefore reported throughout the results section. 
The prevalence analysis as well as the ANOVAs were conducted with the sample grouped by days incarcerated in order to equalize the groups and control for time at risk. To ensure that there were no significant gender differences in time at risk, $t$-tests were conducted to compare the mean number of days incarcerated between men and women in all three different time groups, with a Bonferroni corrected alpha $(p=.05 / 3=.017)$. Results demonstrated non-significant findings for group $1, t(999)=0.69, p=.49, d=.04$, where days incarcerated were similar between both men $(M=216.03, S D=67.42)$ and women $(M=213.12, S D=63.73)$. A larger gap was noted between the men $(M=$ $511.77, S D=92.62)$ and the women $(M=494.67, S D=100.60)$ in group 2 . It is important to note that although this finding nearly reached significance, $t(741)=2.36, p$ $=.019$, Cohen's $d$ was relatively small (.18). Finally, the mean number of days incarcerated for men $(M=941.50, S D=137.67)$ and women $(M=919.18, S D=157.73)$ in group 3 did not differ significantly, $t(156)=.86, p=.39, d=.15$.

The misconduct data was screened for normality of the distribution. Given that the measure of misconduct involved count data, there was an evident positive skew for both types of misconduct with both genders. Log transformation was used for minor misconduct and an inverse transformation was used for major misconduct. Several ANOVAs comparing misconduct between males and females were performed on both transformed and non-transformed variables. Results followed the same pattern and no significant differences were found when using the transformed data. For ease of interpretation, the non-transformed misconduct variables were therefore used for all count analyses. 
For the Cox regression, the assumption of proportionality (assumption that survival functions are the same for all groups over time) was tested for both genders and for both forms of misconduct. To test the assumption, the time variable (days incarcerated - which undergoes a logarithmic transformation) is tested as an interaction with each covariate in the model, with significant results indicating a violation of proportionality (Tabachnick \& Fidell, 2007). Given that the tests of proportionality were not significant for major misconducts with both women $\chi^{2}(8, N=951)=15.44, p=.05$ and men $\chi^{2}(8, N=951)=10.40, p=.24$, the assumption of proportionality was met for the major misconduct data. As for the minor misconduct, $\chi^{2}(8, N=951)=39.41, p$ $<.001$, only offence type and motivation level emerged as problem variables for the women. Results for the men were also significant, $\chi^{2}(8, N=951)=23.14, p=.003$, with offence type as the only problem variable. In order to adjust for this, the significant variables were entered into all subsequent models as interactions with logged time in addition to the other covariates so that assumptions could be met (Tabachnick \& Fidell, 2007).

Certain variables also had to be collapsed as a result of inflated parameter estimates and hazard ratios due to issues of cell size. For example, as one would expect, there were not many cases of low risk when assessing maximum security offenders. Dynamic risk, static risk, motivation and reintegration were all collapsed into two categories for maximum and minimum security men with major misconducts. Reintegration level was re-categorized into low versus medium while the dynamic and static risk variables were collapsed into medium versus high for maximum security women with major misconduct. Motivation level was collapsed into medium versus high 
for minimum security women engaging in major misconduct. Given that there weren't many offenders with life sentences, aggregate sentence length was also collapsed into two separate categories (three years or less, more than three years) for all analyses. Finally, despite efforts to collapse certain variables, dynamic risk and reintegration level had to be removed from the proportional hazards model for minor misconduct with maximum security males (i.e., the majority of offenders were high risk and low motivation).

Research Question 1: Are there gender differences in the prevalence and incidence rates of misconduct among federally incarcerated offenders by security level?

The total number of misconduct charges for the full sample was $3,300(2,390$ minor, 910 major). For descriptive purposes, the frequency of misconduct events is outlined in Table 6. The means, standard deviations and ranges for each type of misconduct are also presented for the full sample and for males and females in each security level in Tables 7 to 10 .

Table 6

Total Number of Misconduct Events by Gender, Security Level and Misconduct Type

\begin{tabular}{|c|c|c|c|c|c|c|}
\hline \multirow[b]{2}{*}{$\begin{array}{l}\text { Misconduct } \\
\text { Type }\end{array}$} & \multicolumn{2}{|c|}{$\begin{array}{l}\text { Minimum } \\
\text { Security }\end{array}$} & \multicolumn{2}{|c|}{$\begin{array}{l}\text { Medium } \\
\text { Security }\end{array}$} & \multicolumn{2}{|c|}{$\begin{array}{l}\text { Maximum } \\
\text { Security }\end{array}$} \\
\hline & $\begin{array}{c}\text { Female } \\
\text { Events } \\
\%(n)\end{array}$ & $\begin{array}{c}\text { Male } \\
\text { Events } \\
\%(n)\end{array}$ & $\begin{array}{c}\text { Female } \\
\text { Events } \\
\%(n)\end{array}$ & $\begin{array}{c}\text { Male } \\
\text { Events } \\
\%(n)\end{array}$ & $\begin{array}{c}\text { Female } \\
\text { Events } \\
\%(n)\end{array}$ & $\begin{array}{c}\text { Male } \\
\text { Events } \\
\%(n)\end{array}$ \\
\hline Major & $6.37(58)$ & $4.18(38)$ & $41.65(379)$ & $29.01(264)$ & $10.11(92)$ & $8.68(79)$ \\
\hline Minor & $\begin{array}{l}12.01 \\
(287)\end{array}$ & $\begin{array}{l}10.42 \\
(249)\end{array}$ & $\begin{array}{c}43.18 \\
(1,032)\end{array}$ & $22.64(541)$ & $6.49(155)$ & $5.27(126)$ \\
\hline
\end{tabular}


Table 7

Mean Number of Misconducts for Total Sample

\begin{tabular}{lcccccc} 
& \multicolumn{2}{c}{ Female Offenders } & \multicolumn{3}{c}{ Male Offenders } \\
& \multicolumn{2}{c}{$N=951$} & & & \\
Misconduct \\
\cline { 2 - 7 } Type & Mean $(S D)$ & Median & Range & Mean $(S D)$ & Median & Range \\
\hline Major & $0.56(1.78)$ & 0 & $0-23$ & $0.40(1.28)$ & 0 & $0-16$ \\
Minor & $1.55(2.83)$ & 0 & $0-18$ & $0.96(2.01)$ & 0 & $0-22$ \\
\hline
\end{tabular}

Table 8

Mean Number of Misconducts for Maximum Security Offenders

\begin{tabular}{lcccccc} 
& \multicolumn{2}{c}{ Female Offenders } \\
& \multicolumn{2}{c}{$N=55$} & & \multicolumn{2}{c}{ Male Offenders } \\
Misconduct \\
\cline { 2 - 7 } Type & Mean $(S D)$ & Median & Range & Mean $(S D)$ & Median & Range \\
\cline { 2 - 7 } Major & $1.67(3.16)$ & 0 & $0-20$ & $1.44(2.54)$ & 0 & $0-15$ \\
Minor & $2.82(4.01)$ & 1 & $0-16$ & $2.29(3.41)$ & 1 & $0-19$ \\
\hline
\end{tabular}

Table 9

Mean Number of Misconducts for Medium Security Offenders

\section{Female Offenders}

$$
N=399
$$

Misconduct

Type

Major

Minor

M

M

\section{Male Offenders}

$$
N=400
$$


Table 10

Mean Number of Misconducts for Minimum Security Offenders

\begin{tabular}{|c|c|c|c|c|c|c|}
\hline \multirow[b]{3}{*}{$\begin{array}{l}\text { Misconduct } \\
\text { Type }\end{array}$} & \multicolumn{3}{|c|}{ Female Offenders } & \multicolumn{3}{|c|}{ Male Offenders } \\
\hline & \multicolumn{3}{|c|}{$N=497$} & \multicolumn{3}{|c|}{$N=496$} \\
\hline & Mean $(S D)$ & Median & Range & Mean $(S D)$ & Median & Range \\
\hline Major & $0.12(0.60)$ & 0 & $0-11$ & $0.08(0.35)$ & 0 & $0-3$ \\
\hline Minor & $0.58(1.26)$ & 0 & $0-10$ & $0.50(1.06)$ & 0 & $0-9$ \\
\hline
\end{tabular}

Gender differences in prevalence rates. Chi-square analyses were performed to examine gender differences in the prevalence of major and minor misconduct. The familywise error rate was held at .05 by applying a Bonferroni correction for each comparison $(p=.05 / 6)$. The alpha level of significance was therefore designated as .008 . Comparisons were conducted with each time group to take into account time at risk (group 1, group 2, and group 3). Where $20 \%$ or more of the expected cell counts were less than 5, Fisher's Exact Test was implemented.

As shown in Table 11, differences in major misconduct were not significant, whereas differences in minor misconduct were $\chi^{2}(1, N=271)=11.77, p<.001, \Phi_{c}=$ 0.21 , with $50.83 \%$ of the females engaging in minor misconduct in comparison to only $28.89 \%$ of males. In both cases, effect sizes were within the small category. There were no significant differences in prevalence rates in minimum or maximum security.

Results for group 2 (Table 12) followed a similar pattern in medium security. Differences, in minor misconduct were significant, $\chi^{2}(1, N=430)=21.14, p<.001, \Phi_{c}=$ 0.22 , with $67.91 \%$ of women engaging in misconduct in comparison to $45.68 \%$ of men. Unlike the other groups, significant results were also found for major misconduct within 
minimum security, $\chi^{2}(1, N=249)=8.25, p=.004, \Phi_{c}=0.18$, with $18.89 \%$ of women engaging in misconduct in comparison to $6.92 \%$ of men. Again, effect sizes fell within the small category. There were no significant results within maximum security.

The only significant finding for group 3 was for minor misconduct in medium security $\chi^{2}(1, N=98)=9.50, p=.002$, with $87.10 \%$ of the females engaging in minor misconduct, in comparison to $55.22 \%$ of the males. This was the only difference to produce a moderate effect size of $\Phi_{c}=0.31$. Additional results are presented in Table 13 .

Table 11

The Prevalence of Offenders Engaging in Misconduct by Security Level - Group 1

\begin{tabular}{|c|c|c|c|c|}
\hline & $\begin{array}{l}\text { Female } \\
\%(n)\end{array}$ & $\begin{array}{l}\text { Male } \\
\%(n)\end{array}$ & $x^{2}$ & $\boldsymbol{\Phi}_{\mathrm{c}}$ \\
\hline Minimum Security & $N=401$ & $N=312$ & & \\
\hline Major Misconduct & $5.74(23)$ & $4.17(13)$ & 0.90 & .04 \\
\hline Minor Misconduct & $25.94(104)$ & $20.83(65)$ & 2.5 & .06 \\
\hline Medium Security & $N=181$ & $N=90$ & & \\
\hline Major Misconduct & $24.31(44)$ & $14.44(13)$ & 3.52 & .11 \\
\hline Minor Misconduct & $50.83(92)$ & $28.89(26)$ & $11.77^{* *}$ & .21 \\
\hline Maximum Security & $N=11$ & $N=6$ & & \\
\hline Major Misconduct & $45.45(5)$ & $16.67(1)$ & 1.41 & .29 \\
\hline Minor Misconduct & $54.55(6)$ & $50.00(3)$ & 0.03 & .04 \\
\hline
\end{tabular}

Note. $\Phi_{\mathrm{c}}=$ Cramer's V.

** $\mathrm{p}<.001$. 
Table 12

The Prevalence of Offenders Engaging in Misconduct by Security Level - Group 2

\begin{tabular}{|c|c|c|c|c|}
\hline & $\begin{array}{l}\text { Female } \\
\%(n)\end{array}$ & $\begin{array}{l}\text { Male } \\
\%(n)\end{array}$ & $\chi^{2}$ & $\boldsymbol{\Phi}_{\mathrm{c}}$ \\
\hline Minimum Security & $N=90$ & $N=159$ & & \\
\hline Major Misconduct & $18.89(17)$ & $6.92(11)$ & $8.25^{*}$ & .18 \\
\hline Minor Misconduct & $48.89(44)$ & $41.51(66)$ & 1.27 & .07 \\
\hline Medium Security & $N=187$ & $N=243$ & & \\
\hline Major Misconduct & $39.04(73)$ & $28.40(69)$ & 5.4 & .11 \\
\hline Minor Misconduct & $67.91(127)$ & $45.68(111)$ & $21.14^{* *}$ & .22 \\
\hline Maximum Security & $N=31$ & $N=33$ & & \\
\hline Major Misconduct & $35.48(11)$ & $45.45(15)$ & 0.66 & .10 \\
\hline Minor Misconduct & $58.06(18)$ & $54.55(18)$ & 0.08 & .04 \\
\hline
\end{tabular}

Note. $\Phi_{\mathfrak{c}}=$ Cramer's V.

${ }^{*} p<.008,{ }^{* *} \mathrm{p}<.001$. 
Table 13

The Prevalence of Offenders Engaging in Misconduct by Security Level - Group 3

\begin{tabular}{|c|c|c|c|c|}
\hline & $\begin{array}{l}\text { Female } \\
\%(n)\end{array}$ & $\begin{array}{l}\text { Male } \\
\%(n)\end{array}$ & $\chi^{2}$ & $\Phi_{\mathrm{c}}$ \\
\hline Minimum Security & $N=6$ & $N=25$ & & \\
\hline Major Misconduct & - & - & - & - \\
\hline Minor Misconduct & $16.67(1)$ & $40.00(10)$ & 1.15 & .19 \\
\hline Medium Security & $N=31$ & $N=67$ & & \\
\hline Major Misconduct & $51.61(16)$ & $46.27(31)$ & 0.24 & .05 \\
\hline Minor Misconduct & $87.10(27)$ & $55.22(37)$ & $9.50^{*}$ & .31 \\
\hline Maximum Security & $N=13$ & $N=16$ & & \\
\hline Major Misconduct & $69.23(9)$ & $62.50(10)$ & 0.14 & .07 \\
\hline Minor Misconduct & $92.31(12)$ & $75.00(12)$ & 1.51 & .23 \\
\hline
\end{tabular}

Note. $\Phi_{\mathrm{c}}=$ Cramer's V. - indicates too few cases to present data $* p<.008$.

Gender differences in incidence rates (person-time). In addition to calculating prevalence rates, incidence rates were examined to assess the number of misconducts relative to the amount of time each offender was incarcerated, a concept known as person-time. The purpose is to provide additional descriptive information regarding misconduct, while accounting for both time at risk and the number of offenders at risk. More specifically, offenders who were incarcerated for longer periods of time represent a 
'heavier' contribution to the rate.

The overall mean number of days incarcerated for women was $341.40(S D=$ $205.00)$ while the mean number of days for men was higher $(M=433.70$ days, $S D=$ 248.20). The calculated person-time for each gender and the number of misconduct events that occurred within each person-days period is presented in Table 14 .

Table 14

Number of Misconduct Events and Person-Time for Male and Female Offenders in Minimum, Medium and Maximum Security

\begin{tabular}{|c|c|c|c|c|c|c|}
\hline & \multicolumn{2}{|c|}{ Minimum Security } & \multicolumn{2}{|c|}{ Medium Security } & \multicolumn{2}{|c|}{ Maximum Security } \\
\hline & $\begin{array}{l}\text { Female } \\
N=497\end{array}$ & $\begin{array}{c}\text { Male } \\
N=496\end{array}$ & $\begin{array}{l}\text { Female } \\
N=399\end{array}$ & $\begin{array}{c}\text { Male } \\
N=400\end{array}$ & $\begin{array}{l}\text { Female } \\
N=55\end{array}$ & $\begin{array}{c}\text { Male } \\
N=55\end{array}$ \\
\hline \multicolumn{7}{|l|}{ Major } \\
\hline \multicolumn{7}{|l|}{ Misconduct } \\
\hline $\begin{array}{l}\text { Number of } \\
\text { Events }\end{array}$ & 58 & 38 & 379 & 264 & 92 & 79 \\
\hline $\begin{array}{l}\text { Person-Time } \\
\text { (Days) }\end{array}$ & 130,617 & 170,083 & 162,970 & 209,282 & 31,108 & 33,077 \\
\hline \multicolumn{7}{|l|}{ Minor } \\
\hline \multicolumn{7}{|l|}{ Misconduct } \\
\hline $\begin{array}{l}\text { Number of } \\
\text { Events }\end{array}$ & 287 & 249 & 1032 & 541 & 155 & 126 \\
\hline $\begin{array}{l}\text { Person-Time } \\
\text { (Days) }\end{array}$ & 130,617 & 170,083 & 162,970 & 209,282 & 31,108 & 33,077 \\
\hline
\end{tabular}

The number of misconduct events relative to the person-time provides incidence rates. For example, in minimum security, there were approximately 0.0022 minor 
misconducts (287 events/130,617 person-days) per person-day (22 per 10,000 persondays) for the women and 0.0015 (249 events/170,083 person days) per person-day (15 per 10,000 person-days) for the men. In contrast, there were only 0.0004 major misconducts per person-day ( 4.0 per 10,000 person-days) for the women, and 0.0002 major misconducts per person-day ( 2.0 per 10,000 person-days) for the men in the same security level. As for medium security, there were 0.0023 major misconducts per personday (23 per 10,000 person-days) for women and 0.0013 major misconducts per personday (13 per 10,000 person-days) for men. Interpreted in a more intuitive way, using the numbers provided for major misconducts in medium security as an example, if the approximately 400 women incarcerated in medium security were followed for approximately 25 days, there would be 23 major misconducts in comparison to only 13 misconducts for 400 men within the same timeframe.

All incidence rates (person-days) and corresponding $95 \%$ confidence intervals are provided in Table 15 for major and minor misconduct. In order to assess gender differences in incidence rates, rate ratios were calculated and are also provided in Table 15 with corresponding $95 \%$ confidence intervals. If the rate ratio confidence limits exclude 1 , the rates significantly differ. All rate ratios demonstrated significance, except for the comparison of major misconduct rates between men and women in maximum security, $1.24,95 \% \mathrm{CI}[.97-1.70]$. In all cases, the rate for misconduct over person-time was higher among women. The largest ratio was found for minor misconducts in medium security, $2.45,95 \% \mathrm{CI}[2.12-2.72]$, while the ratio for minor misconducts in maximum only just reached significance, $1.31,95 \% \mathrm{CI}[1.03-1.67]$. 
GENDER AND INSTITUTIONAL MISCONDUCT

Table 15

Rates and Rate Ratios of Misconduct for Men and Women by Security Level

\begin{tabular}{|c|c|c|c|}
\hline & $\begin{array}{c}\text { Female } \\
\text { Rate }(95 \% \mathrm{CI})\end{array}$ & $\begin{array}{c}\text { Male } \\
\text { Rate }(95 \% \mathrm{CI})\end{array}$ & $\begin{array}{l}\text { Rate Ratio } \\
(95 \% \mathrm{CI})\end{array}$ \\
\hline Minimum Security & $N=497$ & $N=496$ & \\
\hline Rate of Major Misconduct & $\begin{array}{c}0.0004 \\
(0.0004-0.0006)\end{array}$ & $\begin{array}{c}0.0002 \\
(0.0002-0.0003)\end{array}$ & $\begin{array}{c}2.00 \\
(1.30-3.08)\end{array}$ \\
\hline Rate of Minor Misconduct & $\begin{array}{c}.0022 \\
(0.0020-0.0025\end{array}$ & $\begin{array}{c}0.0015 \\
(0.0013-0.0017)\end{array}$ & $\begin{array}{c}1.50 \\
(1.26-1.79)\end{array}$ \\
\hline Medium Security & $N=399$ & $N=400$ & \\
\hline Rate of Major Misconduct & $\begin{array}{c}0.00233 \\
(0.0021-0.0026)\end{array}$ & $\begin{array}{c}0.00126 \\
(0.0011-0.0014)\end{array}$ & $\begin{array}{c}1.84 \\
(1.57-2.17)\end{array}$ \\
\hline Rate of Minor Misconduct & $\begin{array}{c}0.00633 \\
(0.0060-0.0067)\end{array}$ & $\begin{array}{c}0.00258 \\
(0.0024-0.0028)\end{array}$ & $\begin{array}{c}2.45 \\
(2.21-2.72)\end{array}$ \\
\hline Maximum Security & $N=55$ & $N=55$ & \\
\hline Rate of Major Misconduct & $\begin{array}{c}0.0030 \\
(0.002-0.004)\end{array}$ & $\begin{array}{c}0.0024 \\
(0.002-0.003)\end{array}$ & $\begin{array}{c}1.24 \\
(.91-1.70)\end{array}$ \\
\hline Rate of Minor Misconduct & $\begin{array}{c}0.005 \\
(0.0042-0.0058)\end{array}$ & $\begin{array}{c}0.0038 \\
(0.0032-0.0045)\end{array}$ & $\begin{array}{c}1.31 \\
(1.03-1.67)\end{array}$ \\
\hline
\end{tabular}

Note. The rate ratios may not correspond exactly to the ratio of numbers provided in the table due to rounding. 
Although it is important to provide the raw rates and corresponding rate ratios as outlined in Table 15, interpretation of these numbers isn't necessarily intuitive. Accordingly, Table 16 provides a more straightforward example. It demonstrates the approximate number of misconducts one can expect if 100 offenders from this sample were followed for one year (i.e., 36,500 person-days) for each gender and each security level based on the information presented in Table 15 .

Table 16

Rate of Estimated Misconducts per 100 Offenders per 36,500 Person-Days

\begin{tabular}{|c|c|c|c|c|c|c|}
\hline & \multicolumn{2}{|c|}{ Minimum Security } & \multicolumn{2}{|c|}{ Minimum Security } & \multicolumn{2}{|c|}{ Medium Security } \\
\hline & $\begin{array}{l}\text { Female } \\
N=497\end{array}$ & $\begin{array}{c}\text { Male } \\
N=496\end{array}$ & $\begin{array}{l}\text { Female } \\
N=399\end{array}$ & $\begin{array}{c}\text { Male } \\
N=400\end{array}$ & $\begin{array}{l}\text { Female } \\
N=55\end{array}$ & $\begin{array}{l}\text { Male } \\
N=55\end{array}$ \\
\hline \multicolumn{7}{|l|}{ Major Misconduct } \\
\hline $\begin{array}{l}\text { Estimated Number } \\
\text { of Events }\end{array}$ & 16 & 8 & 85 & 46 & 108 & 87 \\
\hline \multicolumn{7}{|l|}{ Minor Misconduct } \\
\hline $\begin{array}{l}\text { Estimated Number } \\
\text { of Events }\end{array}$ & 80 & 53 & 231 & 94 & 182 & 139 \\
\hline
\end{tabular}

Gender differences in group means. Finally, to address the first research question, an analysis of variance (ANOVA) was performed to determine whether or not the mean number of misconducts varied as a function of gender and security level. More specifically, ANOVAs were conducted using a 2 (male, female) $\times 3$ (minimum, medium, maximum) design for each time period (12 months, 24 months, 36 months) and each 
misconduct type (major, minor). Simple effects analysis was used for interactions, and the Tukey method was used for post hoc analysis of the main effects. Given the number of tests used, alpha was set at $.008(.05 / 6)$ to control for Familywise error. For space reasons, only graphs demonstrating significant interactions are provided within text. For additional figures, please see Appendix C.

Group 1. An ANOVA for major misconduct with Group 1 demonstrated a significant main effect of security level $F(2,995)=19.58, p<.001, \eta^{210}=.04,95 \% \mathrm{CI}$ $[0.017,0.062]$. Although misconduct for maximum security $(M=0.53, S D=0.80)$ did not significantly differ from minimum $(p=.18)$ or medium $(p=.10)$ security, offenders engaged in a significantly higher mean number of misconducts in medium security $(M=$ $0.51, S D=1.40)$ in comparison to minimum security $(M=0.07, S D=0.50 ; p<.001)$. There was no significant interaction for major misconduct $F(2,995)=4.16, \mathrm{p}=.02, \eta^{2}=$ $.008,95 \% \mathrm{CI}[0.00,0.022]$ and no significant main effect of gender $F(1,995)=4.84, p=$ $.03, \eta^{2}=.005,95 \% \mathrm{CI}[0.00,0.017]$.

For minor misconduct in group 1 , there was an interaction between gender and security level that reached significance, $F(2,995)=5.07, p=.006, \eta^{2}=.01,95 \% \mathrm{CI}$ $[0.001,0.025]$. Simple effects analysis indicated that the interaction was due to a significant effect of gender at medium security. Women incarcerated at medium security displayed a significantly higher mean number of misconducts $(M=1.75, S D=2.74)$ in comparison to men incarcerated at the same level $(M=0.96, S D=1.98 ; p<.001)$. Males in maximum security $(M=1.50, S D=2.07)$ did not significantly differ from their female counterparts $(M=2.91, S D=4.59 ; p=.49)$, neither did the males in minimum security

\footnotetext{
${ }^{10} \eta^{2}$ Eta squared effect size: $.01=$ small, $.06=$ medium, $.14=$ large $($ Green \& Salkind, 2008$)$.
} 
$(M=0.32, S D=0.73)$ in comparison to females at the same level $(M=0.44, S D=1.01 ; p$ $=.92$ ). Figure 1 provides a graphical representation of the interaction.

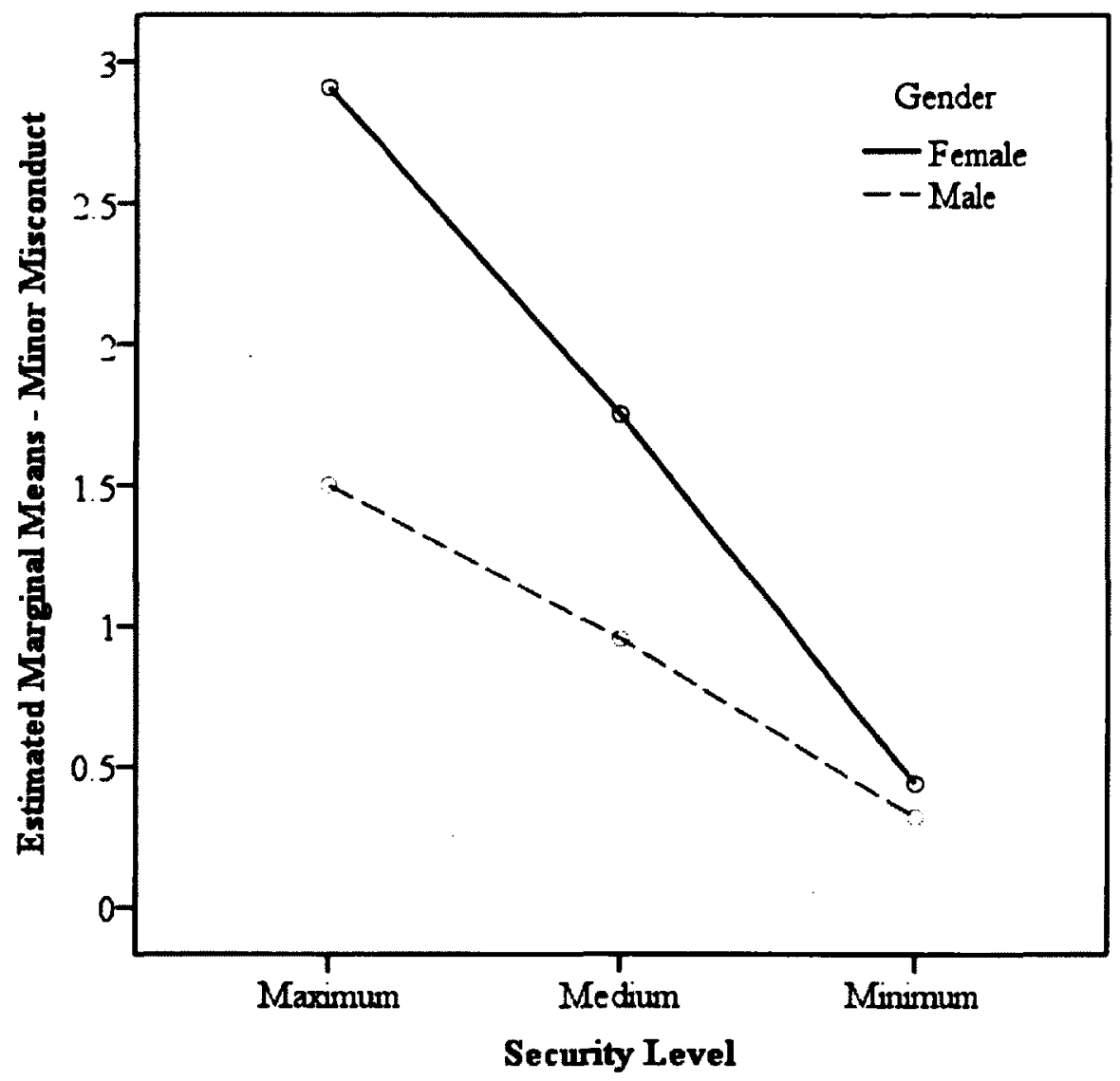

Figure 1. Graph of a significant interaction between security level and gender for minor misconduct in group 1.

Consequently, there was a main effect of security level, $F(2,995)=41.64, p$ $<.001, \eta^{2}=.08,95 \% \mathrm{CI}[0.047,0.109]$ with both maximum $(M=2.41, S D=3.74)$ and medium $(M=1.49, S D=2.54)$ security levels differing significantly from the mean number of misconducts in minimum security $(M=0.39, S D=0.90)$. The significant 
main effect of gender, $F(1,995)=7.73, p=.006, \eta^{2}=.01,95 \% \mathrm{CI}[0.001,0.022]$ demonstrated a higher mean number of misconducts among females $(M=0.90, S D=$ 1.93) than males $(M=0.48, S D=1.18)$.

Group 2. The ANOVA for major misconduct in group 2 demonstrated a significant main effect of security level $F(2,737)=16.96, p<.001, \eta^{2}=.04,95 \% \mathrm{CI}$ $[0.018,0.075]$. Although the mean number of misconducts for maximum security $(M=$ $1.19, S D=1.91)$ did not differ significantly from those in medium security $(M=0.78, S D$ $=1.88 ; p=.16)$, there was a significant difference when compared with minimum security $(M=0.15, S D=0.48 ; p<.001)$. The mean number of misconducts in medium security significantly differed from this group as well $(p<.001)$. There was no significant interaction for major misconduct $F(2,737)=0.60 p=.55, \eta^{2}=.002,95 \% \mathrm{CI}$ $[0.00,0.010]$ and no significant main effect of gender $F(2,737)=2.64, p=.11, \eta^{2}=$ $.004,95 \% \mathrm{CI}[0.00,0.017]$.

In regards to minor misconduct for group 2, the results again indicated that there was a significant main effect of security level $F(2,737)=13.35, p<.001, \eta^{2}=.04,95 \%$ $\mathrm{CI}[0.013,0.063]$. The only significant difference in the mean number of misconducts was between the medium $(M=2.00, S D=3.09)$ and minimum security levels $(M=0.94$, $S D=1.61 ; p<.001)$. Misconduct in maximum security $(M=1.77, S D=2.56)$ did not display significant results when compared with either of the two levels. There was no significant interaction for minor misconduct $F(2,737)=4.07, p=.02, \eta^{2}=.01,95 \% \mathrm{CI}$ $[0.00,0.029]$ and no significant main effect of gender $F(2,737)=6.61, p=.01, \eta^{2}=$ $.009,95 \% \mathrm{CI}[0.001,0.027]$. 
Group 3. The ANOVA for major misconduct within group 3 did not produce any significant results for the interaction, $F(1,152)=0.28, p=.75, \eta^{2}=.004,95 \% \mathrm{CI}[0.00$, $0.032]$, the main effect of security, $F(1,152)=4.88, p=.01, \eta^{2}=.06,95 \%$ CI $[0.004$, $0.136]$ or the main effect of gender, $F(1,152)=0.62, p=.43, \eta^{2}=.004,95 \% \mathrm{Cl}[0.00$, $0.046]$.

The only other notable result was related to minor misconduct, with a significant main effect of security level $F(2,152)=7.71, p<.001, \eta^{2}=.09,95 \%$ CI $[0.018,0.177]$. Following the same patterns previously discussed, the mean number of misconducts for maximum security $(M=4.38, S D=5.10)$ did not differ significantly from those in medium security $(M=3.16, S D=4.08 ; p=.78)$. They did, however, significantly differ from the mean number of misconducts in minimum security $(M=0.84, S D=1.46 ; p$ $=.001)$, as did the mean number of misconducts in medium security $(p=.001)$. There was no significant interaction for minor misconduct $F(2,152)=4.37, p=.01, \eta^{2}=.05$, $95 \% \mathrm{CI}[0.002,0.128]$ and no significant main effect of gender $F(2,152)=4.25, p=.04$, $\eta^{2}=.03,95 \%$ CI $[0.00,0.093]$.

Research Question 2: Are there gender differences in the patterns and predictors of survival time to first misconduct among federally incarcerated offenders by security level?

Gender differences in time to first misconduct. Kaplan-Meier analyses were conducted to assess gender differences in time to failure (i.e., event of misconduct) within each security level. This method of analysis automatically controls for time-at-risk and therefore allowed for the inclusion of the full sample without having to group offenders 
by days incarcerated. Given the number of tests used, alpha was set at $.008(.05 / 6)$ to control for Familywise error.

The only significant results for major misconduct were found within the medium security group (Table 17). Although the majority of the cases were censored for the survival analysis examining major misconducts $(66.67 \%$ of females and $71.75 \%$ of males), the time to failure was significantly different between the genders. Males had a longer survival time to failure $(M=273.86)$ in comparison to females $(M=178.95)$.

Table 17

Survival Analysis Examining Time to Failure for Major Misconduct by Security Level

\begin{tabular}{lccccc} 
& $n / 1902$ & $n$ Failed (\%) & $\begin{array}{c}M \text { Survival } \\
\text { Time (days- } \\
\text { censored) }\end{array}$ & $\begin{array}{c}\text { Time (days- } \\
\text { uncensored) }\end{array}$ & $\chi^{2}$ \\
\hline $\begin{array}{l}\text { Maximum } \\
\text { Security } \\
\text { Female }\end{array}$ & 55 & $25(45.45)$ & 520.30 & 200.12 & .002 \\
$\begin{array}{l}\text { Male } \\
\text { Medium }\end{array}$ & 55 & $26(47.27)$ & 543.52 & 190.31 & \\
$\begin{array}{l}\text { Security } \\
\text { Female }\end{array}$ & 399 & $133(33.33)$ & 383.14 & 178.95 & $11.22 * *$ \\
Male & 400 & $113(28.25)$ & 486.50 & 273.86 & \\
Minimum & & & & & \\
Security & & & & & \\
Female & 497 & $40(8.05)$ & 257.03 & 152.05 & 6.40 \\
Male & 496 & $28(5.65)$ & 337.58 & 228.46 & \\
\hline
\end{tabular}

Note. ${ }^{*} p<.008,{ }^{* *} p<.001 ;$ Log Rank test. 
Graphical representations of the Kaplan-Meier survival curves for major misconduct at all three security levels are provided in Figures 2 to 4 . Figure 2 and Figure 4 show relatively similar or overlapping patterns of survival between the two groups while Figure 3 displays a more prominent gap between the lines, with the females dropping earlier.

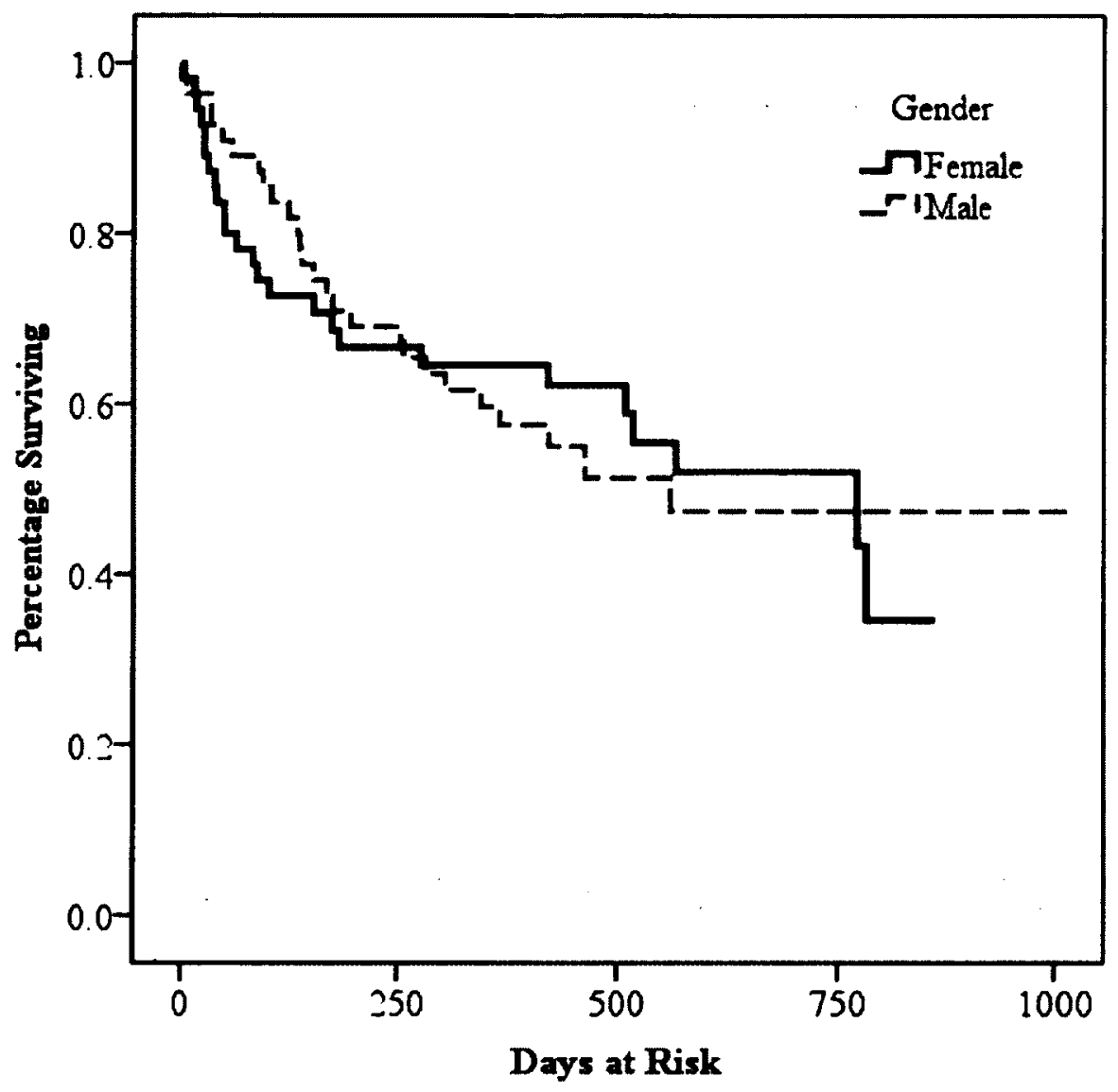

Figure 2. Survival Analysis Examining Time to Failure for Major Misconduct between Genders within Maximum Security. 


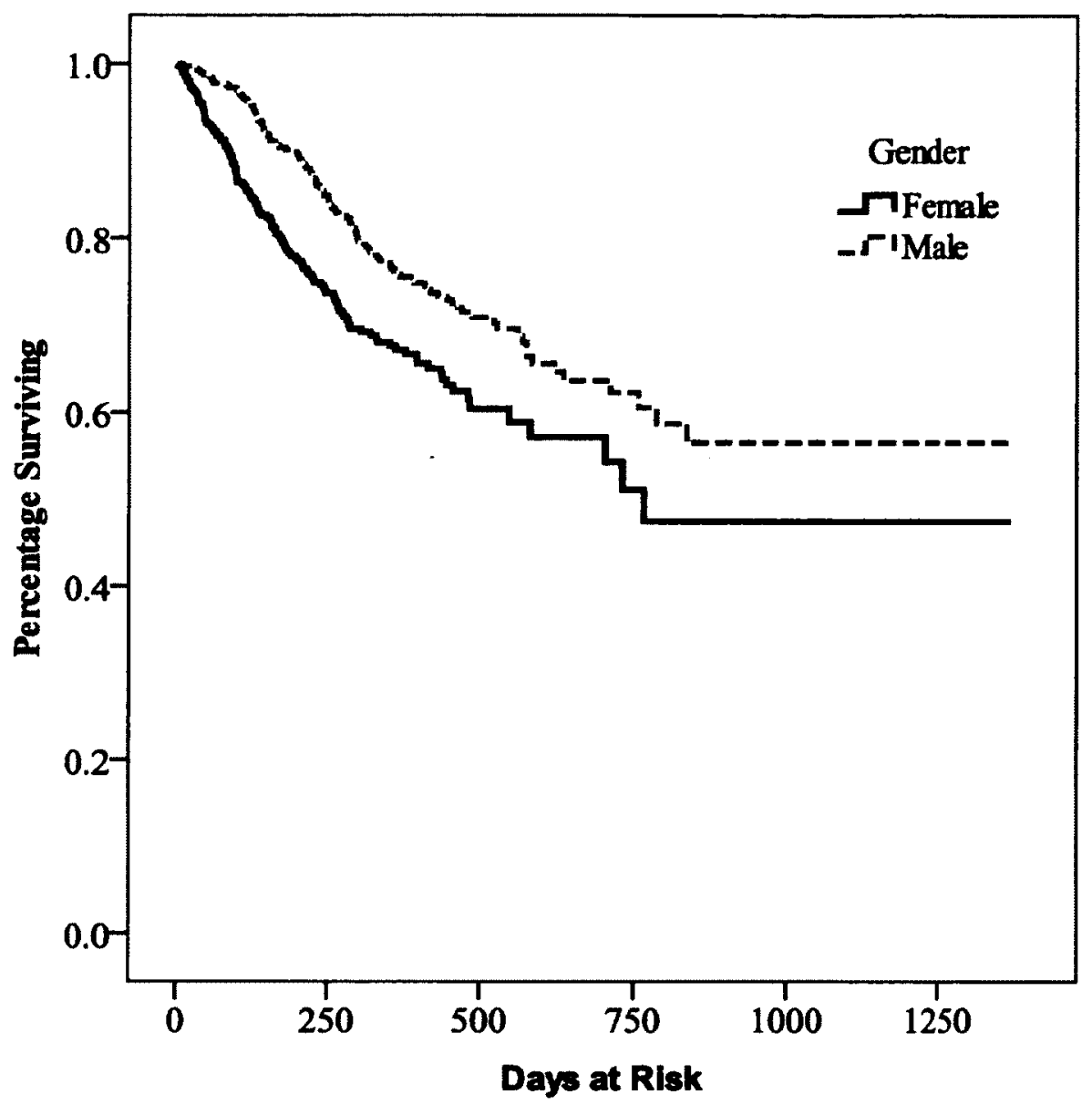

Figure 3. Survival Analysis Examining Time to Failure for Major Misconduct between Genders within Medium Security. 


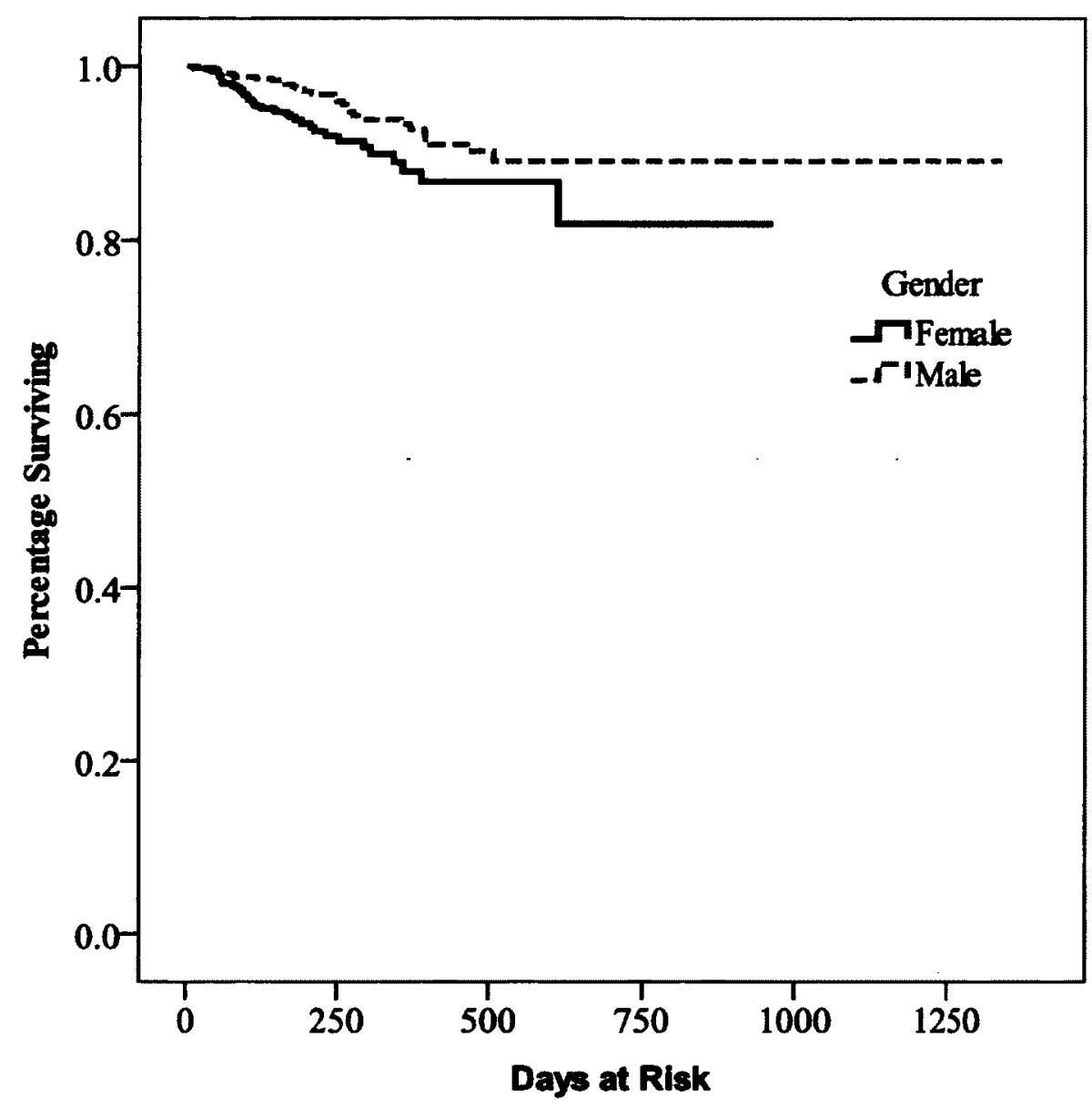

Figure 4. Survival Analysis Examining Time to Failure for Major Misconduct between Genders within Minimum Security.

When analyzing time to failure for minor misconducts, significant differences were again found within the medium security level, while no other significant results were found within minimum or maximum security (as shown in Table18). Medium security males demonstrated a longer survival time $(M=224.23)$ in comparison to their female counterparts $(M=129.21)$. 
Table 18

Survival Analysis Examining Time to Failure for Minor Misconduct by Security Level

\begin{tabular}{lccccc} 
& $n / 1902$ & $n$ Failed (\%) & $\begin{array}{c}\text { TSurvival } \\
\text { Time (days- } \\
\text { censored) }\end{array}$ & $\begin{array}{c}\text { Time (days- } \\
\text { uncensored) }\end{array}$ & $\chi^{2}$ \\
\hline $\begin{array}{l}\text { Maximum } \\
\text { Security } \\
\text { Female }\end{array}$ & 55 & $36(64.45)$ & 486.32 & 183.17 & .54 \\
$\begin{array}{l}\text { Male } \\
\text { Medium }\end{array}$ & 55 & $33(60.00)$ & 524.91 & 164.06 & \\
Security & & & & & \\
Female & 399 & $246(61.65)$ & 356.50 & 129.21 & $60.68 * *$ \\
Male & 400 & $174(43.50)$ & 481.65 & 224.23 & \\
Minimum & & & & & \\
Security & & & & & \\
Female & 497 & $149(29.98)$ & 246.91 & 132.42 & 5.77 \\
Male & 496 & $141(28.43)$ & 315.81 & 186.38 & \\
\hline
\end{tabular}

Note. ${ }^{*} p<.008,{ }^{* *} p<.001 ;$ Log Rank test.

Graphical representations of the Kaplan-Meier curves for all three security levels are provided in Figures 5 to 7 . Figure 5 and Figure 7 show relatively similar or overlapping patterns of survival between the two groups while Figure 6 displays a more prominent gap between the lines, with the females dropping earlier. 


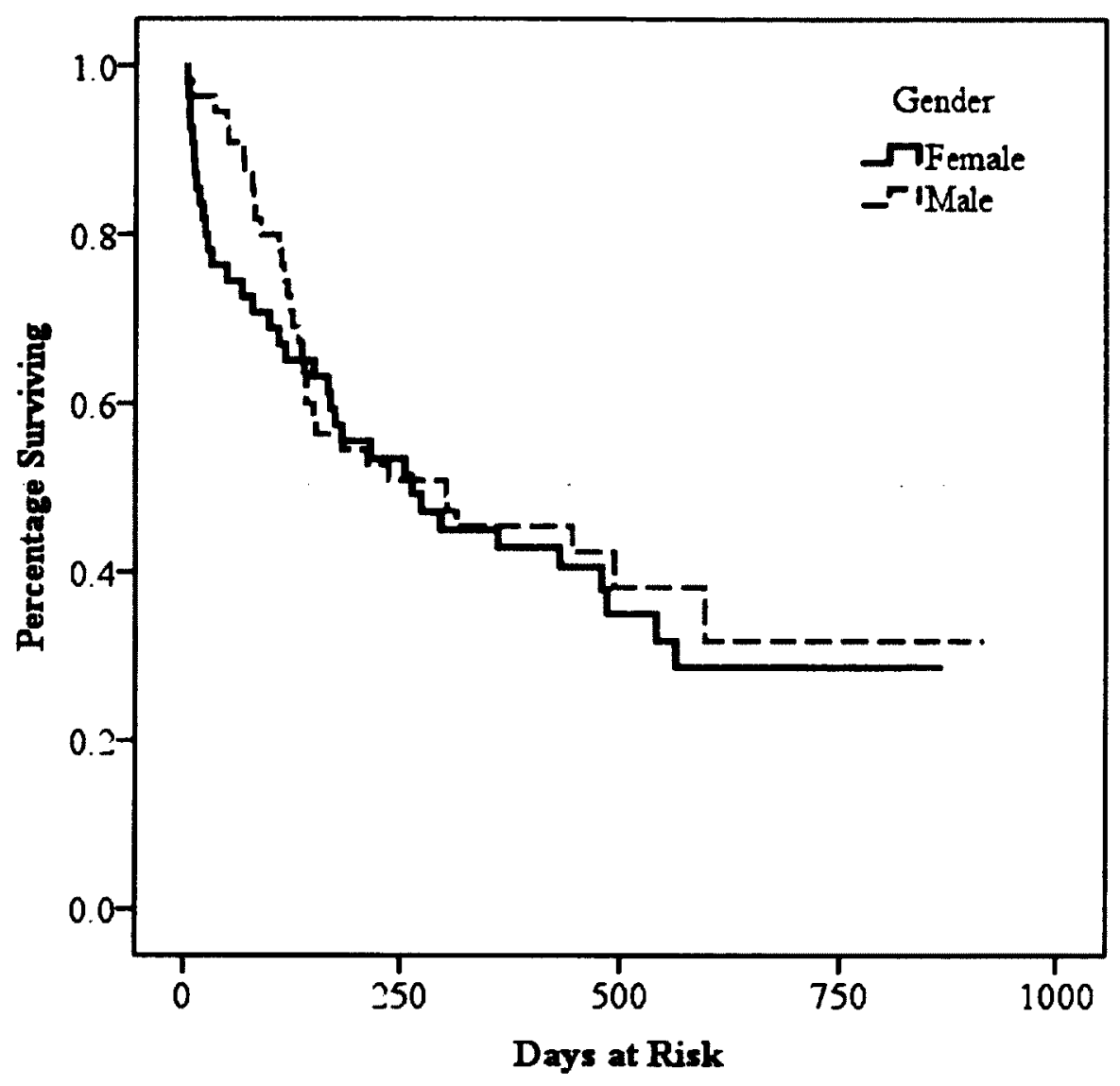

Figure 5. Survival Analysis Examining Time to Failure for Minor Misconduct between Genders within Maximum Security. 


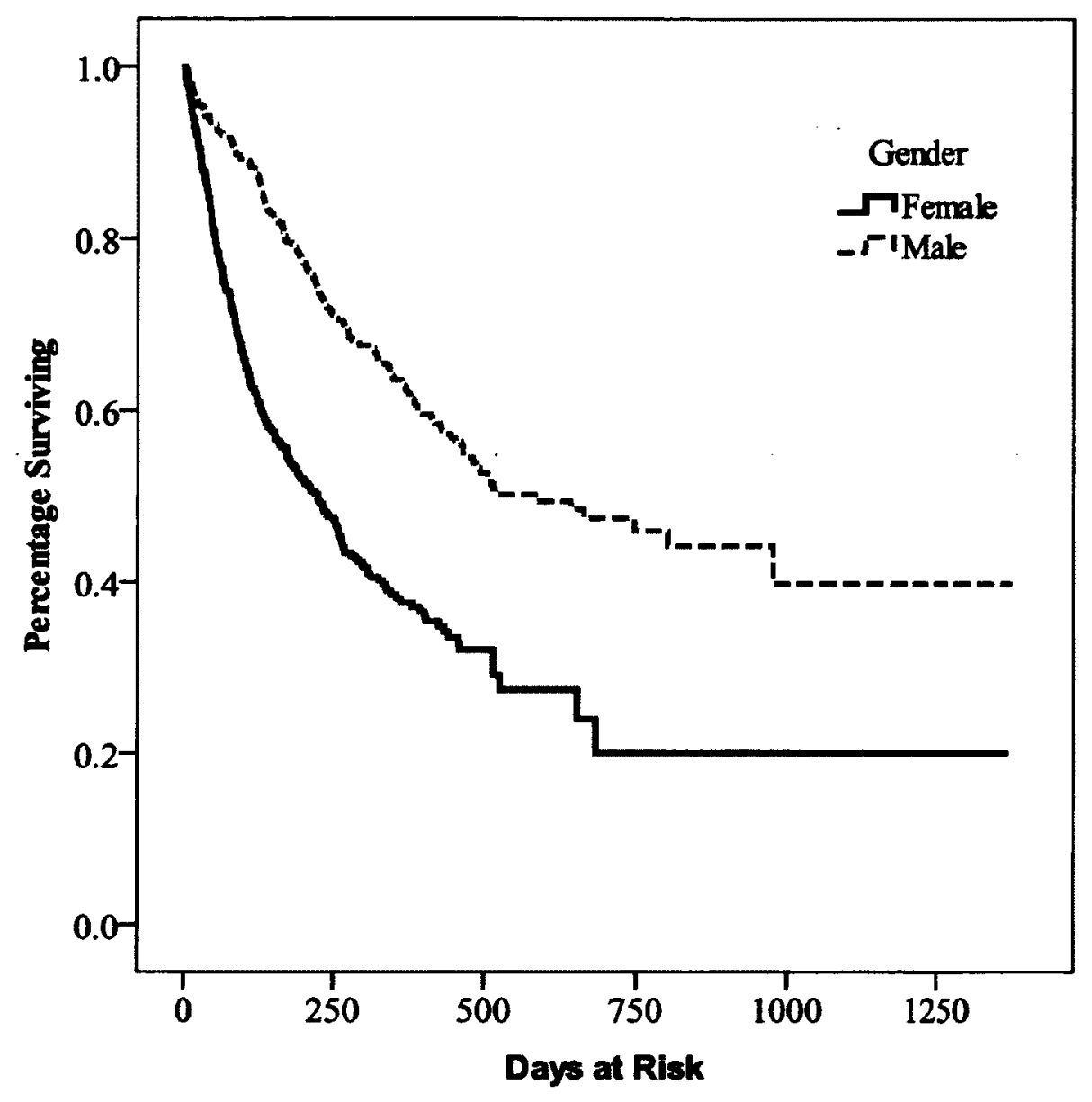

Figure 6. Survival Analysis Examining Time to Failure for Minor Misconduct between Genders within Medium Security. 


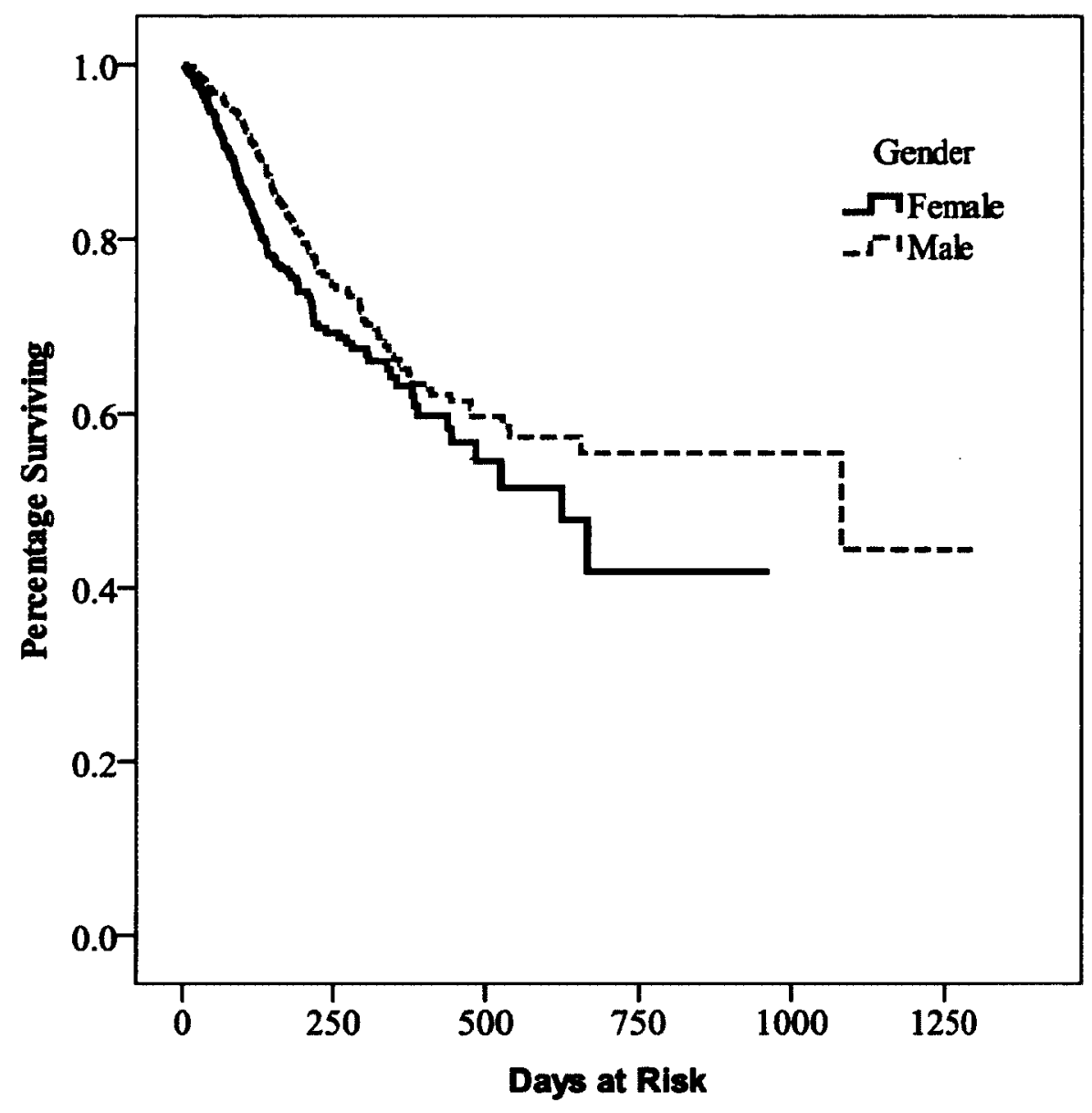

Figure 7. Survival Analysis Examining Time to Failure for Minor Misconduct between Genders within Minimum Security.

Cox regression: the proportional hazards model. A Cox regression survival analysis was performed to assess the potential predictors of the hazard of misconduct over time for both genders. The purpose was to identify which predictors significantly increased/decreased the hazard of misconduct for men and women individually. Each model was tested against the global null hypothesis that all coefficients are equal to 0 
using the likelihood-ratio test. Upon receiving significant findings for the overall model, the Wald chi-square test was used to test the specific null hypothesis that each coefficient is equal to zero. Unless otherwise indicated, the reference group for all RNR variables (static risk, dynamic risk, motivation and reintegration) was designated as 'High'.

Female offenders. The parameter estimates, standard errors and hazard ratios (with corresponding $95 \%$ confidence intervals) for all covariates used in the models for women are presented in Appendix D.

Although the overall model for major misconduct within minimum security was not significant, $\chi^{2}(11, N=495)=9.22, p=.60$, the model for medium security was, $\chi^{2}$ $(12, N=398)=29.04, p=.004$. Results of the individual coefficients indicated that for every one year increase in age among medium security women, there was a $3.3 \%{ }^{11}$ decrease in the hazard of major misconduct, $\chi^{2}(1, N=398)=9.03, p=.003, H R=0.967$, $95 \% \mathrm{CI}[0.945,0.988]$. There were no other significant findings in medium security.

Following a similar pattern, the overall findings for maximum security, $\chi^{2}(9, N=$ $55)=23.56 p=.005$, highlighted that age at admission was the only significant predictor for major misconduct, $\chi^{2}(1, N=55)=10.09, p=.002, H R=0.889,95 \%$ CI $[0.827$, 0.956]. The hazard ratio indicated that for every one year increase in age, there was an $11.10 \%$ decrease in the hazard of misconduct (see Appendix D for additional results). For minor misconduct among minimum security women, $\chi^{2}(11, N=495)=$ $47.00, p<.001$, age was a significant predictor, $\chi^{2}(1, N=495)=10.91, p=.001, H R=$ $0.972,95 \% \mathrm{CI}[0.956,0.989]$, indicating that for every increase in age, there was a $2.8 \%$ decrease in the hazard of misconduct. Dynamic risk was also a significant predictor with

\footnotetext{
${ }^{11}$ Continuous variables in Cox regression are calculated as $(1.00-H R) \times 100$.
} 
this group, $\chi^{2}(2, N=495)=13.68, p=.001$. The hazard rate among women offenders designated as low need was $28.1 \%$ of the hazard among high need women, $\chi^{2}(1, N=$ $495)=13.53, p<.001, H R=0.28195 \% \mathrm{CI}[0.143,0.552]$. In contrast, the hazard of the medium need group was $56.30 \%$ of the hazard among high need women, $\chi^{2}(1, N=495)$ $=6.46 . p=.01, H R=0.563,95 \% \mathrm{CI}[0.362,0.877]$. The model for minor misconduct in medium security also reached significance, $\chi^{2}(11, N=398)=26.25, p=.006$. Every one year increase in age was associated with a $2.3 \%$ decrease in the hazard of misconduct, $\chi^{2}$ $(1, N=398)=9.01 . p=.003, H R=0.97795 \% \mathrm{CI}[0.962,0.992]$. Although the overall findings for maximum security demonstrated significance, $\chi^{2}(8, N=55)=26.54, p=$ .001 , further assessment of the individual coefficients did not find any predictors significant at the Bonferroni adjusted alpha level.

Male Offenders. The parameter estimates, standard errors and hazard ratios (with corresponding $95 \%$ confidence intervals) for all covariates used in the models for men are presented in Appendix E.

For major misconduct in minimum security, $\chi^{2}(12, N=493)=32.67, p=.001$, age again emerged as a predictor for misconduct, $\chi^{2}(1, N=493)=13.29, p<.001, H R=$ $0.924,95 \% \mathrm{CI}[0.886,0.964]$, as was the case for men in medium security, ${ }^{12} \chi^{2}(1, N=$ $395)=32.06, p<.001, H R=0.941 .95 \% \mathrm{CI}[0.921,0.961]$. Reintegration level was another factor that emerged as a predictor of major misconduct within the medium security group, $\chi^{2}(2, N=395)=12.94, p=.002$. The hazard of major misconduct was 3.01 times higher among males with low reintegration potential in comparison to men with high reintegration potential, $\chi^{2}(1, N=395)=8.81, p=.003, H R=3.013,95 \% \mathrm{CI}$

\footnotetext{
${ }^{12}$ Overall likelihood ratio $=\chi^{2}(12, N=395)=61.74, p<.001$
} 
$[1.454,6.241]$. In contrast, the rate of the medium reintegration group was only 1.30 times higher than that of the high reintegration group, $\chi^{2}(1, N=395)=0.71, p=.40, H R$ $=1.302,95 \% \mathrm{CI}[0.704 .2 .410]$. There were no significant predictors for major misconduct within the maximum security group. ${ }^{13}$

The overall model for minor misconduct in minimum security demonstrated significance, $\chi^{2}(12, N=493)=52.96, p<.001$, with age once again as a significant predictor, $\chi^{2}(1, N=493)=26.08, p<.001, H R=0.960,95 \% \mathrm{Cl}[0.946,0.975]$. This was also the case for minor misconduct in medium security, ${ }^{14}, \chi^{2}(1, N=395)=39.22, p<$ $.001, H R=0.949,95 \% \mathrm{CI}[0.933,0.965]$. After adjusting for small cell size and removing two variables (reintegration and dynamic risk) from the model for minor misconduct in maximum security, the likelihood ratio was no longer significant $\chi^{2}(7, N$ $=55)=18.94, p=.0084$. For additional information, please refer to Appendix E.

Research Question 3: Do major incidents of misconduct differ qualitatively based on perpetrator gender?

For the final research question of the current study, misconduct reports were coded blind to gender in order to qualitatively assess gender differences in the nature and severity of misconduct. Given the small sample size and the limited detail provided in the reports, the following analysis was conducted between males and females to provide an overall representation of the findings (i.e., the samples were not separated by security level). That being said, the frequencies for each theme separated by gender and security level are provided in Appendix F. Each overarching theme and corresponding results are

\footnotetext{
${ }^{13}$ Overall likelihood ratio $=\chi^{2}(8, N=55)=11.30, p=.19$

${ }^{14}$ Overall likelihood ratio $=\chi^{2}(12, N=395)=60.74, p<.001$
} 
described below, and illustrative quotations ${ }^{15}$ are provided. Frequencies are provided based on the number of cases where relevant information was available for each section.

Offender role. All 28 of the males and 27 of the females were coded as being instigators, with only one woman identified as an associate to the incident. For the most part, offenders acted alone, with only one male and two females acting with an accomplice.

Misconduct type. All 56 cases were coded for type of misconduct. Almost half of the women $(46.4 \% ; n=13 / 28)$ engaged in physical altercations (i.e., fighting, pushing and shoving) and another $46.4 \%(n=13 / 28)$ engaged in physical assault (i.e., punching, kicking). The remaining $7.1 \%(n=2 / 28)$ were charged for uttering threats. The males followed a relatively similar pattern with the majority being involved in physical altercations $(42.9 \% ; n=12 / 28)$ and assaults $(35.7 \% ; n=10 / 28)$, with a small portion $(10.7 \% ; n=3 / 28)$ being charged for uttering threats. The male offenders were the only ones to engage in assault using bodily fluids $(10.7 \% ; n=3 / 28)$.

An example of threatening misconduct.

M-MAX24 ${ }^{16}:$ IM A $^{17}$ Is disrespectful and makes threats toward a staff member ("wait till I get out of my cell I will cut your head off"). Inmate has been advised of this report.

\footnotetext{
${ }^{15}$ The gender was 'reconnected' for the provided quotations and gender identifying terms are no longer blacked out for ease of reading and interpretation.

${ }^{16}$ The number refers to the report ID and the letters preceding it refer to the gender of the offender ( $F=$ female, $M=$ male) and their security level (MAX = maximum, $M E D=$ medium, $M I N=$ minimum)

${ }^{17} \mathrm{I} / \mathrm{M}=$ Inmate. Inmates' names are replaced with generic letters. The offender being coded for is always underlined and bold.
} 
An example of a physical altercation.

F-MED09: While in the unit, staff heard UMA say the word "[expletive]" and observed inmates $\underline{A}$ and $B$ yelling at each other near the kitchen table. Staff observed I/M A hit $1 / M$ B in the neck with an open left hand. The inmates were instructed to stop and they separated.

An example of an assault.

F-MED11: As staff interviewed other inmates of the units, it was determined that

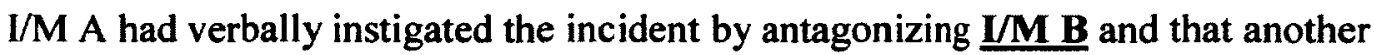
inmate had physically separated them. I/M A stated that $\mathbf{V} \mathbf{M}$ B had punched her in the face, pulled her hair, and then kicked her numerous times about the head and mid section after she fell to the floor. I/M A repeated that she did not hit $\underline{\mathbf{L}} \mathbf{M}$ B.

An example of an assault using bodily fluids.

M-MAX33: An officer was on the range when I/MA threw a liquid substance that landed over the Officer's leg and waist area, the unknown liquid is suspected to be urine due to its smell [...] The officers were negotiating a cell move for $\underline{\mathbf{I M}}$ $\underline{A}$ to a solid door cell. This cell move was for staff safety due to the inmate threatening and attempting to throw urine through his cell bars on them during their walks. I/M A became assaultive and grabbed a cup of unknown liquid (suspected urine) and attempted to throw it towards Officers.

Offender method. Several potential categories of method/weapon were coded for. Information was available for all 56 cases. Each category was classified based on whether or not the instigator used the method/weapon to make contact with the victim or to threaten the victim (e.g., used physical force to harm the victim versus used force to threaten/control the victim). The primary method used during misconducts was physical force for both men $(64.3 \% ; n=18 / 28)^{18}$ and women $(92.9 \% ; n=26 / 28)$. In the same

\footnotetext{
${ }^{18}$ The sum of percentages may exceed $100 \%$ given that offenders could use more than one method during the misconduct.
} 
vein, $3.6 \%$ of women and $10.7 \%$ of men threatened the use of physical force. That being said, women clearly relied more so on a purely physical method in comparison to men. There were only individual cases where a woman used a blunt object to harm someone (3.6\%), a blunt object to threaten someone (e.g., a rock; $3.6 \%$ ), or threw an object at their intended victim (e.g., a book; 3.6\%). In contrast, males tended to vary in their methods to a wider degree. For example, unlike women, men used bodily fluids to harm $(10.7 \%$; $n=$ $3 / 28)$ and threaten $(7.1 \% ; n=2 / 28)$ individuals, while just over $14 \%(n=4 / 28)$ threw an object at their intended victims in order to harm them (e.g., chairs, food tray). Although there were no cases where a blunt object was used to harm an individual, there were 2 cases $(7.1 \%)$ where a blunt object was used to threaten someone (e.g., tray, handmade weapon - sock filled with gravel and secured with tape).

Location. There were four cases in both the male and female groups where location was marked as unknown. Percentages are therefore provided out of 24 for both groups. For the most part, misconduct between women occurred within the cells/living units $(62.5 \% ; n=15 / 24)$ with recreational/common areas being the second most cited location $(16.7 \% ; n=4 / 24)$. The range was a frequent location for the males $(29.2 \% ; n=$ $7 / 24)$ as were the recreational/common areas such as the gym $(29.2 \% ; n=7 / 24)$. The only other notable location for men included the kitchen/dining area $(16.7 \% ; n=4 / 24)$. 
Use of force. The degree of force ${ }^{19}$ used by the staff to bring the situation under control was also assessed. Given the strict guidelines regarding staff use of force, the degree of intervention should typically reflect the severity of the misconduct (i.e., the more serious the incident, the more serious the use force) and if the incident escalates, the degree of force should increase accordingly (see Appendix $G$ for the Use of Force guideline chart). The potential categories include (in order of seriousness): none, verbal instruction, negotiation ${ }^{20}$, minor physical handling, restraint equipment, major physical handling, inflammatory sprays/chemical agents, ${ }^{21}$ intermediary impact weapons, the Emergency Response Team (ERT) and finally, the use of firearms. ${ }^{22}$

Unfortunately, there were several cases where information regarding the use of force was not provided in the report for both men $(n=7 / 28)$ and women $(n=9 / 28)$. Results are therefore presented based on the number of known cases. Coding results demonstrated that $36.8 \%(n=7 / 19)$ of the misconduct cases for women did not require any use of force by the staff. For the most part, the presence of staff was sufficient to defuse the situation, or in some cases, staff were only informed of the misconduct after its occurrence and force was therefore not necessary. The second most common method (31.6\%; $n=6 / 19)$ used with women involved minor physical intervention (e.g., stepping

\footnotetext{
${ }^{19}$ By definition, use of force is $[\ldots]$ "any action by staff on or off institutional property, that is intended to obtain the cooperation and gain control of an inmate, by using one or more of the following measures: (a) non-routine use of restraint equipment; (b) physical handling/control; (c) use of inflammatory and/or chemical agents; (d) use of batons or other intermediary weapons; (e) use of firearms; and (f) deployment of the Emergency Response Team (ERT), in conjunction with at least one of the use of force measures identified above" (CSC, 2009a, p. 2).

${ }^{20}$ This typically involves a qualified staff member (e.g., psychologist) or an actual specialist is brought it.

${ }^{21} \mathrm{OC}$ Spray is not carried by staff in men's minimum security facilities, or women's minimum and medium security facilities.

${ }^{22}$ Firearms are not carried by any staff within any of the women's facilities.
} 
between inmates to separate them, escorting them away from the situation). In three cases $(15.8 \%)$ verbal warnings were sufficient to terminate the misconduct while two cases $(10.5 \%)$ required major physical handling (e.g., physically restraining the offender, reacting in self-defence). Only one case resulted in the use of chemical agents to deter the offender.

In contrast, the most common method of force used with male offenders involved inflammatory sprays/chemical agents $(33.3 \% ; n=7 / 21)$. Only four cases $(19.0 \%)$ did not require use of force while verbal intervention was sufficient in one case $(4.8 \%)$. Other methods included negotiation (9.5\%), minor physical involvement $(9.5 \%)$ and use of restraint equipment such as a body belt (9.5\%). Only individual cases (4.8\%) warranted major physical handling, use of the ERT, or staff firearms.

An example of minor physical handling.

F-MAX49: Officers responded to the pod and at this point, $1 / \mathrm{M} \mathrm{A}$ was on the

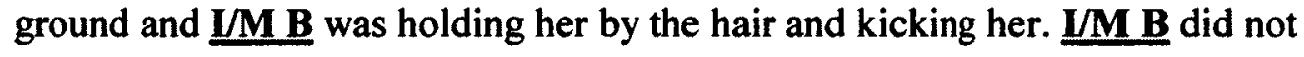
comply with orders to stop fighting and it was not until officers stood directly in between the two inmates that $\mathbf{M} \mathbf{M}$ stopped her behaviour. Both inmates were ordered to lock up and ultimately did so.

An example of major handling.

F-MAX45: I/MA refused direction, reasoning and conflict resolution continued to no avail. Officers gave 3 warnings that physical handling may be used if $\underline{\mathbf{I} M}$ A continued to refuse direction to move [...] After the three counts, I/MA had still made no effort to comply and officers seized her right and left arms. $\mathbf{M} \mathbf{A}$ was placed in a rear wrist lock providing control and I/MA was escorted to [her] cell.

An example of chemical agents.

M-MAX48: It was noted that two inmates were engaged in a fist fight on the floor of the gymnasium. Two verbal orders were given to cease and desist, both were ignored. At this point the catwalk officer deployed one (1) T-21 powdered OC 
round into the gymnasium, after which a third order to cease and desist was given and the two inmates fighting complied with the orders.

Victim selection. The most notable difference in the nature of misconduct between men and women involved the victim selection. Information for all 56 cases was available. Although inmates were the most common victim for both groups, males clearly selected staff members more frequently than the females did (42.9\% versus $14.3 \%)$. In contrast, females were more likely to select another inmate in comparison to males $(89.3 \% \text { versus } 57.1 \%)^{23}$ In all four cases where women were involved in misconduct with a staff victim, the individuals were correctional officers, as was the case for $90.0 \%$ of the males' victims $(n=9 / 10) .{ }^{24}$

Although the original goal was to identify the connection between a perpetrator and his/her inmate victim, insufficient report information resulted in limited findings. Out of the all the reports where the victim was an inmate $(n=16$ for men, $n=25$ for women), only two cases for the men and nine cases for the women provided relevant information. The only identified relationship among the men was related to a friendship and/or acquaintance $(100.0 \% ; n=2 / 2)$. Several of the inmate victims in the female sample were identified as being the instigator's cell/house mate $(66.7 \% ; n=6 / 9)$ while only two were identified as having a romantic relationship with their perpetrator $(22.2 \%)$. The final report involved an acquaintance/friend as a victim $(11.1 \% ; n=1 / 9)$.

\footnotetext{
${ }^{23}$ The percentages for women exceed 100 given that one case involved both a staff and inmate victim. ${ }^{24}$ Information was only available for 10 cases regarding staff victims. The remaining victim was a kitchen staff member.
} 


\section{Examples of identified relationships between instigator and victim.}

M-MIN07: Staff had opened all cells for uncleared offenders to go to the gym; staff noticed a physical altercation had begun outside [the] cell [...] It should be noted that both offenders stated that they were from Cape Breton and had spent time in the CBCC community centre and did allude to knowing each other on the street.

F-MED51: I/M A stated that she and I/M B were not in a relationship but did have sexual encounters. IM A stated that $B$ became very jealous of everyone and would follow I/M A around. I/M A gave B the silent treatment for a couple of days.

The final victim-related factor that was coded for was the degree of physical harm/injury inflicted on the victim. The score ranged from 1 (no physical harm) to 7 (death) with 4 (moderate physical harm) as a middle point (please refer to Appendix B for further details regarding the rating categories). For the male offenders, the mean rating was $2.5(S D=1.3)^{25}$ while the mean rating for females was only slightly lower $(M$ $=2.3, S D=0.64)^{26}$.

An example of minor/superficial injury (level 3 rating).

M-MAX04: I/M A is reported as having blood coming from his nose, mouth and a cut on the arm.

An example of moderate physical harm (level 4 rating) involved a case (MMED25) where an inmate kicked a correctional officer down on the ground and

\footnotetext{
${ }^{25}$ This is based on 20 known ratings. The remaining 8 cases did not provide sufficient information to select a rating.

${ }^{26}$ This is based on 19 known ratings. The remaining 9 cases did not provide sufficient information to select a rating.
} 
continued to kick him until staff intervened. This resulted in a significant knee injury that required the officer to seek outside hospital treatment and to take time off work. ${ }^{27}$

Offender motivation. Offender motivation was another theme that would have provided pertinent information in understanding misconduct. Inadequate information however, lead to limited findings again ( $n=5$ for the men, $n=15$ for the women). All five identifiable cases for the males were coded as having 'instrumental/acquisitive' purposes $(100.0 \%)$. Although still limited, the reports referring to female perpetrated misconduct tended to be somewhat more informative. In contrast to the men, only one case $(6.7 \%)$ was identified as being instrumentally driven, while three cases $(20.0 \%)$ were as a result of a relational dispute. Just over $26 \%(n=4 / 15)$ engaged in misconduct as a form of retaliation or in response to being provoked. Finally, nearly half of the reports $(46.67 \% ; n=7 / 15)$ were coded as having 'other' motivations behind the inmates' actions, the most common being issues regarding living space and having to share space with other women.

An example of instrumental motivation.

M-MED41: During lunch break a PPA ${ }^{28}$ call came from the servery. Staff responded to the servery. Upon entering, staff noticed $\mathrm{I} / \mathrm{M} \mathbf{A}$ and $\mathrm{V} / \mathrm{M} \mathrm{B}$ fighting

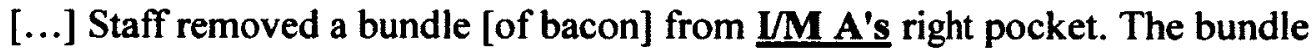
was wrapped in plastic and was 20cm's long and 6-8 cm's in diameter [...] Staff interviewed $\mathbf{L} \mathbf{M}$ A who said the fight was over smuggling meat out of the kitchen [...] Staff asked if $\mathrm{I} / \mathrm{M} \mathrm{A}$ is in debt and if taking the bacon was to pay his debt off. [M A] wants to speak to inmate committee regarding his debt.

\footnotetext{
${ }^{27}$ Given that the original report was in French, an English summary was provided rather than using a direct quote.

${ }^{28}$ PPA = Personal Portable Alarm System.
} 


\section{An example of relational motivation.}

F-MED21: I/M A and I/M B were observed to be in an altercation, a staff member observed inmate I/MA strike I/M B several times in the face/chest area and kicked her in the back area. Both inmates separated without further incident, subsequent interviews indicated that the contributing factor was a relationship that had ended.

\section{An example of motivation related to problems with living space.}

F-MED54:Officers witnessed I/M A shove someone on the North side living unit of the $\operatorname{SLE}^{29}[\ldots]$ When asked what was going on $\mathbf{Y M A}$ explained that there were various unit issues but the main issue was that food was going missing and many of her items had been stolen.

Misconduct severity. The final qualitative coding pertained to the overall severity rating of the misconduct. This consisted of a general assessment of the incident, as opposed to the severity of physical harm previously discussed. A combination of factors had to be considered in order to provide a rating: the misconduct type, the degree of harm inflicted, the degree of staff response and the overall safety of the institution. The rating ranged from 1 (not severe) to 5 (extremely severe). For further details regarding the severity ratings, please refer to Appendix $B$. The mean rating for the male perpetrated misconduct was $2.92(S D=0.81)^{30}$ while the mean rating for the female perpetrated misconduct was slightly lower $(M=2.77, S D=0.71)^{31}$.

\footnotetext{
${ }^{29}$ SLE = Structure Living Environment: this is a separate unit for high need women requiring specific mental health interventions and who cannot be managed within the general population (Sly \& Taylor, 2005).

${ }^{30}$ This is based on 25 known ratings. The remaining 3 cases did not provide sufficient information to select a rating.

${ }^{31}$ This is based on 27 known ratings. The remaining 1 case did not provide sufficient information to select a rating.
} 
An example of a Level 2 severity rating.

F-MED36: On this date staff walking in the compound heard shouting coming from living unit 4. As they approached the Unit they heard a female voice yelling "I'm going to take a rock and smash you in the head you [expletives]!" As staff entered the Unit they found $\underline{\mathbf{L}} \mathbf{M A}$ in her room. They asked if she had been the one yelling and she admitted she was but would not divulge the name of the person to whom she was yelling the threat. When reminded of the seriousness of uttering threats, IM A shrugged her shoulders and stated "Yeah, I said it". I/M A was removed from the Unit and placed in Segregation.

\section{An example of a Level 3 severity rating.}

M-MED14: I/M A was in the cultural center talking to other inmates about his inciting he was doing in a unit the night before. As this inmate left the cultural center to help the $\mathrm{ALO}^{32}$ take dishes back to the kitchen from a cultural feast, he observed another inmate being escorted down the breezeway towards SIS $^{33}$ on his release go-round. IMA grabbed at the inmate that was being escorted and tried to pull him away from the escorting officer. I/M A then sucker punched the inmate in the left cheek, as the officer separated them, two other officers arrived there and escorted I/M A to the Correctional Managers office. I/M B was escorted to Health care to be assessed where the nurse noted redness to the left cheek with no swelling or other injuries to report. B was escorted back to his cell. $\underline{\text { I/M A was }}$ placed in segregation for his actions and institutionally charged.

\section{An example of a Level 4 severity rating.}

F-MAX40: I/M A was observed leaning over and punching $\mathrm{I} / \mathrm{M} \mathrm{B}$, who was sitting at the pod table on East Pod, with both fists [...] Upon reaching the pod door, officers immediately directed I/M A to stop, however I/M A continued to assault I/M B. An officer immediately approached $\mathbf{I} / \mathbf{M}$ A and attempted to grab both of her arms from behind and take her to the floor. I/M A began to struggle with the officer and was able to get away once being pulled to the floor. $\mathbf{M} \mathbf{M A}$ then slid along the floor to position her back against the wall in a sitting position. She then proceeded to kick the officer twice in the abdomen area as well as the hands/arms as the officer attempted to defend herself. The officer tried to stop IMA from kicking and attempted to grab her arm. I/M A then used her other

\footnotetext{
${ }^{32}$ ALO = Aboriginal Liaison Officer.

${ }^{33}$ SIS = Supervisor of Institutional Services.
} 
arm and punched the officer in the jaw area of the left side of her face. At this time, another officer was able to gain control of $\mathbf{Y} / \mathbf{M ~ A}$ 's free arm and placed it in a straight arm bar with a wristlock. Control of IM A's arms was maintained and she was pulled to the floor and placed in a prone control position where handcuffs and leg irons were applied. During this time, LMA began yelling obscenities and uttering threats to staff. Officers maintained a low profile rear wristlock with a cclamp on her elbow while escorting $\mathbf{I} / \mathbf{M} \mathbf{A}$ to segregation[...] Healthcare attended the pod and assessed I/M B. Abrasions were present to her face (left side of forehead and just under left eye) as well as a cut under her left eye. She also had some dried blood present on her upper ear and an abrasion was also present to her left knuckle (middle and index fingers). The officer who was assaulted by $\underline{\mathbf{I}} \mathbf{M} \mathbf{A}$ was seen by healthcare. Officer reported pain to her left temporomandibular ${ }^{34}$ joint at the time of assessment. Pain was markedly worse on palpation of the area.

Overall, the qualitative results provided preliminary information that, as will be addressed in the discussion, may provide further insight into gender differences in institutional misconduct.

\section{Discussion}

The current study was conducted to extend the gender debate into the institutional setting, while addressing several gaps in the misconduct literature. Previous research examining institutional misconduct has predominantly focused solely on male offenders and has been based within the United States. Although literature regarding female offenders has begun to accumulate, it is still rare for studies to incorporate a male comparison group, thus the notion of gender differences in misconduct has still only been preliminarily assessed. Accordingly the purpose of the present study was to examine gender differences in institutional misconduct within security levels in a Canadian federal correctional context using a male comparison group and a mixed-methods design. The

\footnotetext{
${ }^{34}$ Temporomandibular is referring to the jaw joint.
} 
results will be reviewed and discussed in relation to the research questions and hypotheses.

Research Question 1: Are there gender differences in the prevalence and incidence rates of misconduct among federally incarcerated offenders by security level?

For the first research question, it was hypothesized that the frequency and prevalence rates of misconduct would be higher within the male offender sample. It was expected that this would hold true, even when comparing by gender within each of the three security levels. In order to test this, prevalence rates were first calculated using chisquare analysis, while grouping the sample by length of incarceration to take into account time at risk. Based on the results found, it was concluded that this hypothesis was not supported. Aside from one finding within the minimum security group incarcerated for 24 months, there were no significant differences in prevalence rates between men and women within minimum and maximum security levels. The majority of significant results were for offenders in medium security, with more women engaging in misconduct in comparison to men.

Notwithstanding these findings, it is important to note that the majority of the corresponding effect sizes were relatively small, ranging from .18 to .22 . The only moderate effect was observed in group three $\left(\Phi_{c}=.31\right)$, perhaps suggesting that greater differences in adjustment patterns emerge over a longer periods of incarceration.

In addition to calculating prevalence rates for the first research question, incidence rates were examined to assess the number of misconducts relative to the number of offenders at risk and the amount of time each offender was incarcerated (i.e., person-time). The purpose was to provide additional descriptive information while 
identifying potential differences by using rate ratios. Surprisingly, almost all rate ratios suggested that women demonstrated more events over person-time, which again did not support the hypothesis. Consistent with other results, findings from the maximum security group were either minimal or entirely non-significant. Again, results pertaining to the medium security group demonstrated the most notable differences, especially when considering minor misconduct.

It is important to note at this point, that although the use of this analytic technique is an emerging practice in forensic psychology that provides important descriptive information, the most ideal method of calculation is often debated. The use of different methods can result in varied findings and there has yet to be an overall consensus regarding the way in which incidence rates should be calculated and reported (Gallagher \& Dobrin, 2007). In this situation, using person-time as the denominator was the most ideal technique in order to take into account time-at-risk within the institution. That being said, rate ratios have been identified as being potentially sensitive to recurring events and results should therefore be interpreted with caution.

The final analysis for the first research question consisted of an ANOVA to assess whether the mean number of misconducts varied as a function of gender and security level. Using a $2 \times 3$ design, ANOVAs were conducted for each time period and each misconduct type. For the most part, there was a significant main effect of security level. Although maximum and medium security offenders did not significantly differ, both groups consistently differed from the minimum security offenders. These findings are in line with previous research and are not surprising given that security level is typically 
indicative of an offender's level of risk and expected misconduct behaviour (Blanchette et al., 2002).

What was unexpected was the relatively limited finding regarding gender differences which were restricted to group 1 . The only significant interaction was found with minor misconduct. Based on simple effects analysis, the interaction was due to a significant effect of gender at medium security with the mean number of misconducts for women being higher than the mean number of misconducts for men. Individually, gender and security demonstrated significant main effects as well. It is important to note again that although differences were found, the effect sizes were still relatively small for the interaction and gender effects, $\left(\eta^{2}=.01\right)$, suggesting only a minor difference between the groups.

Overall, the findings from the first research question do not support the hypothesis that men engage in more misconduct and more serious misconduct than women. It is evident that the most notable findings were consistently related to minor misconduct within medium security. It is important to understand these findings and address potential explanations prior to discussing further results.

Although the results regarding minor misconduct were not originally hypothesized, they are not completely unexpected and may simply highlight the presence of more problematic behaviours among women. Findings in current literature have been inconsistent and conflicting and clear gender distinctions have not yet been established. Despite research suggesting that women overall commit less misconducts, some contrasting studies have also demonstrated that if female offenders do in fact act out more than males, their behaviour tends to be of a less serious nature (e.g., Bosworth, 2007; 
Lindquist, 2008). Craddock (1996) for example found that female offenders tend to commit more disciplinary infractions for minor incidents in comparison to men. Even when looking at only women, Casey Acevedo \& Bakken (2004) found that only a small portion of women engage in serious behaviours, while the majority engage in far more frequent and minor misconducts. Perhaps the findings of the current study simply indicate that women, specifically those designated as medium security, engage in more minor misconduct behaviours in comparison to men.

In addition to the explanation that women simply engage in more misconduct, other explanations for misconduct differences have been offered in the literature as well. Firstly, one of the biggest arguments is related to the fact that disciplinary practices are, to a certain extent, subjective and this may lead to disparity in the sanctions used with male and female offenders. Four main reasons for discrepancies have been proposed: (1) staff biases; (2) differential staff training; (3) differences in the formal charge process; and (4) differences in institutional environments.

Research by McClellan (1994) found differences in disciplinary practices as a function of gender, with women being cited for a greater number of minor rule violations. In contrast, comparable behaviours found in men were often overlooked. In this specific study, a unique 'reprimand' category was even developed as part of correctional policy, specifically for women's disruptive or non-conforming behaviour. This category drastically increased the female rate $(3,698$ citations for 245 female inmates) in comparison to the male rate (786 citations for 271 males). Craddock (1996) also supports these findings, suggesting that significant differences in minor misconduct may be in part due to sanctioning practices rather than behavioural patterns. It is argued that staff tend 
to view women's confrontational and assaultive behaviour (e.g., swearing, fighting) as being more deviant (i.e., not conforming to a 'stereotypical' gender role) and thus, requiring formal sanctions. In contrast, staff may view comparable behaviour in men as being expected within the male gender role, and therefore do not discipline as frequently.

The dynamic in women's institutions may also lead to staff being more aware of women's actions and misconduct. CSC women-centered training emphasizes the importance of increased staff involvement and contact with female offenders in order to facilitate a positive community environment (CSC, 2006). Recent research looking at women offenders' perspectives of dynamic security and working alliances with staff showed that correctional officers are cited as being the most involved and interactive with the women - having to maintain regular contact and visibility at all times (Harris, Taylor, Brown, \& Booth, in press). Although this is a very positive finding that may facilitate a more cohesive/rehabilitative environment, it may also increase the likelihood of misconduct being detected, and thus create an appearance of a higher number of misconducts among women.

Finally, a more operational/organizational explanation may also be applicable. The current study only included analysis of charges which are misconduct events that go through a formal charge process that requires disciplinary hearings and a finding of guilt. This is in contrast to an incident, which is merely recorded on file but does not undergo a formal procedure. The charge process requires more paperwork, increased resources and increased staff involvement. There is the potential that, given the smaller population of female offenders and the more 'hands on' approach staff initiate in women's institutions, the formal charge process may be accessed and utilized more frequently within the 
women's system. Findings from the McClellan (1994) study showed that three fourths of female infractions were processed formally, while less than half of the male infractions went through the same process. Female offenders were subject to more vigilant attention, with a larger portion of female perpetrated misconducts being processed and charged. In contrast, behaviours in the men's institution were more likely to be overlooked or dealt with informally. Future research should look at practices of formal versus informal processing in Canadian corrections while taking into account the staff-offender ratio and the availability of resources.

As for the evident difference within medium security, in comparison to minimum and maximum security findings, an explanation of environmental differences may offer some insight. The correctional structure and environment is comparable between men and women at minimum security (typically based on a residential-style infrastructure), and men and women at maximum security (structured, high static security environment). In contrast, women in medium security reside in residential-style housing while men in medium security reside in a more traditional prison setting with separated cells (Blanchette, 2000; CSC, 2010). The situation for women requires living with other offenders in a housing unit in an environment that is perhaps less structured in comparison to men's. The medium security environment may therefore provide more opportunities for women to engage in minor misconduct in comparison to men. 
Research Question 2: Are there gender differences in the patterns and predictors of survival time to first misconduct among federally incarcerated offenders by security level?

To examine the first part of the research question, survival analysis was used; assessing gender differences in time from admission to first failure (i.e., an event of misconduct). Analysis of major misconduct demonstrated that although the majority of offenders did not fail, (66.67\% of females and $71.75 \%$ of males), women still demonstrated a significantly shorter survival time compared to their male counterparts. The largest noted difference in survival time was evident when assessing minor misconduct in medium security, with women again acting out earlier in their incarceration in comparison to men.

Given that this analysis was exploratory in nature, an outcome was not hypothesized. That being said, results suggest that evidence of maladjustment seems to manifest itself sooner among medium security women. Several potential explanations are offered to better understand this survival pattern.

Some research argues that women's adjustment to prison and the institutional environment is different than men's and may therefore lead to different behavioural patterns and difficulty in adjusting (e.g., Van Tongern \& Klebe, 2010; Warren et al., 2004). Wright et al., (2007) explain that women's needs (e.g., backgrounds of victimization, mental health issues, substance abuse, parenting and relationships) are qualitatively different from men's needs and lead to increased risk of maladjustment upon admission into custody. Thompson \& Loper (2005) for example, argue that poor adjustment to the prison environment is likely exacerbated by distance from and limited 
contact with family members and children. Women's needs regarding mental health may be especially relevant as well, given that related issues have been linked to poor adjustment problems and misconduct among women (Drury \& Delisi, 2010), and female offenders are far more likely than male offenders to be diagnosed with mental health problems upon admission (Public Safety Canada, 2009).

Unfortunately, as noted in the data screening process, the current study was not able to obtain information regarding previous incarcerations. This may have been pertinent to explaining women's adjustment patterns as well. Gover et al., (2008) found that, unlike male offenders, experience with previous incarceration actually decreased women's likelihood of institutional misconduct; perhaps suggesting that being familiar with the environment facilitates an easier transition for women, while being unfamiliar leads to increased stress, anxiety and maladjustment. Given that women are rarely repeat offenders in comparison to men, especially within the federal system (Bonta, Rugge, \& Dauvergne, 2003), this could have been potentially crucial information in understanding women's behaviour over time. Future research should investigate this further.

For the second part of this research question, Cox regression survival analysis was used to identify potential predictors of misconduct for men and women separately. It was hypothesized that all the predictors would play a role in misconduct, with certain ones emerging as stronger predictors for women in comparison to men. Findings demonstrated that, aside from predictors of major misconduct with minimum security women, all the models showed overall significance in relation to the hazard of misconduct, suggesting that the combination of variables provided the most accurate results. That being said, there were only three variables that demonstrated significance 
individually. For both genders and both types of misconduct, age was consistently a strong predictor, with older offenders showing a reduced hazard of misconduct. This finding was not surprising given that age has been identified as one of the strongest predictors of inmate behaviour (e.g., Blackburn \& Trulson, 2010; Craddock, 1996; Steiner \& Wooldredge, 2009). The only other significant findings were related to dynamic risk and reintegration potential. Dynamic risk was significant among minimum security women for minor misconduct; the only variable unique to women. Although the other factors that are assessed during the OIA process did not prove to be significant (e.g., static risk), the findings regarding dynamic risk support part of the hypothesis and are consistent with previous research that links criminogenic need to offending behaviour (e.g., Andrews \& Bonta, 2010). Reintegration level was the only variable unique to men in regards to major misconduct, with men designated as low reintegration potential having a significantly higher hazard rate in comparison to those with a high potential. Given that this item assesses the risk an offender poses to the community and the probability of an offender's successful reintegration into society, it is not surprising that low reintegration potential among male offenders is indicative of poor institutional behaviour. That being said, interpreting this finding as an indication that reintegration plays a role with men and not for women is cautioned. The overall potential is calculated differently between men and women as certain measures used to designate reintegration level (i.e., the Statistical Information on Recidivism-Revised Scale) are not used on the female population (CSC, 2012b). Although this finding may warrant further investigation, firm conclusions cannot be drawn. 
Research Question 3: Do major incidents of misconduct differ qualitatively based on perpetrator gender?

For the final research question, misconduct reports were coded to assess whether the nature of misconduct varies qualitatively based on the gender of the perpetrator. $\mathrm{A}$ subsample of 56 offenders ( $n=28$ males, $n=28$ females) with major assaultive charges were randomly selected for this analysis. Although this portion was predominantly exploratory and descriptive in nature, based on typical female offending behaviours it was originally hypothesized that differences would emerge in regards to victim selection, weapon use and degree of harm inflicted. In this case, the hypothesis was partially supported. Although small in scope, certain patterns emerged that may highlight areas that warrant further investigation. Not surprisingly, given the sample selection, both males and females predominantly engaged in physical altercations and assault. Interestingly, differences emerged when assessing the method and weapon selection. Although the majority of both genders used physical force in their misconduct, it was evident that women predominantly relied on purely physical methods, while men tended to be more varied in their approach. Men were the only ones who used or threatened to use bodily fluids in their assault - an action which carries some potentially serious health consequences for the victim. Men were also more likely to use available or homemade objects as weapons for harming and/or threatening their victims. Overall, there were only three cases $(10.71 \%)$ where women used or threatened to use some form of weapon or object in the course of their misconduct. In contrast, there were 11 cases $(39.30 \%)$ where men relied on methods other than physical force in the course of misconduct. This is a finding that has been supported in previous literature (e.g., Harer \& Langan, 2001). 
In reviewing the degree of force required to cease the misconduct, it was also evident that the majority of women's cases required what would be considered less serious methods (i.e., no force, verbal warning, or minor physical handling). The methods used with men tended to vary to a greater degree, with the most common method being sprays/chemical agents. ${ }^{35}$ Other frequent methods included no force, negotiation, minor physical handling and restraint equipment. Although only consisting of individual incidents, males were also the only cases where the Emergency Response Team was used. Firearms were also presented with males, but given operational differences and the prohibited use of firearms in women's facilities, comparisons cannot be made. Use of force does follow detailed guidelines and training regarding the level of intervention required that is relative to the seriousness of the incident and the offender involved. That being said, it should be acknowledged that given the nature of most incidents, use of force is likely and understandably, reactive and in the moment. Notwithstanding this issue, it does appear that women require a lesser degree of staff intervention in comparison to men.

Interestingly, the most notable difference found from the coding was in regards to victim selection. Although inmates were overall the most common victim, women were much less likely to select staff $(14.3 \%)$ in comparison to men $(42.9 \%)$. From the information that was available, women's victims were often a housemate, friend, or partner. In addition to this, women's motivations revolved around retaliation, relational issues, and conflicts arising from sharing space with other women. Unfortunately, these

\footnotetext{
${ }^{35}$ It is important to note that, as previously stated, differences in regulations regarding the use of chemical agents in men and women's institutions need to be considered when interpreting these findings.
} 
details were rarely provided in the men's reports, the only notable finding was that where motivation was identified, it was consistently coded as being instrumental (e.g., paying debts, gaining privileges). As outlined in the literature review, this is fairly consistent with literature regarding gender differences in offence gestalts. Women typically know their victims well (e.g., other inmates, housemates), and are motivated by interpersonal issues (e.g., retaliation, relational disputes). Males on the other hand follow a more predatory pattern involving victims they are not close to (e.g., correctional officers) and are often instrumentally motivated (Greenfeld \& Snell, 1999).

The final two themes that were coded for involved degree of harm inflicted on the victim, and the overall severity of misconduct. These factors involved continuous rating scales and provided an overall mean for both genders. Although males had higher scores for both the level of harm inflicted and the severity, they were only marginally higher in comparison to the women's scores. For both genders, the severity of incident and the degree of harm tended to be within the low to moderate range.

Although it may seem that certain ratings were similar for both groups, there were also patterns that highlighted evident differences, suggesting that the nature of misconduct may still vary based on gender and could potentially require different methods of intervention. Overall, the qualitative results offered preliminary insight into potential gender differences that warrant further investigation.

\section{Limitations and Future Research}

There are certain limitations in the current study that are important to acknowledge. Although archival data is beneficial in that it allows access to extensive information and large sample sizes, which are not easily accessible (especially in regards 
to female offenders), there are some drawbacks. First, the use of archival data in the current study did not allow for the primary researcher to access information that may have been pertinent to this study. Instead, analysis was based on the information that was available. For example, the misconduct reports varied extensively in the amount of detail made available to the coder, which resulted in some incomplete results for the qualitative section. Second, the researcher had no control over what was reported and what was not. Despite policies and guidelines, the practice of recording events of misconduct can still vary based on the regions, the institutions, and the staff involved. Aside from inconsistent details, there is also the chance that many incidents are going unreported, as is often the case with official offence records (e.g., Perreault \& Brennan, 2009).

To obtain more detailed information regarding misconduct, future research should include the collection of qualitative data; interviewing both offenders and staff to better understand factors surrounding misconduct that may not be available via archival records. Interviewing offenders (both perpetrators and victims of misconduct) would also potentially identify cases that go unreported in the system.

As pointed out in the discussion, reasons for staff over-reporting or underreporting misconduct may also vary based on staff biases and perspectives. It would be interesting to investigate what a typical correctional staff response would be to a given misconduct situation and whether or not the response/disciplinary reaction differs by gender of the perpetrator. Future research should therefore identify if there are staff biases and attempt to control for them.

Another potential limitation of the study may be related to sampling and matching methods. Although the purpose of the current study was to specifically match offenders 
solely on security level so as not to dilute any findings, perhaps other factors could also be taken into consideration. For example, the female sample did have a significantly larger proportion of Aboriginal offenders, a variable that could potentially have an impact, given that Aboriginal offenders are overrepresented in the system, may receive differential processing, and tend to display higher risk of offending (Public Safety Canada, 2011; Sioui \& Thibault, 2001; Trevethan, Moore, \& Raston, 2002). Although it has been documented (e.g., Public Safety Canada, 2011) that Aboriginal women are in fact overrepresented more so among female offenders ( $31.9 \%$ of incarcerated women) than male offenders $(21.1 \%$ of incarcerated men), perhaps future research could control for this by conducting analyses separately.

In addition to differences in demographic and incarceration characteristics, a significant factor that should be taken into consideration would be mental health. Mental health has been repeatedly linked to poor adjustment problems and institutional misconduct among female youth and adult offenders (Blackburn \& Trulson, 2010; Drury \& Delisi, 2010; Steiner \& Wooldredge, 2009). Although obtaining and assessing this information was beyond the scope of the current study, it would be beneficial to investigate mental health issues and the role mental health plays in men and women's adjustment in prison. This is especially relevant given that the number of federal female offenders identified at admission with mental health problems has significantly increased over the past decade (CSC, 2009b) and female offenders are twice as likely as males to have a mental health diagnosis upon admission into custody (Public Safety Canada, 2009). 
Also, given the nature of the data, the current study relied on behavioural misconduct records as an indicator of offender adjustment. As previously discussed, depending on how adjustment is defined, there are often other aspects that can be considered. Future research could also incorporate such factors as overall inmate wellbeing (via adjustment measures, mental health measures), prison infrastructure (especially in regards to the multilevel nature of women's institutions), available prison resources (e.g., staff to inmate ratio), and overcrowding/double bunking. To incorporate gender-specific variables, future analysis could also include such factors as victimization, mental health, and parenting, similar to previous research (e.g., Wright et al., 2007).

Collectively, results of the current study contribute to the gender debate and suggest that there are in fact gender differences in institutional misconduct. Findings demonstrated that the most distinct difference was for minor misconduct among medium security offenders, with women receiving more charges than men and engaging in misconduct earlier than men. These results may suggest that maladjustment manifests itself differently and earlier among this group of incarcerated women. That being said, knowledge in this area is still in its infancy. As demonstrated with the potential future directions, there are still many other aspects to consider. The present study therefore provides a platform for further investigation of misconduct in order to fully understand gender differences in institutional adjustment and identify the appropriate operational responses. 


\section{References}

Allison, P. (1995) Survival analysis using SAS: A practical guide. Cary, NC: SAS Publishing.

Andrews, D. A., \& Bonta, J. (2010). The psychology of criminal conduct (5 $5^{\text {th }}$ ed.). Cincinnati, $\mathrm{OH}$ : Anderson.

Andrews, D. A., Bonta, J., \& Wormith, J. S. (2004). Level of Service/Case Management Inventory: LS/CMI manual. Toronto, ON: Multi-Health Systems.

Andrews, D. A. \& Dowden, C. (2006). Risk principle of case classification in correctional treatment. International Journal of Offender Therapy and Comparative Criminology, 50, 88-100.

Andrews, D. A., Zinger, I., Hoge, R. D., Bonta, J., Gendreau, P., \& Cullen, F. T. (1990). Does correctional treatment work? A psychologically informed meta-analysis. Criminology, 28, 369-404.

Belknap, J. (2007). The invisible woman: Gender, crime and justice ( $3^{\text {rd }}$ ed.). Belmont, CA: Thomson Wadsworth.

Benda, B. B. (2005). Gender differences in life course theory of recidivism: A survival analysis. International Journal of Offender Therapy and Comparative Criminology. 49, 325-342.

Benda, B. B., \& Toombs, N. J. (2002). Two preeminent theoretical models: A proportional hazard rate analysis of recidivism. Journal of Criminal Justice, 30 , 217-228.

Berg, M. T., \& DeLisi, M. (2006). The correctional melting pot: Race, ethnicity, citizenship, and prison violence. Journal of Criminal Justice, 34, 631-642. 
Blackburn, A. G., \& Trulson, C. R. (2010). Sugar and spice and everything nice? Exploring institutional misconduct among serious and violent female delinquents. Journal of Criminal Justice, 38, 1132-1140.

Blanchette, K. (2000). Effective correctional practice with women offenders. In L. Motiuk \& R.C. Serin (Eds) Compendium 2000 on effective correctional programming. (pp. 160-173). Ottawa, ON: Correctional Service of Canada.

Blanchette, K. (2005). Field test of a gender-informed security-reclassification scale for female offenders (Doctoral dissertation). Available from ProQuest Dissertations and Theses@ Carleton University. (No. NR00795).

Blanchette, K., \& Brown, S. L. (2006). The assessment and treatment of women offenders: An integrative perspective. Chichester, UK: John Wiley.

Blanchette, K. \& Taylor, K. (2005). Development and field test of a gender-informed security reclassification scale for women offenders. Report R-127. Ottawa, ON: Correctional Service of Canada.

Blanchette, K., Verbrugge, P., \& Wichmann, C.G. (2002). The Custody Rating Scale, initial security level placement and women offenders. R-127. Ottawa, ON: Correctional Service of Canada.

Bloom, B., Owen, B., \& Covington, S. (2003). Gender-responsive strategies: Research, practice and guiding principles for women offenders (NIC Accession No.018017) Washington, DC: National Institute of Corrections.

Bonta, J., Rugge, T., \& Dauvergne, M. (2003). The reconviction rate of federal offenders. Ottawa, ON: Solicitor General Canada. 
Bosworth, M. (2007). Creating the responsible prisoner: Federal admission and orientation packs. Punishment and Society, 9, 277-294.

Bourgon, G., \& Armstrong, B. (2005). Transferring the principles of effective treatment into a "real world" prison setting. Criminal Justice and Behavior, 32, 3-25.

Brown, S.L. \& Motiuk, L.L. (2005).The Dynamic Factor Identification Analysis (DFLA) component of the Offender Intake Assessment (OIA) process: A meta-analytic, psychometric and consultative review. Research Report R-164. Ottawa, Ontario: Correctional Service of Canada.

Camp, S. D., Gaes, G. G., Langan, N. P., \& Saylor, W. G. (2003). The influence of prisons on inmate misconduct: A multilevel investigation. Justice Quarterly, 20, $501-533$.

Canadian Centre for Justice Statistics (2004). Canadian crime statistics (Catalogue No. 85-205-XIE). Ottawa, ON: Statistics Canada.

Canadian Centre for Justice Statistics (2011). Women in Canada: A gender-based statistical report (Catalogue No. 89-503-XWE). Ottawa, ON: Statistics Canada.

Casey-Acevedo, K., \& Bakken, T. (2004). Women adjusting to prison. Journal of Health and Social Policy, 17, 37-60.

Chesney-Lind, M. (1989). Girls' crime and woman's place: Toward a feminist model of female delinquency. Crime and Delinquency, 35, 5-29.

Chesney-Lind, M. (2006). Patriarchy, crime, and justice: Feminist criminology in an era of backlash. Feminist Criminology, 1, 6-26. 
Chesney-Lind, M., \& Shelden, R. G. (2003). Girls, delinquency, and juvenile justice ( $3^{\text {rd }}$ ed.) Belmont, CA: Wadsworth Publishing Company.

Comstock, D. L., Hammer, T. R., Strentzsch, J., Cannon, K., Parsons, J. \& Salazar, G. (2008). Relational-cultural theory: A frame-work for bridging relational, multicultural, and social justice competencies. Journal of Counseling and Development, 86, 279-287.

Correctional Service Canada (2002). Regional women's facilities: Operational Plan. Ottawa, ON: Office of the Deputy Commissioner for Women.

Correctional Service of Canada (2006). Commissioner's Directive 560: Dynamic security. Ottawa, ON: Author.

Correctional Service of Canada (2009a). Commissioner's Directive 567-1: Use of Force. Ottawa, ON: Commissioner of the Correctional Service of Canada.

Correctional Service of Canada (2009b). The Changing Offender Population. Highlights, 2009. Ottawa, ON, Canada: Author.

Correctional Service of Canada (2009c). The wearing of stab-resistant vests in women offender institutions (Security Bulletin No. 2009-1). Ottawa, ON: Author. Correctional Service of Canada (2010). Institutional Profiles. Retrieved from http://www.csc-scc.gc.ca/text/region/inst-profil-eng.shtml

Correctional Service of Canada (2012a). Commissioner's Directive 567-4: Use of chemical and inflammatory agents. Ottawa, ON: Author.

Correctional Service of Canada (2012b). Commissioner's Directive 705-6: Correctional planning and criminal profile. Ottawa, ON: Author. 
Correctional Service of Canada (2012c). Corporate reporting system results, Performance Measurement Branch. Ottawa, ON: Author.

Corrections and Conditional Release Act, S. 20 (1992).

Craddock, A. (1996). A comparative study of male and female prison misconduct careers. The Prison Journal, 76, 60-80.

Daly, K. (1992). Women's pathways to felony court: Feminist theories of lawbreaking and problems of representation. Review of Law and Women's Studies, 2, 11-52.

Drury, A. J., \& Delisi, M. (2010). Past is the prologue: Prior adjustment to prison and institutional misconduct. The Prison Journal, 90, 331-352.

Erikson, E.H. (1968). Identity: Youth and Crisis. New York: Norton.

Folsom, J., \& Atkinson, J. L. (2007). The generalizability of the LSI-R and the CAT to the prediction of recidivism in female offenders. Criminal Justice and Behaviour, $34,1044-1056$.

Fortin, D. (2004). Program strategy for women offenders. Ottawa, ON: Correctional Service of Canada.

Franklin, T.W., Franklin, C.A., \& Pratt, T.C. (2006). Examining the empirical relationship between prison crowding and inmate misconduct: A meta-analysis of conflicting research results. Journal of Criminal Justice, 34, 401-412.

Frey, L. L., Beesley, D. \& Miller, M. R. (2006). Relational health, attachment, and psychological distress in college women. Psychology of Women Quarterly, 30, $303-311$. 
Frey, L. L., Tobin, J. \& Beesley, D. (2004). Relational predictors of psychological distress in women and men presenting for university counseling center services. Journal of College Counseling, 7, 129-139.

Gallagher, C. A., \& Dobrin, A. (2007). Risk of suicide in juvenile justice facilities: The problem of rate calculations in high-turnover populations. Criminal Justice and Behaviour, 34, 1362-1376.

Gendreau, P. C., \& Andrews, D. A. (1990). Tertiary prevention : What a meta-analysis of the offender treatment literature tells us about 'what works'. Canadian Journal of Criminology, 32, 173-184.

Gendreau, P., Goggin, C. E., \& Law, M. A. (1997). Predicting prison misconducts. Criminal Justice and Behavior, 24, 414-431.

Gobeil, R. (2008). Staying out: Women's perceptions of challenges and protective factors in community reintegration. Research Report R-201. Ottawa, ON: Correctional Service of Canada.

Goodstein, L., \& Wright, K. (1991). Inmate adjustment to prison. In L. Goodstein, \& D. L. Mackenzie, The American prison (pp. 229-251). New York: Plenum.

Gover, A. R., Mackenzie, D.L., \& Armstrong, G.S. (2000). Importation and Deprivation explanations of juveniles' adjustment to correctional facilities. International Journal of Offender Therapy and Comparative Criminology,44, 450-467.

Gover, A. R., Perez, D. M., \& Jennings, W. G. (2008). Gender differences in factors contributing to institutional misconduct. The Prison Journal, 88, 378-403.

Green, S. B., \& Salkind, N.J. (2008). Using SPSS for Windows and Macintosh; Analyzing and understanding data $\left(5^{\text {th }}\right.$ ed.). Upper Saddle River, NJ: Pearson. 
Greenfeld, L. A., \& Snell, T. L. (1999). Women offenders. Washington, DC: Bureau of Justice Statistics, US Department of Justice. (Special Report NCJ 175688).

Greer, K. R. (2000). The changing nature of interpersonal relationships in a women's prison. The Prison Journal, 80, 442-468.

Hannah-Moffat, K. (1999). Moral agent or actuarial subject: Risk and Canadian women's imprisonment. Theoretical Criminology, 3, 71-94.

Hannah-Moffat, K. (2000). Re-forming the prison: Rethinking our ideals. In: K. HannahMoffat \& M. Shaw (eds), An Ideal Prison? Critical Essays on Women's Imprisonment in Canada (pp.30-40). Halifax, NS: Fernwood Publishing.

Hannah-Moffat, K. (2009). Gridlock or mutability: Reconsidering “gender" and risk assessment. Criminology \& Public Policy, 8, 209-219.

Hanson, R. K., \& Thorton, D. (2000). Improving risk assessments for sex offenders: A comparison of three actuarial scales. Law and Human Behovior, 24, 119-136.

Hardyman, P. L., \& Van Voorhis, P. V. (2004). Developing gender-specific classification systems for women offenders. Washington, DC: National Institute of Corrections.

Harer, M. D., \& Langan, N. P. (2001). Gender differences in predictors of prison violence: Assessing the predictive validity of a risk classification system. Crime \& Delinquency, 47, 513-536.

Harris, G. T., Rice, M. E., \& Quinsey, V. L. (1993). Violent recidivism of mentally disordered offenders: The development of a statistical prediction instrument. Criminal Justice and Behavior, 20, 315-335.

Harris, A., Taylor, K., Brown, S.L., \& Booth, L. (in press). Therapeutic alliance and offender-staff relations. Ottawa, ON: Correctional Service of Canada. 
Howell, D.C. (2007). Statistical methods for Psychology, $\left(6^{\text {th }}\right.$ ed). Belmont, CA: Thomson Wadsworth.

Irwin, C., \& Cressey, D. (1962). Thieves, convicts, and the inmate culture. Social Problems, 10, 142-155.

Islam-Zwart, K. A., \& Vik, P. W. (2004). Female adjustment to incarceration as influenced by sexual assault history. Criminal Justice and Behavior, 31, 521-541.

Jackson, M. \& Stewart, G. (2009). A flawed compass: A human rights analysis of the roadmap to strengthening public safety. Retrieved from http://www.justicebehindthewalls.net/resources/news/flawed_Compass.pdf.

Jiang, S. (2005). Impact of substance use on inmate misconduct: A multilevel analysis. Journal of Criminal Justice, 33, 153-163.

Jiang, S., \& Fisher-Giorlando, M. (2002). Inmate misconduct: A test of the deprivation, importation and situational models. The Prison Journal, 82, 335-358.

Jiang, S., \& Winfree, L. T. (2006). Social support, gender, and inmate adjustment to prison life. The Prison Journal, 86, 32-55.

Jones, N.J. (2011). Merging theoretical frameworks to inform risk assessment for the young female offender (Doctoral dissertation). Available from ProQuest Dissertations and Theses@ Carleton University. (No. NR81577).

Kong, R., \& AuCoin, K. (2008). Female Offenders in Canada. Statistics Canada (No. 85002-X).

Koons-Witt, B. A., \& Schram, P. J. (2003). The prevalence and nature of violent offending by females. Journal of Criminal Justice, 31, 361-371. 
Kropp, P. R., \& Hart, S. D. (2000). The Spousal Assault Risk Assessment (SARA) guide: Reliability and validity in adult male offenders. Law and Human Behavior, 24, 101-118.

Leschied, A. W. (2011). The treatment of incarcerated mentally disordered women offenders: A synthesis of current research (ISBN No. 978-1-100-19161-4). Ottawa, ON: Public Safety Canada.

Lombard, M., Snyder-Duch, J., \& Braken, C.C. (2002). Content analysis in mass communication: Assessment and reporting of intercoder reliability. Human Communication Research, 28, 587-604.

Loper, A. B. (2002). Adjustment to prison of women convicted of possession, trafficking, and nondrug offenses. Journal of Drug Issues, 32, 22-26.

McClellan, D. S. (1994). Disparity in the discipline of male and female inmates in Texas prisons. Women and Criminal Justice, 5, 71-97.

Miller, J. B. (1986). What do we mean by relationships? Work in progress No. 33. Wellesley, MA: Stone Center, Working Paper Series.

Motiuk, L. L. (1997). Classification for correctional programming: The Offender Intake Assessment (OIA) process. Forum on Corrections Research, 9, 18-22.

Motiuk, L. L., \& Serin, R. C. (Eds) (2001). Compendium 2000 on effective correctional programming. Ottawa, ON: Correctional Service Canada.

Nuffield, J. (1982). Parole decision-making in Canada: Research towards decision guidelines. Ottawa, ON: Ministry of Supply and Services Canada.

Office of the Correctional Investigator of Canada, (2008). A Preventable Death. Retrieved from http://www.oci-bec.gc.ca/rpt/oth-aut/oth-aut20080620-eng.aspx. 
Office of the Correctional Investigator of Canada, (2009). Annual Report 2009-2010.

Retrieved from http://www.oci-bec.gc.ca/rpt/annrpt/annrpt20092010eng.aspx\#2.6.

Owen, B. (1998). In the mix: Struggle and survival in a women's prison. Albany, NY: State University of New York Press.

Pate, K. (2010, November 3). The death of Ashley Smith: Prisons can't handle the mentally ill. The Globe and Mail. Retrieved from http://www.theglobeandmail.com/commentary/the-death-of-ashley-smith-prisonscant-handle-the-mentally-ill/article 1216011.

Perkins, K.R. (2010) Examining gender differences in typological membership using latent class analysis: A novel contribution to the gender-specificity/neutrality debate (Master's thesis). Available from ProQuest Dissertations and Theses @ Carleton University. (No. MR79576).

Perreault, S., \& Brennan, S. (2010). Criminal Victimization in Canada, 2009. Statistics Canada (No. 85-002-X). Retrieved from http://www.statcan.gc.ca/pub/85-002x/2010002/article/11340-eng.pdf.

Pollock, J. M. (2002). Women, crime, and prison. Belmont, CA: Wadsworth.

Pollock, J. M., \& Davis, S. M. (2005). The continuing myth of the violent female offender. Criminal Justice Review, 30, 5-29.

Power, J. (2011) Non-Suicidal Self-Injury in Federally Sentenced Women: Prevalence, Nature, Motivations, and Pathways (Doctoral Dissertation). Available from ProQuest Dissertation and Theses @ Carleton University. (No. NR81588). 
Public Safety Canada. (2009). Corrections and conditional release statistical overview: Annual report 2009. (ISSN No. 1713-1073). Retrieved from http://www.publicsafety.gc.ca/res/cor/rep/2009-ccrso-eng.aspx\#c10

Public Safety Canada. (2011) Corrections and conditional release statistical overview: Annual report 2011. (ISSN No. 1713-1073). Retrieved from http://www.publicsafety.gc.ca/res/cor/rep/_fl/2011-ccrso-eng.pdf.

Reisig, M. D., Holtfreter, K., \& Morash, M. (2006). Assessing recidivism risk across female pathways to crime. Justice Quarterly, 23, 384-405.

Report of the New Brunswick Ombudsman and Child and Youth Advocate on the Services Provided to a Youth Involved in the Youth Criminal Justice System (2008). The Ashley Smith Report. Retrieved from http://www.gnb.ca/0073/publications-e.asp.

Rettinger, L. J., \& Andrews, D. A. (2010). General risk and need, gender specificity, and the recidivism of female offenders. Criminal Justice and Behavior, 37, 29-46.

Ross, R. R., \& Fabiano, E. A. (1986). Female offenders: Correctional afterthoughts. Jefferson, NC: McFarland.

Salisbury, E. J., \& Van Voorhis, P. (2009). Gendered pathways: An empirical investigation of women probationers' paths to incarceration. Criminal Justice \& Behavior, 36, 541-566.

Salisbury, E. J., Van Voorhis, P., \& Spiropoulos, G. V. (2009). The predictive valididty of a gender responsive needs assessment: An exploratory study. Crime \& Deliquency, 55, 550-585. 
Sioui, R., \& Thibault, J. (2001). Pertinence of cultural adaptation of Reintegration Potential Reassessment (RPR) scale to Aboriginal context. Research Report R109. Ottawa, ON: Correctional Service Canada.

Sly, A., \& Taylor, K. (2005). Evaluation of Psychosocial Rehabilitation within the Women's Structured Living Environments. Research Report R-163. Ottawa, ON: Correctional Service of Canada.

Smith, P., Cullen, F. T., \& Latessa, E. J. (2009). Can 14, 737 women be wrong? A metaanalysis of the LSI-R and recidivism for female offenders. Criminology \& Public Policy, 8, 183-208.

Solicitor General of Canada (1987). Development of a security classification model for Canadian federal offenders. Ottawa, ON: Correctional service of Canada.

Sorensen, J. R., \& Cunningham, M. D. (2010). Conviction offense and prison violence: A comparative study of murderers and other offenders. Crime \& Delinquency. 56,103-125.

Sorensen, J. R., Cunningham, M. D., Vigen, M. P., \& Woods, S. O. (2011). Serious assaults on prison staff: A descriptive analysis. Journal of Criminal Justice, 39, 143-150.

Steffensmeier, D. (2001). Sex differences in patterns of adult crime, 1965 - 1977: A review and assessment. Social Forces, 58, 1080-1108.

Steiner, B., \& Wooldredge, J. (2009). Individual and environmental effects on assaults and nonviolent rule breaking by women in prison. Journal of Research in Crime and Delinquency, 46, 437-467.

Sykes, G. E. (1958). The society of captives. Princeton, NJ: Princeton University Press. 
Tabachnick, B.G., \& Fidell, L.S. (2007). Using Multivariate Statistics, $5^{\text {th }}$ ed. Boston, MA: Allyn \& Bacon.

Task Force on Federally Sentenced Women (1990). Creating choices: Report of the Task Force on Federally Sentenced Women. Ottawa, ON: Ministry of the Solicitor Genderal Canada.

Thompson, C., \& Loper, A. B. (2005). Adjustment patterns in incarcerated women: An analysis of differences based on sentence length. Criminal Justice and Behavior, $32,714-732$.

Toch, H., \& Adams, K. (2002). Acting out: Maladaptive behavior in confinement. Washington, DC: American Psychological Association.

Trevethan, S., Moore, J.P., \& Rastin, C.J. (2002). A profile of Aboriginal offenders in federal facilities and serving time in the community. Forum on Corrections Research, 14(3), 17-19.

Van Tongeren, D. R., \& Klebe, K. J. (2010). Reconceptualizing prison adjustment: A multidimensional approach exploring female offenders' adjustment to prison life. The Prison Journal, 90, 48-68.

Van Voorhis, P., \& Brown, K. (1996). Risk Classification in the 1990s. Washington, DC: National Institute of Corrections.

Van Voorhis, P., \& Presser, L. (2001). Classification of women offenders: A national assessment of current practices. Washington, DC: National Institute of Corrections. 
Varrette, S., \& Archambault, K. (2011). A review of use of force in three types of correctional facilities. Report R-236. Ottawa ON: Correctional Service of Canada.

Warren, J. I., Hurt, S., Loper, A. B., \& Chauhan, P. (2004). Exploring prison adjustment among female inmates. Criminal Justice and Behavior, 31, 624-645.

Way, B.B., Miraglia, R., Sawyer, D.A., Beer, R., \& Eddy, J. (2005). Factors related to suicide in New York state prisons. International Journal of Law and Psychiatry, $28,207-221$

Webster, C.M., \& Doob, A.N. (2004). Classification without validity or equity: An empirical examination of the Custody Rating Scale for federally sentenced women offenders in Canada. Canadian Journal of Criminology and Criminal Justice, 46, $395-421$.

Webster, C. D., Douglas, K. S., Eaves, D., \& Harts, S. D. (1997). The HCR-20: Assessing Risk for Violence (Version 2). Burnaby, BC: Simon Fraser University.

Weiten, W., \& McCann, D. (2010). Psychology: Themes and variations (2 ${ }^{\text {nd }}$ ed.). Toronto, ON: Nelson Education.

Wolff, N., Blitz, D., Shi, J., Siegel, J., \& Bachman, R. (2007). Physical violence inside prisons: Rates of victimization. Criminal Justice and Behavior, 34, 588-604.

Women Offender Sector, (2010). Women offender statistical overview: Fiscal year 20092010. Ottawa, ON: Correctional Service of Canada.

Wright, K. (1985). Improving correctional classification through a study of the placement of inmates in environmental settings (NIC Accession No. 104543). Washington, DC: National Institute of Corrections. 
Wright, E. M., Salisbury, E. J., \& Van Voorhis, P. (2007). Predicting the prison misconducts of women offenders: The importance of gender-responsive needs. Journal of Contemporary Criminal Justice, 23, 310-340. 


\section{Appendices}

\section{Appendix A: Institutional Charges}

The following charges were included in the current analysis. Each individual charge can be categorized as either minor or major upon administration of the charge.

1. Disobey order

2. In prohibited area

3. Damage/destroy property

4. Theft

5. Possession of stolen property

6. Disrespect/abusive to staff

7. Inmate fight

8. Threaten violence

9. Assault (staff, inmate, visitor, other)

10. Contraband

11. Unauthorized item

12. Ingestion of intoxicants

13. Refusal of urine sample

14. Disturbance

15. Jeopardize safety of institution

16. Escape or assist in escape

17. Bribery

18. Gambling

19. Disobey rule

20. Attempts to commit or assists in any of the above charges 


\section{Appendix B: Coding Manual \\ PERPETRATOR INFORMATION}

1. What was the offender's role in the incident?

[1] $\square$ Instigator

[2] $\square$ Associate

$[88] \square$ Unknown/unclear (not indicated)

2. Was the offender working with another inmate during the incident?

[1] $\square$ No

[2] $\square$ Yes

$[88] \square$ Unknown (not indicated)

2.1 If yes, how many other inmates were involved?

[1] $\square$ One

[2] $\square$ Two

[3] $\square$ Three or more

[88] $\square$ Unknown (not indicated)

[99] $\square$ Not Applicable

\section{INCIDENT DETAILS}

3. What was the incident type?

[1] $\square$ Threat/verbal assault

[Displays aggressive/threatening behaviour, but no contact is made]

[2] $\square$ Fighting/minor assault/physical altercation 
[Contact is made, but non-serious e.g., pushing, shoving, slapping]

[3] $\square$ Physical Assault using force

[Serious contact is made e.g., punching, kicking, weapons]

[4] $\square$ Physical Assault using bodily fluids

[5] $\square$ Sexual assault

[6] $\square$ Hostage-taking

[7] $\square$ Hostage-taking with sexual assault

[8] $\square$ Forcible confinement

[9] $\square$ Forcible confinement with sexual assault

[10] $\square$ Homicide/attempted homicide

[11] $\square$ Other (please specify):

4. Where did the incident take place?

[1] $\square$ Cell/Living Unit/Pod

[2] $\square$ Range

[3] $\square$ Control/security post (including reception post)

[4] $\square$ Segregation cell

$[5] \square$ Interview room

[6] $\square$ Administrative offices

[7] $\square$ Kitchen/dining area

[8] $\square$ Stores/canteen distribution area

[9] $\square$ School/program rooms 
$[10] \square$ Washroom

[11] $\square$ Visiting area

[12] $\square$ Recreational/common area (e.g., yard, gym, library)

[13] $\square$ Medical services area

[14] $\square$ Other (please specify):

$[88] \square$ Unknown (not indicated)

5. What was the primary weapon/method used?

[Check all that apply - inmate can punch/kick and then resort to sharp object. Can also indicate if weapon is found on person or during post incident search-just include it under threaten]

[1] $\square$ Sharp object used to harm victim (e.g., knife, razor, home-made shank)

[2] $\square$ Sharp object used to threaten/control victim

[3] $\square$ Blunt object used to harm victim (e.g., club, pipe, tools)

[4] $\square$ Blunt object used to threaten/control victim

[5] $\square$ Restraints used to harm victim (e.g., rope, belt)

[6] $\square$ Restraints used to threaten/control victim

[7] $\square$ Physical force used to harm victim (e.g., kicking, punching, physically restrain/hold)

[8] $\square$ Physical force used to threaten/control victim

[9] $\square$ Fluids used to harm victim (e.g., spraying/throwing urine, blood, excrement, spit)

[10] $\square$ Fluids used to threaten/control victim

[11] $\square$ Objects thrown to harm the victim (e.g., chair)

[12] $\square$ Threat of throwing object 
[13] $\square$ Other (please specify):

[88] $\square$ Unknown (not indicated)

6. What was the degree of staff intervention (i.e., Use of Force) needed in order to bring the situation under control?

[These are ordered by severity/seriousness of force required. Choose the most serious when a combination of tactics is used].

[1] $\square$ None (offender ceases actions on his/her own, staff are only informed of the incident after it's occurrence, staff presence on unit is enough to end incident).

[2] $\square$ Verbal intervention/Conflict resolution

[3] $\square$ Negotiation (staff engage in negotiation or an actual negotiator is brought in)

[4] $\square$ Minor physical handling (physically intervene, step between, separate \& escort away from the situation)

[5] $\square$ Restraint equipment (handcuffs, leg irons, body belt)

[6] $\square$ Major physical handling (physically restrain/subdue, self defend)

[7] $\square$ Inflammatory and/or chemical agents

[8] $\square$ Use of batons or other intermediary impact weapons

[9] $\square$ Emergency Response Team

$[10] \square$ Use of firearms

[11] $\square$ Not indicated

\section{VICTIM INFORMATION}

7. How many victims were involved in the incident?

[0] $\square 0$ 
[1] $\square 1$

[2] $\square 2$

[3] $\square 3$ or more

[4] $\square$ Unclear/not indicated

8. Who was the victim in the incident? (Check more than one if additional victims are in a different category)

[1] $\square$ Staff

[2] $\square$ Another inmate

[3] $\square$ Visitor

[4] $\square$ Unknown (not indicated)

8.1 If the victim(s) was a staff member, indicate their staff position (Check more than one if there is more than one victim with a different position).

[1] $\square$ Correctional Officer

[2] $\square$ Parole Officer

[3] $\square$ Program facilitator

[4] $\square$ Psychology staff (e.g., psychologist, counsellor)

[5] $\square$ Medical Staff (e.g., nurse, doctor)

[6] $\square$ Administrative or functional/services staff (e.g., clerical staff, kitchen/canteen staff)

$[88] \square$ Unknown/not indicated

[99] $\square$ Not Applicable

9. What was the perpetrator's relationship to the victim? 
9.1 If the victim was another inmate:

[1] $\square$ Cell/house mate

[2] $\square$ Friend/ Acquaintance

[This may seem like it overlaps with the above category, only check this if it is specifically stated that they are friends or associate frequently. If it just states they are housed together, select \#1]

[3] $\square$ Partner (indicates intimate relationship with the victim)

[4] $\square$ Rival gang member

[5] $\square$ No relationship - random selection

[6] $\square$ Other (please indicate):

[88] $\square$ Unknown (not indicated)

[99] $\square$ Not Applicable (i.e. victim was staff)

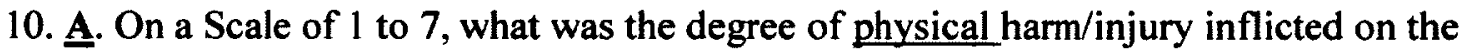
victim?

[1] $\square$ 1. No physical harm inflicted. No assault/contact

[This would likely be a case where an offender threatens a victim and is verbally aggressive]

[2] $\square$ 2. None to minor harm inflicted: contact made without injury

[Assault without injury: contact is made but there is little physical impact. E.g., pushing/shoving]

[3] $\square$ 3. Minor physical harm inflicted

[Superficial injuries would require some first aid treatment (ice, bandages) but would not require serious medical attention. E.g., small cuts, bruises,]

[4] $\square$ 4. Moderate physical harm inflicted 
[Injuries require more serious medical attention (e.g., cast, stitches) but the victim is still relatively functional post event i.e., not life-threatening or extensively long lasting. E.g., broken limb]

[5] $\square$ 5. Moderate to severe physical harm

[Immediate physical injuries are not severe, but the nature of the assault is potentially life-threatening \& long lasting. This will mainly apply to use of bodily fluids - potential for contracting serious illness or infectious diseases (HIV/AIDS, Hepatitis). Another potential example would include breaking skin with potential contagious object (e.g., needle)]

[6] $\square$ 6. Severe physical harm inflicted [physical injuries are severe and the nature of the assault is potentially life-threatening \& long lasting - violent sexual assault, serious head injury, spinal injury]

[7] $\square$ 7. Death

[88] $\square$ Unclear/not indicated [if minimal to no information is provided]

10. B. If there was a second victim - on a Scale of 1 to 7 , what was the degree of physical harm/injury inflicted on this victim?

[1] $\square$ 1. No physical harm inflicted. No assault/contact

[This would likely be a case where an offender threatens a victim and is verbally aggressive]

[2] $\square$ 2. No to minor harm inflicted: contact made without injury

[Assault without injury: contact is made but there is little physical impact. E.g., pushing/shoving]

[3] $\square$ 3. Minor physical harm inflicted

[Superficial injuries would require some first aid treatment (ice, bandages) but would not require serious medical attention. E.g., small cuts, bruises,]

[4] $\square$ 4. Moderate physical harm inflicted

[Injuries require more serious medical attention (e.g., cast, stitches) but the victim is still relatively functional post event i.e., not life-threatening or extensively long lasting. E.g., broken limb] 
[5] $\square$ 5. Moderate to severe physical harm

[Immediate physical injuries are not severe, but the nature of the assault is potentially life-threatening \& long lasting. This will mainly apply to use of bodily fluids - potential for contracting serious illness or infectious diseases (HIV/AIDS, Hepatitis). Another potential example would include breaking skin with potential contagious object (e.g., needle)]

[6] $\square$ 6. Severe physical harm inflicted [physical injuries are severe and the nature of the assault is potentially life-threatening \& long lasting - violent sexual assault, serious head injury, spinal injury]

[7] $\square$ 7. Death

[88] $\square$ Unclear/not indicated [if minimal to no information is provided]

[99] $\square$ Not Applicable

\section{MOTIVATION}

11. What was the offender(s) motivation(s) for the incident?

[1] $\square$ Instrumental (acquisition of property/goods, status/power, privileges)

Please specify:

[2] $\square$ Expressive (wanting to be heard, wanting attention)

Please specify:

[3] $\square$ Relational (has a relation to the victim, e.g., result of a dispute)

[4] $\square$ Sexual

[5] $\square$ Gang-related

$[6] \square$ Retaliation/in response to being provoked

[7] $\square$ Psychological distress (Offender is unstable \& acting out - needs to clearly be specified, i.e., offender is seen by medical staff afterwards \& this assessment is made). 
[8] $\square$ Escape

[9] $\square$ Other (please specify):

[88] $\square$ Unknown (not indicated)

\section{OVERALL SEVERITY RANKING}

12. On a scale of $1-5$, what was the degree of severity of the incident?

[Refer to following page for detailed instructions]

$\square 1$ Not severe

2 Somewhat severe

$\square 3$ Moderately severe

$\square 4$ Very severe

$\square 5$ Extremely severe

$\square 6$ Not enough information to provide answer 
Note:

Need to look at this as an overall assessment of the incident, as opposed to \#10 which only refers specifically to the degree of physical harm of the victim. For example, a confinement/hostage taking situation may not result in much contact/harm, but overall it is a serious form of misconduct. There is a combination of factors to consider: the act itself, the harm inflicted, staff response and the safety of the institution.

\section{Not severe}

Offender behaviour: Likely more of a minor verbal resistance, disciplinary issue. No contact made

Harm inflicted: None

Staff response: Verbal intervention is sufficient to de-escalate the situation.

Safety: Safety of institution not at serious risk.

\section{Somewhat severe}

Offender behaviour: Verbally aggressive/assaultive, threatening violence, not cooperative \& verbally resistive. Minimal to no contact made.

Harm inflicted: None

Staff response: Verbal intervention/negotiation is needed.

Safety: Safety of institution not at serious risk.

\section{Moderately severe}

Offender behaviour: Fighting, minor assault, physical contact is made. Offender is physically uncooperative.

\section{Harm inflicted: Minor}

Staff response: Verbal intervention- negotiation. Minor physical staff involvement staff physically intervene, step between offenders, escort offender away from the situation, standard restrain equipment used.

Safety: Safety of the institution at minor risk.

\section{Very severe}

Offender behaviour: Moderate assault, physical contact is made and/or weapon is used. 
Harm inflicted: Moderate to major but not life-threatening/long-term.

Staff response: Major physical handling required (staff actions are to physically restrain offender or are in self-defence). Chemical sprays/agents may be used.

Safety: Safety of institution at moderate risk.

\section{Extremely severe}

Offender behaviour: Serious assault/attempted homicide, attempted escape.

Harm inflicted: Grievous bodily harm - injuries are significant and potentially lifethreatening/long term.

Staff response: Major physical handling required, chemical sprays/agents used, ERT brought in, impact weapons/lethal force required.

Safety: Safety of institution at serious risk. 
Appendix C: Additional ANOVA Figures

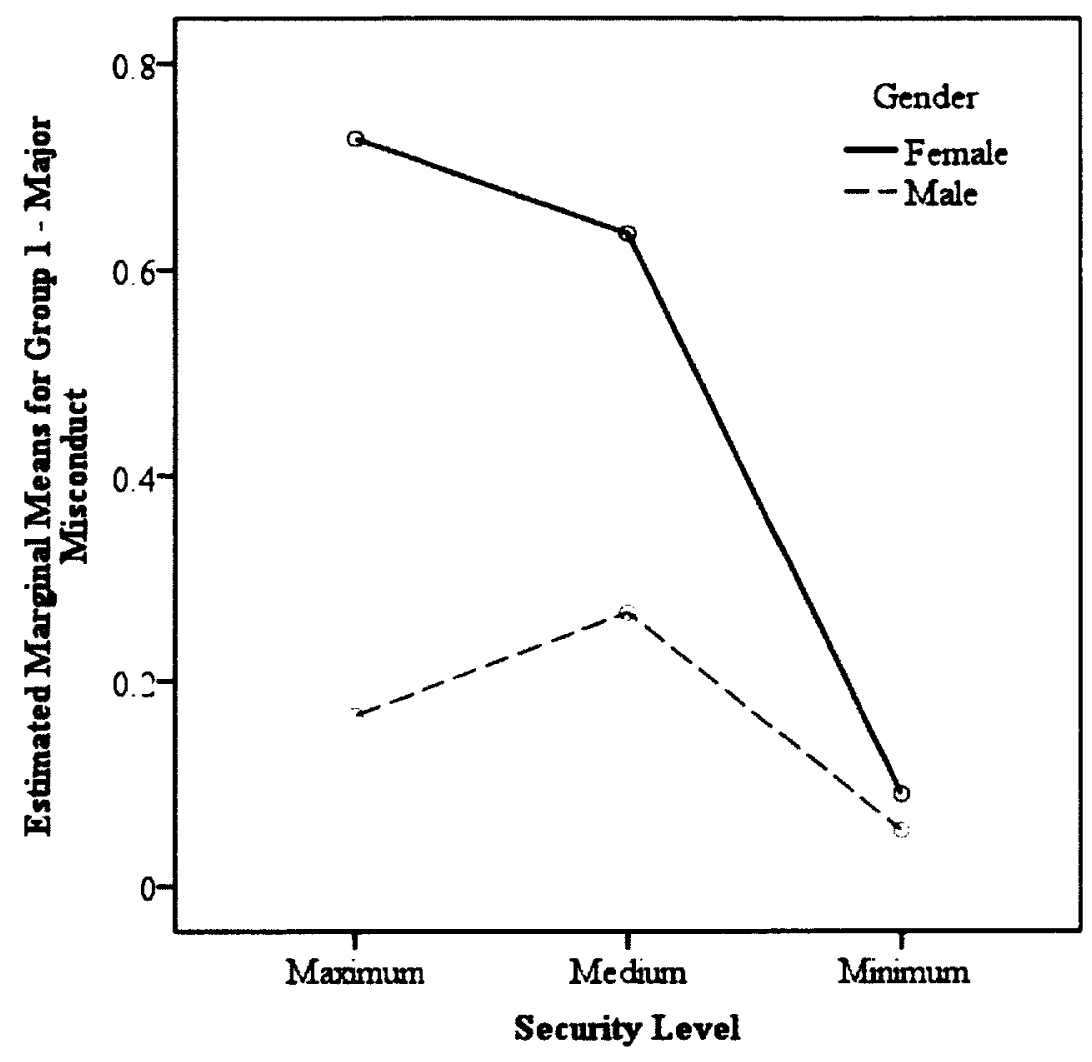

Figure 1. Graph of a non-significant interaction between security level and gender for major misconduct in group 1. 


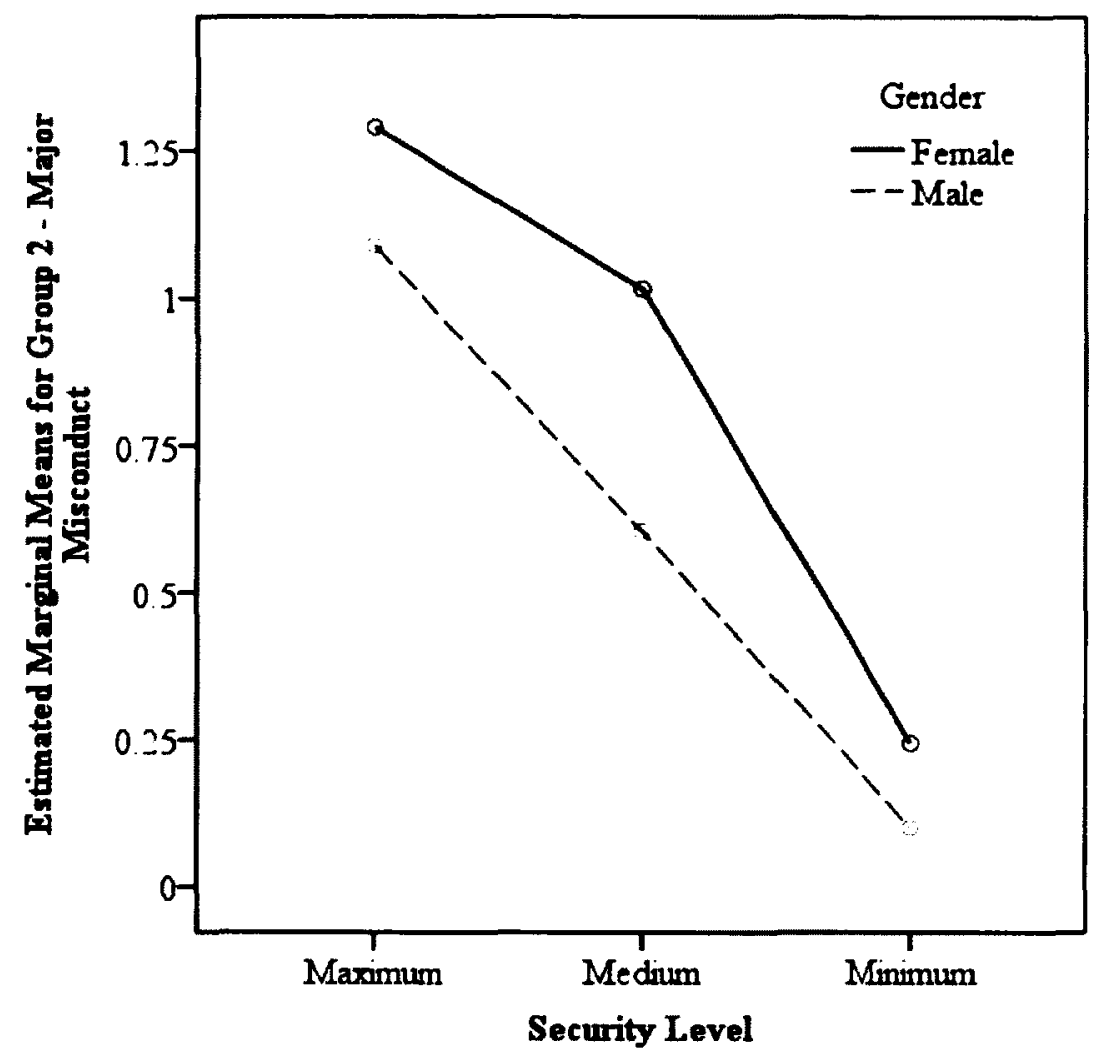

Figure 2. Graph of a non-significant interaction between security level and gender for major misconduct in group 2 


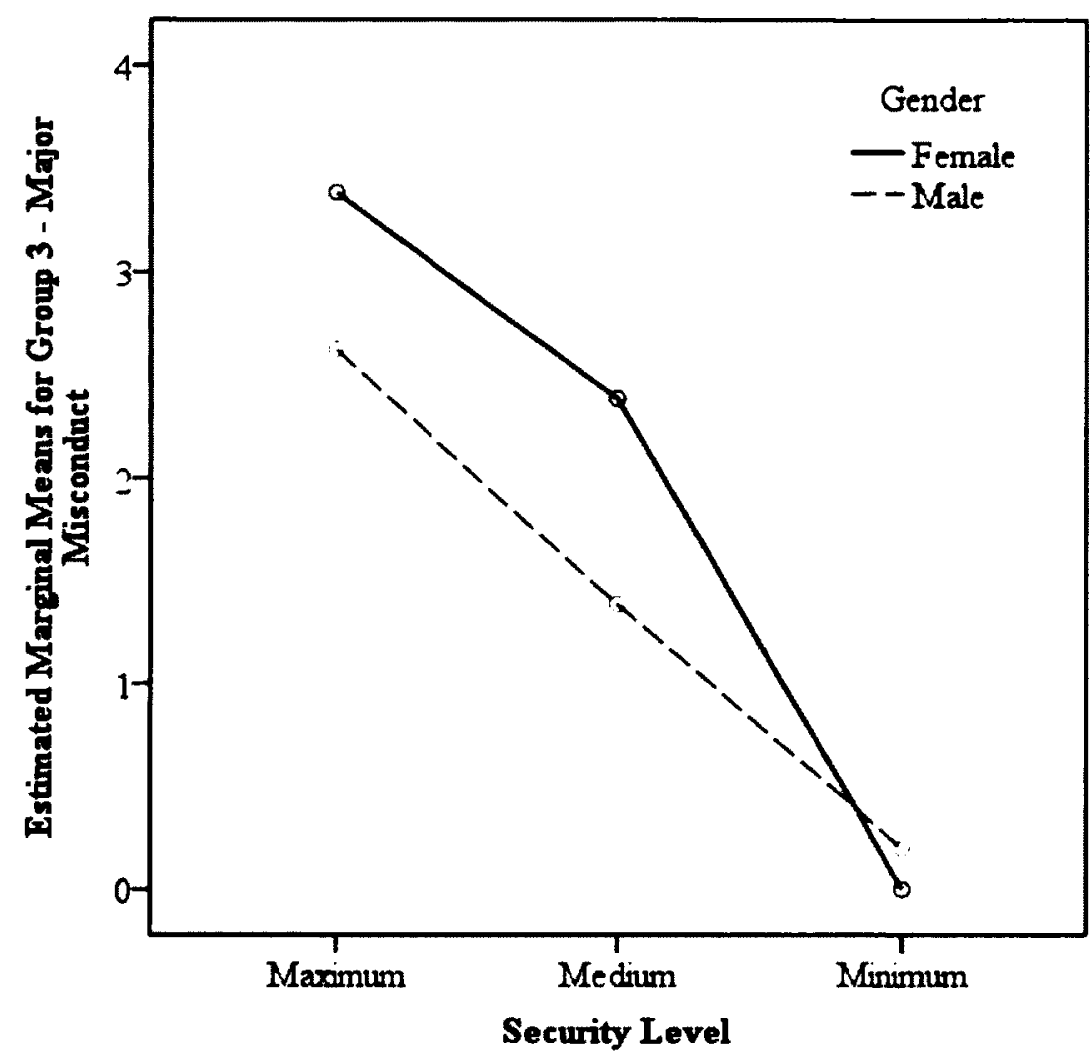

Figure 3. Graph of a non-significant interaction between security level and gender for major misconduct in group 3 


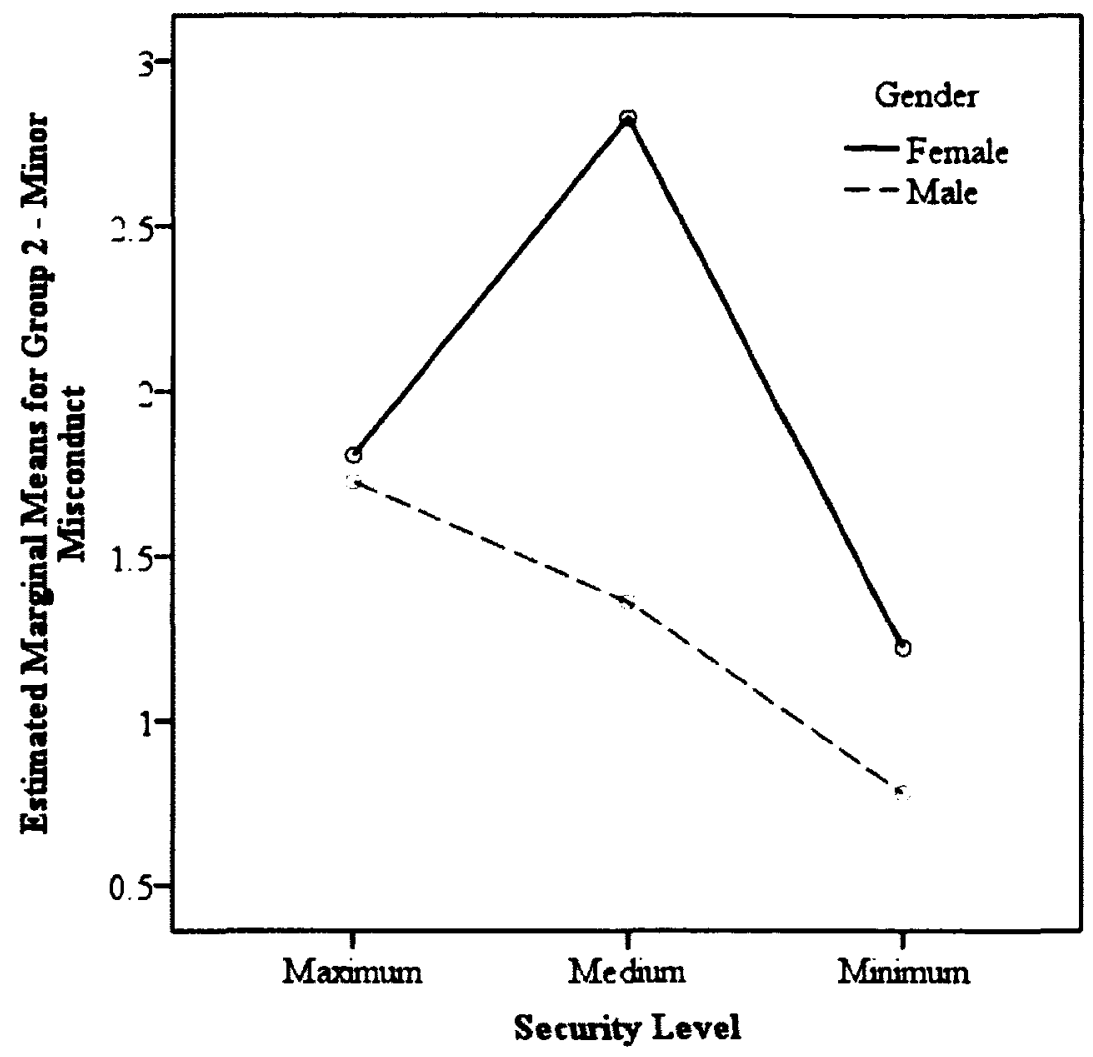

Figure 4. Graph of a non-significant interaction between security level and gender for minor misconduct in group 2 


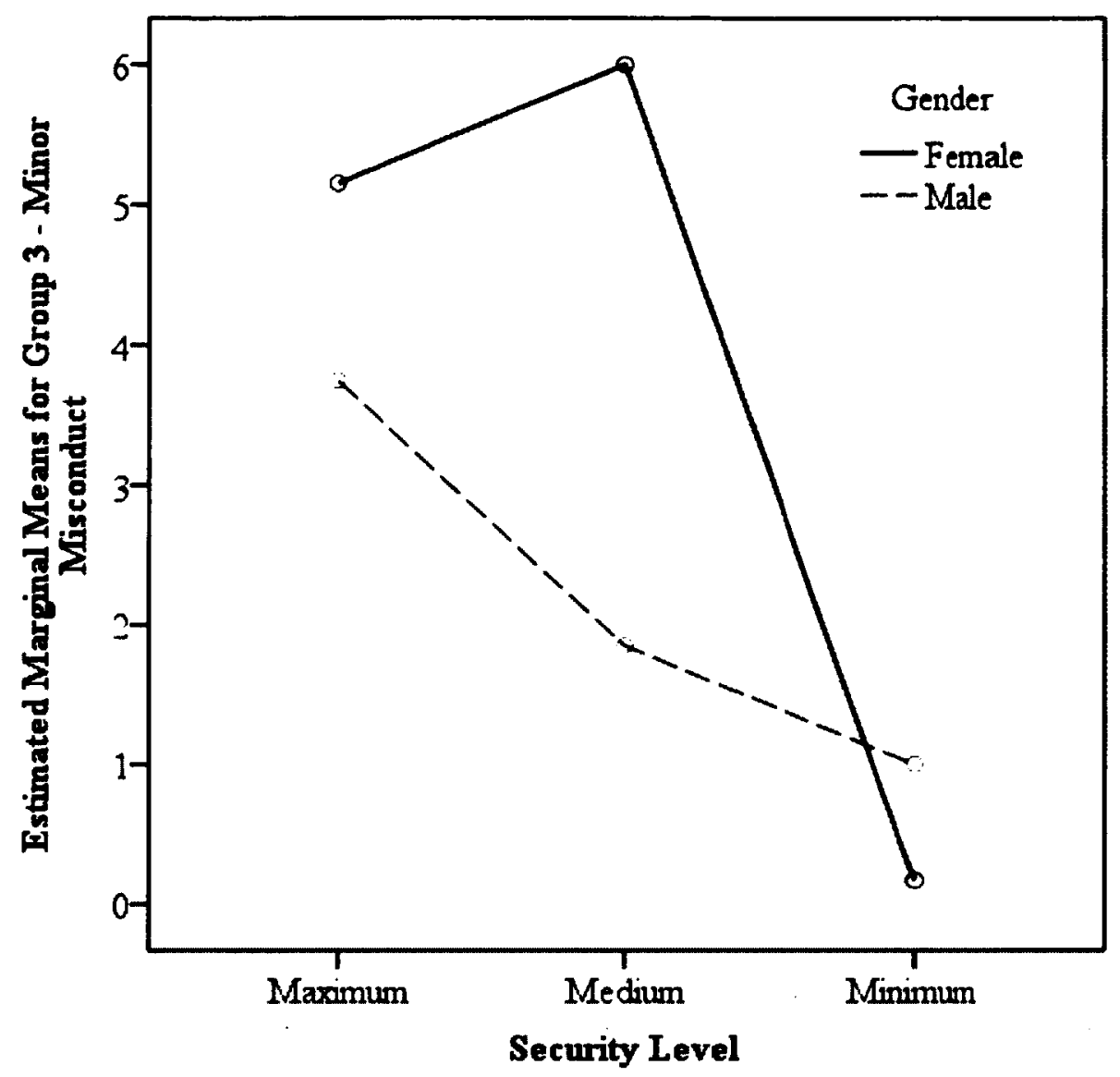

Figure 5. Graph of a non-significant interaction between security level and gender for minor misconduct in group 3 
Appendix D: Cox Regression Analysis Results for Women

Cox Proportional Hazards Model: Major Misconduct for Women Grouped by Security Level

\begin{tabular}{|c|c|c|c|c|c|c|c|c|c|}
\hline \multirow[b]{2}{*}{ Variable } & \multicolumn{3}{|c|}{$\begin{array}{l}\text { Minimum Security } \\
\qquad N=495^{\mathrm{a}}\end{array}$} & \multicolumn{3}{|c|}{$\begin{array}{l}\text { Medium Security } \\
\qquad N=398^{\mathrm{b}}\end{array}$} & \multicolumn{3}{|c|}{$\begin{array}{c}\text { Maximum Security } \\
N=55\end{array}$} \\
\hline & B & SE & $\begin{array}{c}\mathrm{HR} \\
(95 \% \mathrm{CI}) \\
\end{array}$ & $\beta$ & SE & $\begin{array}{c}\mathrm{HR} \\
(95 \% \mathrm{Cl})\end{array}$ & $\beta$ & SE & $\begin{array}{c}\mathrm{HR} \\
(95 \% \mathrm{Cl})\end{array}$ \\
\hline Age & -0.010 & 0.0160 & $\begin{array}{c}0.990 \\
(0.959-1.021)\end{array}$ & $-.034^{*}$ & 0.011 & $\begin{array}{c}0.967 \\
(0.945-0.988)\end{array}$ & -0.118 & 0.037 & $\begin{array}{c}0.889 \\
(0.827-0.956)\end{array}$ \\
\hline $\begin{array}{l}\text { Sentence } \\
\text { Length }\end{array}$ & -0.892 & 0.499 & $\begin{array}{c}0.410 \\
(0.154-1.090)\end{array}$ & -0.375 & 0.204 & $\begin{array}{c}0.687 \\
(0.461-1.024)\end{array}$ & -1.160 & 0.570 & $\begin{array}{c}0.314 \\
(0.103-0.958)\end{array}$ \\
\hline $\begin{array}{l}\text { Offence } \\
\text { Type }\end{array}$ & -0.395 & 0.373 & $\begin{array}{c}0.673 \\
(0.324-1.399)\end{array}$ & -0.014 & 0.203 & $\begin{array}{c}0.985 \\
(0.662-1.467)\end{array}$ & 1.075 & 1.022 & $\begin{array}{c}2.930 \\
(0.396-20.69)\end{array}$ \\
\hline Race & 0.389 & 0.438 & $\begin{array}{c}1.475 \\
(0.625-3.481)\end{array}$ & 0.320 & 0.186 & $\begin{array}{c}1.378 \\
(0.956-1.987)\end{array}$ & -0.246 & 0.485 & $\begin{array}{c}0.781 \\
(0.302-2.023)\end{array}$ \\
\hline \multicolumn{10}{|l|}{ Static Risk } \\
\hline Low & 0.302 & 0.913 & $\begin{array}{c}1.352 \\
(0.226-8.088)\end{array}$ & 0.061 & 0.329 & $\begin{array}{c}1.063 \\
(0.558-2.027)\end{array}$ & - & - & - \\
\hline Medium & 0.444 & 0.872 & $\begin{array}{c}1.560 \\
(0.282-8.618)\end{array}$ & 0.140 & 0.235 & $\begin{array}{c}1.151 \\
(0.726-1.824)\end{array}$ & $0.105^{c}$ & 0.745 & $\begin{array}{c}1.11 \\
(0.258-4.791)\end{array}$ \\
\hline \multicolumn{10}{|l|}{ Dynamic } \\
\hline $\begin{array}{l}\text { Risk } \\
\text { Low }\end{array}$ & -0.587 & 0.651 & $\begin{array}{c}0.556 \\
(0.155-1.991)\end{array}$ & -0.967 & 0.618 & $\begin{array}{c}0.380 \\
(0.113-1.277)\end{array}$ & - & - & - \\
\hline Medium & -0.118 & 0.451 & $\begin{array}{c}0.888 \\
(0.367-2.150)\end{array}$ & -0.255 & 0.229 & $\begin{array}{c}0.775 \\
(0.494-1.216)\end{array}$ & $-0.347^{d}$ & 0.961 & $\begin{array}{c}0.707 \\
(0.107-4.562)\end{array}$ \\
\hline \multicolumn{10}{|c|}{$\begin{array}{l}\text { Reintegration } \\
\text { Level }\end{array}$} \\
\hline Low & 0.636 & 1.098 & $\begin{array}{c}1.890 \\
(0.220- \\
16.240)\end{array}$ & 0.169 & 0.412 & $\begin{array}{c}1.184 \\
(0.528-2.654)\end{array}$ & $-0.326^{\mathrm{e}}$ & 0.669 & $\begin{array}{c}0.722 \\
(0.195-2.678)\end{array}$ \\
\hline
\end{tabular}




\begin{tabular}{|c|c|c|c|c|c|c|c|c|c|}
\hline Medium & -0.111 & 0.443 & $\begin{array}{c}0.895 \\
(0.376-2.133)\end{array}$ & 0.230 & 0.310 & $\begin{array}{c}1.259 \\
(0.685-2.314)\end{array}$ & - & - & - \\
\hline \multicolumn{10}{|l|}{$\begin{array}{l}\text { Motivation } \\
\text { Level }\end{array}$} \\
\hline Low & - & - & & 0.861 & 0.386 & $\begin{array}{c}2.366 \\
(1.109-5.047)\end{array}$ & -0.135 & 0.753 & $\begin{array}{c}0.873 \\
(0.199-3.824)\end{array}$ \\
\hline Medium & $-0.185^{f}$ & 0.371 & $\begin{array}{c}0.831 \\
(0.402-1.719)\end{array}$ & 0.183 & 0.194 & $\begin{array}{c}1.201 \\
(0.822-1.755)\end{array}$ & -0.127 & 0.536 & $\begin{array}{c}0.881 \\
(0.308-2.519)\end{array}$ \\
\hline
\end{tabular}

Note. $\beta=$ Parameter Estimate; $\mathrm{SE}=$ Standard Error; $\mathrm{HR}=$ Hazard Ratio; $\mathrm{Cl}=$ Confidence Interval.

${ }^{a} n=2$ missing. ${ }^{b} n=1$ missing. ${ }^{c}$ Assessment is only between medium and high static risk. ${ }^{d}$ Assessment is only between medium and high dynamic risk. ${ }^{e}$ Assessment is only between low and medium reintegration level. ${ }^{f}$ Assessment is only between medium and high motivation level.

$* p<.008$.

Cox Proportional Hazards Model: Minor Misconduct for Women Grouped by Security Level

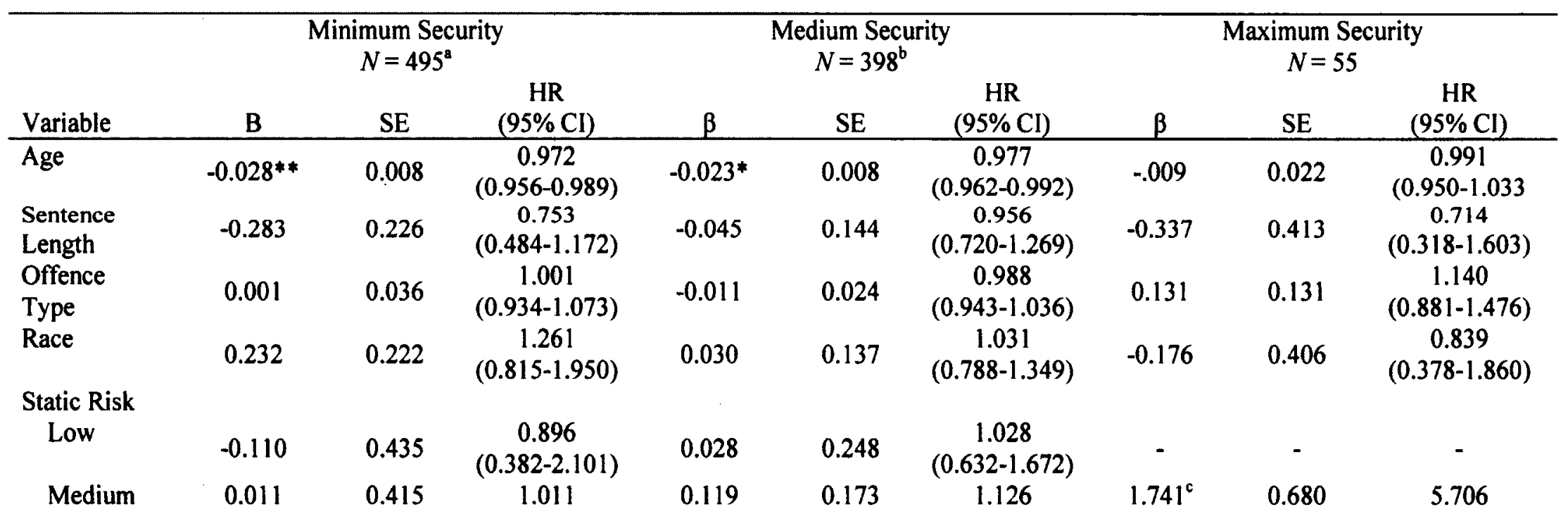




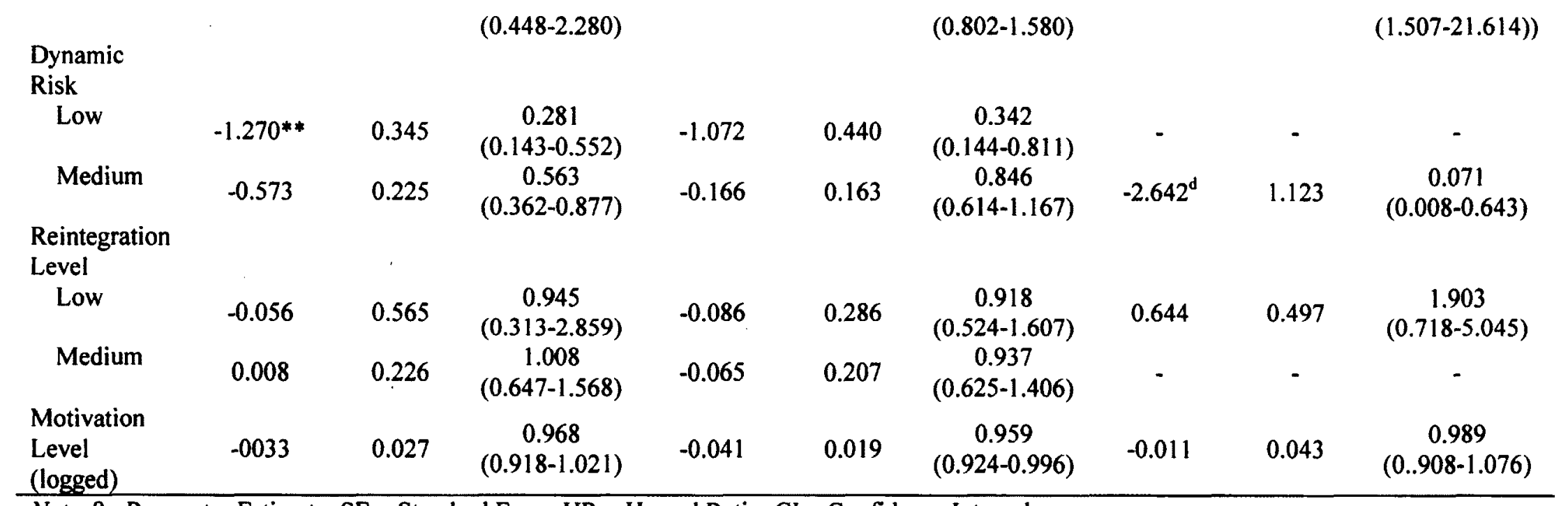

Note. $\beta=$ Parameter Estimate; $\mathrm{SE}=$ Standard Error; $\mathrm{HR}=$ Hazard Ratio $\mathrm{CI}=$ Confidence Interval.

${ }^{a} n=2$ missing. ${ }^{b} n=1$ missing. ${ }^{c}$ Assessment is only between medium and high static risk. ${ }^{d}$ Assessment is only between medium and high dynamic risk. ${ }^{e}$ Assessment is only between low and medium reintegration level.

$* p<.008 * * p<.001$. 


\section{Appendix E: Cox Regression Analysis Results for Men}

Cox Proportional Hazards Model: Major Misconduct for Men Grouped by Security Level

\begin{tabular}{|c|c|c|c|c|c|c|c|c|c|}
\hline \multirow[b]{2}{*}{ Variable } & \multicolumn{3}{|c|}{$\begin{array}{c}\text { Minimum Security } \\
\qquad N=493^{\mathrm{a}}\end{array}$} & \multicolumn{3}{|c|}{$\begin{array}{c}\text { Medium Security } \\
\qquad N=395^{\mathrm{b}}\end{array}$} & \multicolumn{3}{|c|}{$\begin{array}{c}\text { Maximum Security } \\
\qquad N=55\end{array}$} \\
\hline & B & SE & $\begin{array}{c}\mathrm{HR} \\
(95 \% \mathrm{CI}) \\
\end{array}$ & $\beta$ & $\mathrm{SE}$ & $\begin{array}{c}\text { HR } \\
(95 \% \mathrm{Cl}) \\
\end{array}$ & $\beta$ & SE & $\begin{array}{c}\mathrm{HR} \\
(95 \% \mathrm{CI}) \\
\end{array}$ \\
\hline Age & $-0.076^{*}$ & 0.021 & $\begin{array}{c}0.927 \\
(0.889-0.966)\end{array}$ & $-0.061^{*}$ & 0.010 & $\begin{array}{c}0.941 \\
(0.921-0.961)\end{array}$ & -0.032 & 0.026 & $\begin{array}{c}0.968 \\
(0.920-1.019)\end{array}$ \\
\hline $\begin{array}{l}\text { Sentence } \\
\text { Length }\end{array}$ & -0.157 & 0.407 & $\begin{array}{c}0.854 \\
(0.385-1.896)\end{array}$ & 0.154 & 0.203 & $\begin{array}{c}1.166 \\
(0.783-1.736)\end{array}$ & -0.873 & 0.545 & $\begin{array}{c}0.418 \\
(0.144-1.216)\end{array}$ \\
\hline $\begin{array}{l}\text { Offence } \\
\text { Type }\end{array}$ & -0.029 & 0.417 & $\begin{array}{c}0.972 \\
(0.429-2.202)\end{array}$ & 0.132 & 0.205 & $\begin{array}{c}1.141 \\
(0.764-1.705)\end{array}$ & -0.385 & 0.763 & $\begin{array}{c}0.680 \\
(0.152-3.039)\end{array}$ \\
\hline Race & 1.566 & 1.032 & $\begin{array}{c}4.787 \\
(0.633- \\
36.181)\end{array}$ & 0.666 & 0.262 & $\begin{array}{c}1.945 \\
(1.165-3.249)\end{array}$ & -0.148 & 0.555 & $\begin{array}{c}0.863 \\
(0.291-2.561)\end{array}$ \\
\hline $\begin{array}{l}\text { Static Risk } \\
\text { Low }\end{array}$ & -0.265 & 0.718 & $\begin{array}{c}0.767 \\
(0.187-3.139)\end{array}$ & 0.115 & 0.692 & $\begin{array}{c}1.123 \\
(0.289-4.354)\end{array}$ & - & - & - \\
\hline Medium & -0.435 & 0.625 & $\begin{array}{c}0.647 \\
(0.190-2.204)\end{array}$ & 0.452 & 0.247 & $\begin{array}{c}1.572 \\
(0.968-2.552)\end{array}$ & $0.415^{\mathrm{d}}$ & 0.794 & $\begin{array}{c}1.516 \\
(0.320-7.187)\end{array}$ \\
\hline \multicolumn{10}{|l|}{ Dynamic } \\
\hline Low & -2.194 & 0.866 & $\begin{array}{c}0.111 \\
(0.020-0.608)\end{array}$ & 0.229 & 0.971 & $\begin{array}{c}1.257 \\
(0.187-8.425)\end{array}$ & - & - & - \\
\hline Medium & -0.320 & 0.471 & $\begin{array}{c}0.727 \\
(0.289-1.828)\end{array}$ & -0.255 & 0.280 & $\begin{array}{c}0.775 \\
(0.447-1.343)\end{array}$ & $1.130^{e}$ & 1.083 & $\begin{array}{c}3.094 \\
(0.370- \\
25.849)\end{array}$ \\
\hline $\begin{array}{l}\text { Reintegration } \\
\text { Level } \\
\text { Low }\end{array}$ & - & - & & $1.102^{*}$ & 0.371 & 3.013 & $-1.061^{f}$ & 1.590 & 0.346 \\
\hline
\end{tabular}




\begin{tabular}{|c|c|c|c|c|c|c|c|c|c|}
\hline Medium & $-0.171^{c}$ & 0.501 & $\begin{array}{c}0.842 \\
(0.315-2.248)\end{array}$ & 0.264 & 0.314 & $\begin{array}{c}(1.454-6.241) \\
1.302 \\
(0.704-2.410)\end{array}$ & - & - & $\begin{array}{c}(0.015-7.819) \\
-\end{array}$ \\
\hline \multicolumn{10}{|l|}{$\begin{array}{l}\text { Motivation } \\
\text { Level }\end{array}$} \\
\hline Low & 0.057 & 1.076 & $\begin{array}{c}1.058 \\
(0.128-8.731)\end{array}$ & 0.611 & 0.474 & $\begin{array}{c}1.842 \\
(0.727-4.664)\end{array}$ & $1.100^{8}$ & 0.479 & $\begin{array}{c}3.003 \\
(1.174-7.683)\end{array}$ \\
\hline Medium & -0.011 & 0.412 & $\begin{array}{c}0.989 \\
(0.441-2.218) \\
\end{array}$ & -0.091 & 0.443 & $\begin{array}{c}0.913 \\
(0.383-2.176)\end{array}$ & - & - & - \\
\hline
\end{tabular}

Note. $\beta=$ Parameter Estimate; $\mathrm{SE}=$ Standard Error; $\mathrm{HR}=$ Hazard Ratio; $\mathrm{CI}=$ Confidence Interval.

${ }^{\mathrm{a}} n=3$ missing ${ }^{\mathrm{b}} n=5$ missing. ${ }^{\mathrm{c}}$ Assessment is only between medium and high reintegration level. ${ }^{\mathrm{d}}$ Assessment is only between medium and high static risk. ${ }^{\circ}$ Assessment is only between medium and high dynamic risk. ${ }^{f}$ Assessment is only between low and medium reintegration level. ${ }^{8}$ Assessment is only between low and medium motivation level.

$* p<.008 * * p<.001$.

Cox Proportional Hazards Model: Minor Misconduct for Men Grouped by Security Level

\begin{tabular}{|c|c|c|c|c|c|c|c|c|c|}
\hline \multirow[b]{2}{*}{ Variable } & \multicolumn{3}{|c|}{$\begin{array}{l}\text { Minimum Security } \\
\qquad N=493^{\mathrm{a}}\end{array}$} & \multicolumn{3}{|c|}{$\begin{array}{l}\text { Medium Security } \\
\qquad N=395^{\mathrm{b}}\end{array}$} & \multicolumn{3}{|c|}{$\begin{array}{c}\text { Maximum Security } \\
\qquad N=55\end{array}$} \\
\hline & B & $\mathrm{SE}$ & $\begin{array}{c}\text { HR } \\
(95 \% \mathrm{Cl})\end{array}$ & $\beta$ & SE & $\begin{array}{c}\text { HR } \\
(95 \% \mathrm{Cl})\end{array}$ & $\beta$ & SE & $\begin{array}{c}\text { HR } \\
(95 \% \mathrm{Cl})\end{array}$ \\
\hline Age & $-0.040^{* *}$ & 0.008 & $\begin{array}{c}0.960 \\
(0.946-0.975)\end{array}$ & $-0.053^{* *}$ & 0.008 & $\begin{array}{c}0.949 \\
(0.933-0.965)\end{array}$ & $-0.077^{*}$ & 0.028 & $\begin{array}{c}0.926 \\
(0.877-0.978)\end{array}$ \\
\hline $\begin{array}{l}\text { Sentence } \\
\text { Length }\end{array}$ & -0.020 & 0.185 & $\begin{array}{c}0.980 \\
(0.681-1.410)\end{array}$ & 0.009 & 0.164 & $\begin{array}{c}1.009 \\
(0.732-1.392)\end{array}$ & -1.033 & 0.521 & $\begin{array}{c}0.356 \\
(0.128-0.987)\end{array}$ \\
\hline $\begin{array}{l}\text { Offence } \\
\text { Type }\end{array}$ & -0.023 & 0.033 & $\begin{array}{c}0.978 \\
(0.917-1.042)\end{array}$ & -0.029 & 0.026 & $\begin{array}{c}0.971 \\
(0.923-1.022)\end{array}$ & 0.175 & 0.135 & $\begin{array}{c}1.191 \\
(0.915-1.551)\end{array}$ \\
\hline Race & 0.344 & 0.304 & $\begin{array}{c}1.410 \\
(0.778-2.556)\end{array}$ & 0.137 & 0.207 & $\begin{array}{c}1.148 \\
(0.766-1.720)\end{array}$ & -0.573 & 0.474 & $\begin{array}{c}0.564 \\
(0.223-1.426)\end{array}$ \\
\hline
\end{tabular}




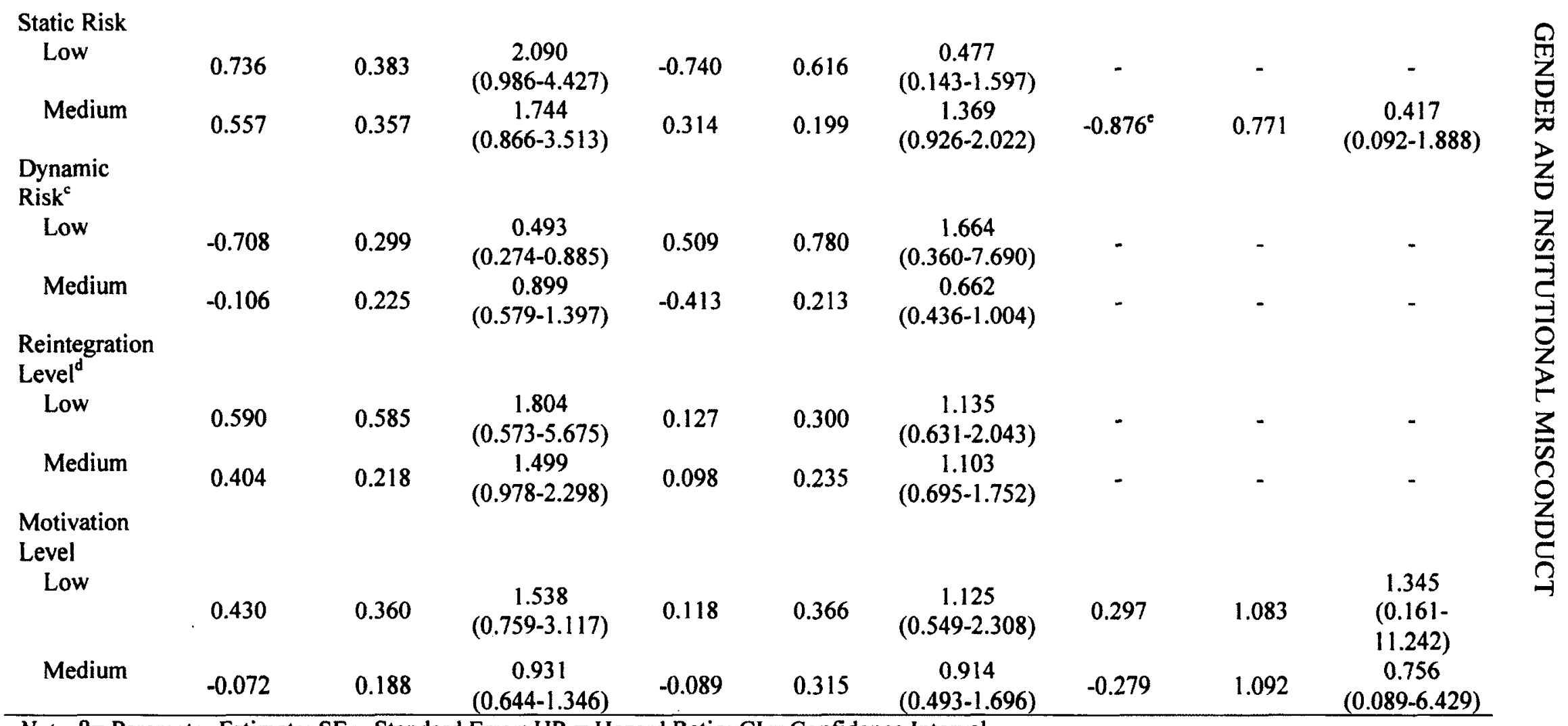

Note. $\beta=$ Parameter Estimate; $\mathrm{SE}=$ Standard Error; $\mathrm{HR}=$ Hazard Ratio; $\mathrm{CI}=$ Confidence Interval.

${ }^{a} n=3$ missing ${ }^{b} n=5$ missing. ${ }^{c}$ Variable dropped for maximum security due to cell size. ${ }^{d}$ Variable dropped for maximum security due to cell size.

${ }^{\circ}$ Assessment is only between medium and high static risk.

$* p<.006 * * p<.001$ 


\section{Appendix F: Qualitative Results by Security Level}

Theme Frequencies for the Qualitative Analysis; Maximum Security Offenders

\begin{tabular}{|c|c|c|}
\hline & $\begin{array}{c}\text { Males } \\
(n=10)\end{array}$ & $\begin{array}{c}\text { Females } \\
(n=10)\end{array}$ \\
\hline \multicolumn{3}{|l|}{ Offender Role } \\
\hline Instigator & 10 & 10 \\
\hline Associate & 0 & 0 \\
\hline Accomplice (Yes/No) & 1 & 1 \\
\hline \multicolumn{3}{|l|}{ Misconduct Type } \\
\hline Threat & 1 & 0 \\
\hline Physical altercation & 2 & 3 \\
\hline Physical assault & 4 & 7 \\
\hline Assault with Bodily Fluids & 3 & 0 \\
\hline \multicolumn{3}{|l|}{ Misconduct Location } \\
\hline Cell & 1 & 6 \\
\hline Range & 2 & 1 \\
\hline Kitchen & $\mathbf{0}$ & 1 \\
\hline Programs & $\mathbf{0}$ & 1 \\
\hline Washroom & 1 & 0 \\
\hline Common area & 4 & 0 \\
\hline Medical services & 1 & 0 \\
\hline Unknown & 1 & 1 \\
\hline \multicolumn{3}{|l|}{ Method/Weapon } \\
\hline Harm - Blunt object & 0 & 1 \\
\hline Threaten - Blunt object & $\mathbf{0}$ & 0 \\
\hline Harm - Physical force & 5 & 10 \\
\hline Threaten - Physical force & 2 & 0 \\
\hline Harm - Bodily fluids & 3 & 0 \\
\hline Threaten - Bodily fluids & 1 & 0 \\
\hline Harm - Throw object & 1 & 1 \\
\hline \multicolumn{3}{|l|}{ Use of Force } \\
\hline None & 1 & 0 \\
\hline Verbal & 0 & 0 \\
\hline Negotiation & 1 & 0 \\
\hline Minor physical & $\mathbf{0}$ & 2 \\
\hline Restraint equipment & 1 & 0 \\
\hline Major physical & 0 & 2 \\
\hline
\end{tabular}




\begin{tabular}{|c|c|c|}
\hline Sprays/chemical agents & 5 & 1 \\
\hline ERT & 0 & 0 \\
\hline Firearms & $\mathbf{0}$ & $\mathbf{0}$ \\
\hline Unknown & 2 & 5 \\
\hline \multicolumn{3}{|l|}{ Victim Number } \\
\hline 1 & 7 & 8 \\
\hline 2 & 0 & 1 \\
\hline 3 or more & 2 & 1 \\
\hline Unclear & 1 & 0 \\
\hline Victim - Staff (Yes/No) & 4 & 2 \\
\hline \multicolumn{3}{|l|}{ Staff Position } \\
\hline Correctional Officer & 3 & 2 \\
\hline Other & 1 & 0 \\
\hline Victim - Inmate (Yes/No) & 6 & 9 \\
\hline \multicolumn{3}{|l|}{ Relation to Inmate Victim } \\
\hline Cell/house mate & 0 & 2 \\
\hline Friend/acquaintance & 0 & 0 \\
\hline Partner & 0 & 0 \\
\hline Unknown & 6 & 7 \\
\hline \multicolumn{3}{|l|}{ Motivation } \\
\hline Instrumental & 0 & 1 \\
\hline Relational & 0 & 0 \\
\hline Retaliation/provoked & 0 & 1 \\
\hline Other & 0 & 3 \\
\hline \multirow[t]{2}{*}{ Unknown } & 10 & 5 \\
\hline & $M(S D)$ & $M(S D)$ \\
\hline Degree of Harm Inflicted & $2.8(1.67)$ & $2.4(0.52)$ \\
\hline Severity Rating & $3.33(.87)$ & $3.00(.67)$ \\
\hline
\end{tabular}


Theme Frequencies for the Qualitative Analysis; Medium Security Offenders

\begin{tabular}{|c|c|c|}
\hline & $\begin{array}{c}\text { Males } \\
(n=18)\end{array}$ & $\begin{array}{l}\text { Females } \\
(n=18)\end{array}$ \\
\hline \multicolumn{3}{|l|}{ Offender Role } \\
\hline Instigator & 18 & 17 \\
\hline Associate & 0 & 1 \\
\hline Accomplice (Yes/No) & 0 & 1 \\
\hline \multicolumn{3}{|l|}{ Misconduct Type } \\
\hline Threat & 2 & 2 \\
\hline Physical Altercation & 10 & 10 \\
\hline Physical Assault & 6 & 6 \\
\hline Assault with Bodily Fluids & 0 & 0 \\
\hline \multicolumn{3}{|l|}{ Misconduct Location } \\
\hline Cell & 1 & 9 \\
\hline Range & 5 & 0 \\
\hline Kitchen & 4 & 0 \\
\hline Program & 0 & 1 \\
\hline Washroom & 1 & 0 \\
\hline Common area & 3 & 4 \\
\hline Medical services & 1 & 1 \\
\hline Unknown & 3 & 3 \\
\hline \multicolumn{3}{|l|}{ Method/Weapon } \\
\hline Harm - Blunt object & 0 & 0 \\
\hline Threaten - Blunt object & 1 & 1 \\
\hline Harm - Physical force & 13 & 16 \\
\hline Threaten - Physical force & 1 & 1 \\
\hline Harm - Bodily fluids & 1 & 0 \\
\hline Threaten - Bodily fluids & 0 & 0 \\
\hline Harm - Throw object & 3 & 0 \\
\hline \multicolumn{3}{|l|}{ Use of Force } \\
\hline None & 3 & 7 \\
\hline Verbal & 1 & 3 \\
\hline Negotiation & 1 & 0 \\
\hline Minor physical & 2 & 4 \\
\hline Restraint equipment & 1 & 0 \\
\hline Major physical & 1 & 0 \\
\hline Sprays/chemical agents & 2 & 0 \\
\hline ERT & 1 & 0 \\
\hline
\end{tabular}




\begin{tabular}{|c|c|c|}
\hline Firearms & 1 & 0 \\
\hline Unknown & 5 & \\
\hline \multicolumn{3}{|l|}{ Victim Number } \\
\hline 1 & 18 & 16 \\
\hline 2 & 0 & 1 \\
\hline 3 or more & 0 & 1 \\
\hline \multicolumn{3}{|l|}{ Unclear } \\
\hline Victim - Staff (Yes/No) & 8 & 2 \\
\hline \multicolumn{3}{|l|}{ Staff Position } \\
\hline Correctional Officer & 6 & 2 \\
\hline Other & 2 & 0 \\
\hline Victim - Inmate (Yes/No) & 10 & 16 \\
\hline \multicolumn{3}{|l|}{ Relation to Inmate Victim } \\
\hline Cell/house mate & 0 & 4 \\
\hline Friend/acquaintance & 2 & 1 \\
\hline Partner & $\mathbf{0}$ & 2 \\
\hline Unknown & 8 & 9 \\
\hline \multicolumn{3}{|l|}{ Motivation } \\
\hline \multicolumn{3}{|l|}{ Instrumental } \\
\hline \multicolumn{3}{|l|}{ Relational } \\
\hline \multicolumn{3}{|l|}{ Retaliation/Provoked } \\
\hline \multicolumn{3}{|l|}{ Other } \\
\hline \multicolumn{3}{|l|}{ Unknown } \\
\hline & $M(S D)$ & $M(S D)$ \\
\hline Degree of Harm Inflicted & $2.25(.87)$ & $2.23(0.73)$ \\
\hline Severity Rating & $2.69(.70)$ & $2.63(.72)$ \\
\hline
\end{tabular}




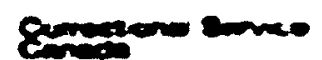

\section{Use of Force Management Model}

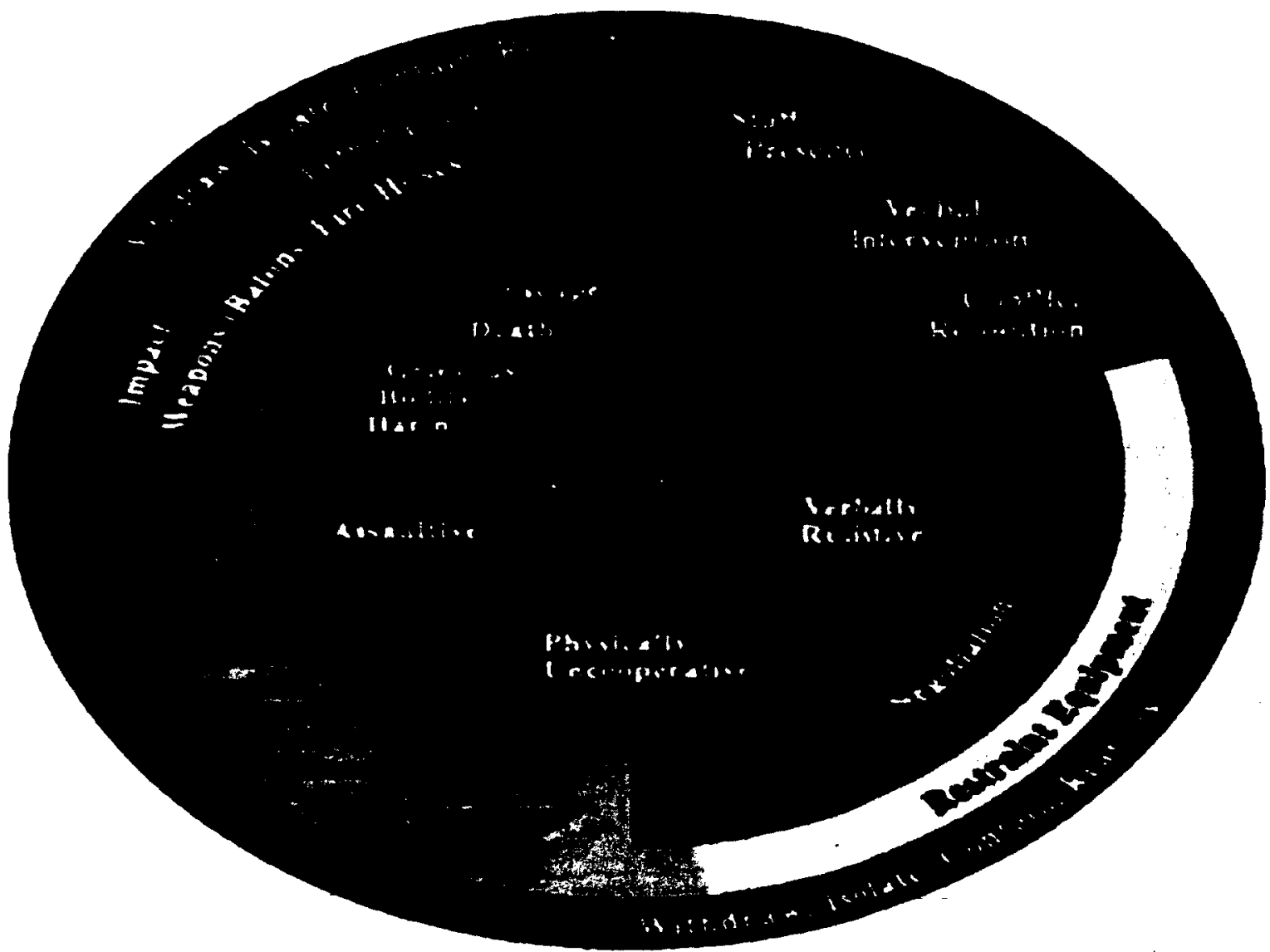

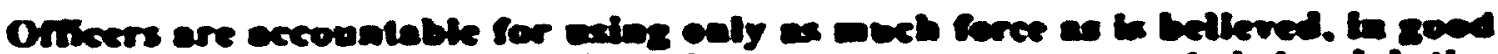

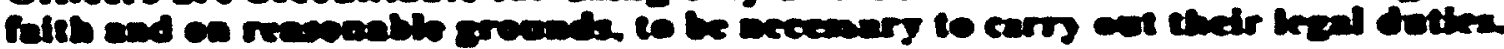

The diagram shows schemata of the Use of Force Management Model. It is a circular diagram with inner and outer circles indicating the chosen use of force for a given situation. Officers must use only as much force as is required to carry out legal duties. The outside rim specifies that officers withdraw, isolate, contain and reassess for all situations. The next layer specifies different options in each section of the layers: the upper left quadrant specifies lethal force, the larger section next to it specifies impact weapons, batons and fire hoses in response to situations involving escape, grievous bodily harm and death. The lower quadrant specifies chemical agent, spray irritant, physical handling, patrol dogs in response to assaultive behaviour and non cooperation. 
The lower right quadrant specifies restraint equipment for non cooperative offenders. The next section is the largest section of the model and it specifies negotiation, conflict resolution, verbal intervention and staff presence for offenders who are verbally resistant or cooperative. ${ }^{36}$

\footnotetext{
${ }^{36}$ Diagram and description are taken directly from Appendix A as provided in: Varrette, S. \& Archambault, K. (2011). A review of use of force in three types of correctional facilities. Report R-236. Ottawa ON:

Correctional Service of Canada.
} 